\title{
The prebiotic molecular inventory of Serpens SMM1
}

\section{An investigation of the isomers $\mathrm{CH}_{3} \mathrm{NCO}$ and $\mathrm{HOCH}_{2} \mathrm{CN}$}

\author{
N.F.W. Ligterink ${ }^{1}$, A. Ahmadi ${ }^{2}$, A. Coutens ${ }^{3}$, Ł. Tychoniec ${ }^{2}$ H. Calcutt ${ }^{4}, 5$, E.F. van Dishoeck ${ }^{2,6}$, H. Linnartz ${ }^{7}$, J.K. \\ Jørgensen $^{8}$, R.T. Garrod ${ }^{9}$, and J. Bouwman ${ }^{7}$
}

1 Physics Institute, University of Bern, Sidlerstrasse 5, 3012 Bern, Switzerland e-mail: niels.ligterink@csh.unibe.ch

${ }^{2}$ Leiden Observatory, Leiden University, PO Box 9513, 2300 RA Leiden, The Netherlands

${ }^{3}$ Laboratoire d'Astrophysique de Bordeaux, Univ. Bordeaux, CNRS, B18N, allée Geoffroy Saint-Hilaire, 33615 Pessac, France

${ }^{4}$ Department of Space, Earth and Environment, Chalmers University of Technology, 41296, Gothenburg, Sweden

5 Institute of Astronomy, Faculty of Physics, Astronomy and Informatics, Nicolaus Copernicus University, Grudziadzka 5, 87-100 Torun, Poland

${ }^{6}$ Max-Planck Institut für Extraterrestrische Physik (MPE), Giessenbachstr. 1, 85748 Garching, Germany

7 Laboratory for Astrophysics, Leiden Observatory, Leiden University, PO Box 9513, 2300 RA Leiden, The Netherlands

${ }^{8}$ Centre for Star and Planet Formation, Niels Bohr Institute \& Natural History Museum of Denmark, University of Copenhagen, Øster Voldgade 5-7, 1350 Copenhagen K., Denmark

9 Departments of Chemistry and Astronomy, University of Virginia, Charlottesville, VA 22904, USA

Received October 8, 2020; accepted December 22, 2020

\begin{abstract}
Aims. Methyl isocyanate $\left(\mathrm{CH}_{3} \mathrm{NCO}\right)$ and glycolonitrile $\left(\mathrm{HOCH}_{2} \mathrm{CN}\right)$ are isomers and prebiotic molecules that are involved in the formation of peptide structures and the nucleobase adenine, respectively. These two species are investigated to study the interstellar chemistry of cyanides $(\mathrm{CN})$ and isocyanates $(\mathrm{NCO})$ and to gain insight into the reservoir of interstellar prebiotic molecules.

Methods. ALMA observations of the intermediate-mass Class 0 protostar Serpens SMM1-a and ALMA-PILS data of the low-mass Class 0 protostar IRAS 16293B are used. Spectra are analysed with the CASSIS line analysis software package in order to identify and characterise molecules.

Results. $\mathrm{CH}_{3} \mathrm{NCO}, \mathrm{HOCH}_{2} \mathrm{CN}$, and various other molecules are detected towards SMM1-a. $\mathrm{HOCH}_{2} \mathrm{CN}$ is identified in the PILS data towards IRAS 16293B in a spectrum extracted at a half-beam offset position from the peak continuum. $\mathrm{CH}_{3} \mathrm{NCO}_{\text {and }} \mathrm{HOCH} \mathrm{CN}$ are equally abundant in SMM1-a at $[\mathrm{X}] /\left[\mathrm{CH}_{3} \mathrm{OH}\right]$ of $5.3 \times 10^{-4}$ and $6.2 \times 10^{-4}$, respectively. A comparison between SMM1-a and IRAS 16293B shows that $\mathrm{HOCH}_{2} \mathrm{CN}$ and $\mathrm{HNCO}$ are more abundant in the former source, but $\mathrm{CH}_{3} \mathrm{NCO}$ abundances do not differ significantly. Data from other sources are used to show that the $\left[\mathrm{CH}_{3} \mathrm{NCO}\right] /[\mathrm{HNCO}]$ ratio is similar in all these sources within $\sim 10 \%$. Conclusions. The new detections of $\mathrm{CH}_{3} \mathrm{NCO}$ and $\mathrm{HOCH}_{2} \mathrm{CN}$ are additional evidence for a large interstellar reservoir of prebiotic molecules that can contribute to the formation of biomolecules on terrestrial planets. The equal abundances of these molecules in SMM1-a indicate that their formation is driven by kinetic processes instead of thermodynamic equilibrium, which would drive the chemistry to one product. $\mathrm{HOCH}_{2} \mathrm{CN}$ is found to be much more abundant in SMM1-a than in IRAS 16293B. From the observational data, it is difficult to indicate a formation pathway for $\mathrm{HOCH}_{2} \mathrm{CN}$, but the thermal Strecker-like reaction of $\mathrm{CN}^{-}$with $\mathrm{H}_{2} \mathrm{CO}$ is a possibility. The similar $\left[\mathrm{CH}_{3} \mathrm{NCO}\right] /[\mathrm{HNCO}]$ ratios found in the available sample of studied interstellar sources indicate that these two species either are chemically related or their formation is affected by physical conditions in the same way. Both species likely form early during star-formation, presumably via ice mantle reactions taking place in the dark cloud or when ice mantles are being heated in the hot core. The relatively high abundances of $\mathrm{HOCH}_{2} \mathrm{CN}$ and $\mathrm{HNCO}$ in SMM1-a may be explained by a prolonged stage of relatively warm ice mantles, where thermal and energetic processing of $\mathrm{HCN}$ in the ice results in the efficient formation of both species.
\end{abstract}

Key words. Astrochemistry - Astrobiology - Individual Objects: Serpens SMM1 - ISM: abundances - Submillimeter: ISM

\section{Introduction}

Observations of molecules towards star-forming regions give insight into the kind of species that end up in planet-forming discs. These molecules not only aid planet formation but can also seed newly formed planets with a cocktail of molecules from which larger organic molecules can be formed. Prebiotic molecules are of particular interest, as they are involved in the formation of biomolecules, such as amino acids, nucleobases, proteins, and lipids (Sandford et al. 2020). In the interstellar medium (ISM) and on planets, prebiotic molecules are the building blocks from which biomolecules are made.

In the ISM, several prebiotic molecules have been detected. Examples are formamide $\left(\mathrm{NH}_{2} \mathrm{CHO}\right.$, Rubin et al. 1971) a precursor to nucleobases and amino acids (Saladino et al. 2012), the simplest sugar-like molecule glycolaldehyde $\left(\mathrm{HOCH}_{2} \mathrm{CHO}\right.$, Hollis et al. 2000; Jørgensen et al. 2012), methylamine $\left(\mathrm{CH}_{3} \mathrm{NH}_{2}\right.$, Kaifu et al. 1974; Bøgelund et al. 2019) and aminoacetonitrile $\left(\mathrm{NH}_{2} \mathrm{CH}_{2} \mathrm{CN}\right.$, Belloche et al. 2008), building blocks of the amino acid glycine (Holtom et al. 2005; Lee et al. 2009), the peptide building blocks acetamide $\left(\mathrm{CH}_{3} \mathrm{C}(\mathrm{O}) \mathrm{NH}_{2}\right)$ 
Methyl isocyanate

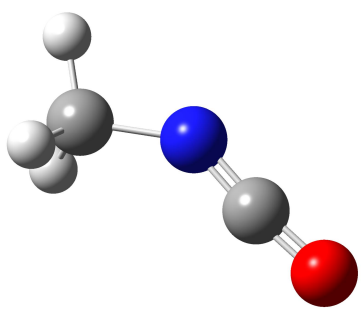

Fig. (1) Structures of the $\mathrm{C}_{2} \mathrm{H}_{3} \mathrm{NO}$ isomers methyl isocyanate $\left(\mathrm{CH}_{3} \mathrm{NCO}\right.$, left) and glycolonitrile $\left(\mathrm{HOCH}_{2} \mathrm{CN}\right.$, right $)$.

and N-methylformamide $\left(\mathrm{CH}_{3} \mathrm{NHCHO}\right.$, Hollis et al. 2006; Halfen et al. 2011; Belloche et al. 2017, 2019; Ligterink et al. $2020)$, the chiral molecule propylene oxide $\left(\mathrm{CH}_{3} \mathrm{CHCH}_{2} \mathrm{O}\right.$, McGuire et al. 2016), cyanomethanimine (NHCHCN), which can oligomerise to form adenine (Zaleski et al. 2013; Rivilla et al. 2019), and the nucleobase precursors cyanamide $\left(\mathrm{NH}_{2} \mathrm{CN}\right.$, Turner et al. 1975; Coutens et al. 2018), hydroxylamine $\left(\mathrm{NH}_{2} \mathrm{OH}\right.$, Rivilla et al. 2020) and carbamide (also known as urea, $\mathrm{NH}_{2} \mathrm{C}(\mathrm{O}) \mathrm{NH}_{2}$, Belloche et al. 2019). Over the past years, methyl isocyanate $\left(\mathrm{CH}_{3} \mathrm{NCO}\right.$, Halfen et al. 2015; Cernicharo et al. 2016; Ligterink et al. 2017) has been detected in several interstellar sources and recently its isomer glycolonitrile (also known as hydroxy acetonitrile, $\mathrm{HOCH}_{2} \mathrm{CN}$, Zeng et al. 2019) was identified for the first time in the ISM towards the low-mass protostar IRAS 16293-2422B (hereafter IRAS 16293B). Both these isomers are prebiotic molecules. $\mathrm{CH}_{3} \mathrm{NCO}$ can engage in reactions that form peptide-like structures, while $\mathrm{HOCH}_{2} \mathrm{CN}$ is known to accelerate the oligomerisation of $\mathrm{HCN}$ in liquids and ice under terrestrial conditions, forming the nucleobase adenine (Schwartz \& Goverde 1982; Schwartz et al. 1982).

Besides their relevance to prebiotic chemistry, $\mathrm{CH}_{3} \mathrm{NCO}$ and $\mathrm{HOCH}_{2} \mathrm{CN}$ are also interesting molecules to gain insight into interstellar nitrogen chemistry. While these molecules, being isomers, have the same elemental composition $\left(\mathrm{C}_{2} \mathrm{H}_{3} \mathrm{NO}\right)$, their chemical structures differ significantly, see Fig. 1. Recent quantum chemical calculations of the stability of $\mathrm{C}_{2} \mathrm{H}_{3} \mathrm{NO}$ isomers in general, also reveal that $\mathrm{CH}_{3} \mathrm{NCO}$ is the most stable species of those, followed by $\mathrm{HOCH}_{2} \mathrm{CN}$ (Fourré et al. 2020). Therefore, observations of this isomer couple provide information on interstellar reactions involving cyanides $(-\mathrm{CN})$ and isocyanates (-NCO), two important nitrogen-bearing chemical groups, and the physical conditions that steer or prohibit this chemistry.

After the first detection of $\mathrm{CH}_{3} \mathrm{NCO}$ (Halfen et al. 2015; Cernicharo et al. 2016), HNCO was suggested to be involved in its formation due to their structural similarity and the large $\mathrm{HNCO}$ abundances in interstellar gas and ice (in the form of $\mathrm{OCN}^{-}$ Boogert et al. 2015). Various gas-phase and solid-state methylation (the addition of a $\mathrm{CH}_{3}$ functional group to a molecule) reactions of $\mathrm{HNCO}$, the $\mathrm{OCN}$ radical, and the $\mathrm{OCN}^{-}$anion have been proposed as possible reaction pathways. Experimental investigations (Ligterink et al. 2017; Maté et al. 2018) and modeling studies (Martín-Doménech et al. 2017; Quénard et al. 2018; Majumdar et al. 2018) indicate solid-state methylation in the ice mantle as the main pathway to form $\mathrm{CH}_{3} \mathrm{NCO}$ :

$\mathrm{CH}_{3}+\mathrm{NCO} \longrightarrow \mathrm{CH}_{3} \mathrm{NCO}$
Variations of this pathway, such as the methylation of HNCO or $\mathrm{OCN}^{-}$may be possible as well, while completely different reactions, such as the hydrogenation of $\mathrm{HCN}$...CO may form $\mathrm{CH}_{3} \mathrm{NCO}$ as well.

No gas-phase formation pathways are known for glycolonitrile, but solid-state production routes have been studied theoretically (Woon 2001) and experimentally (Danger et al. 2012, 2014). Laboratory work indicates that the thermally activated reaction between a cyanide anion $\left(\mathrm{CN}^{-}\right)$and formaldehyde $\left(\mathrm{H}_{2} \mathrm{CO}\right)$ forms $\mathrm{HOCH}_{2} \mathrm{CN}$ :

$\left[\mathrm{XH}^{+} \mathrm{CN}^{-}\right]+\mathrm{H}_{2} \mathrm{CO} \longrightarrow \mathrm{HOCH}_{2} \mathrm{CN}+\mathrm{X}$,

where $\mathrm{X}$ is a molecule that can act as a base, such as ammonia $\left(\mathrm{NH}_{3}\right)$ or water $\left(\mathrm{H}_{2} \mathrm{O}\right)$. This reaction is the solid-state equivalent of the Strecker synthesis, which is a sequence of chemical reactions that produce amino acids. The Streckerlike formation of $\mathrm{HOCH}_{2} \mathrm{CN}$ is linked to the formation of aminomethanol $\left(\mathrm{HOCH}_{2} \mathrm{NH}_{2}\right.$, Bossa et al. 2009) and aminoacetonitrile $\left(\mathrm{NH}_{2} \mathrm{CH}_{2} \mathrm{CN}\right.$, Danger et al. 2011). The latter of these species is detected in the ISM and known as a possible intermediate in the formation of the amino acid glycine (Belloche et al. 2008). Irradiation of $\mathrm{HOCH}_{2} \mathrm{CN}$ results in the photoproducts formylcyanide $(\mathrm{HC}(\mathrm{O}) \mathrm{CN})$ and ketenimine $\left(\mathrm{CH}_{2} \mathrm{CNH}\right)$. Although not investigated, hydrogenation and oxygen additions of these two species may provide pathways to form $\mathrm{HOCH}_{2} \mathrm{CN}$ in the ISM. The solid-state radical-radical reactions $\mathrm{HO}+\mathrm{CH}_{2} \mathrm{CN}$ and $\mathrm{HOCH}_{2}+\mathrm{CN}$ can also form glycolonitrile, but neither of these reactions has been investigated (Margulès et al. 2017). However, precursor species to these reactions can be present in ice mantles, in particular when methanol $\left(\mathrm{CH}_{3} \mathrm{OH}\right)$ or acetonitrile $\left(\mathrm{CH}_{3} \mathrm{CN}\right)$ are energetically processed (Allamandola et al. 1988; Hudson \& Moore 2004; Bulak et al. 2020).

Methyl isocyanate and glycolonitrile can thus be used as tracers of reactions involving $\mathrm{CN}$ and $\mathrm{NCO}$ and investigating their interstellar abundances reveals information about the chemical and physical processes that drive these reactions and interstellar nitrogen chemistry as a whole. $\mathrm{CH}_{3} \mathrm{NCO}$ and $\mathrm{HOCH}_{2} \mathrm{CN}$ have only been detected simultaneously in the low-mass protostar IRAS 16293B (Ligterink et al. 2017; Martín-Doménech et al. 2017; Zeng et al. 2019), albeit in different observational data sets. Due to this limited sample size, it is difficult to derive correlations or variations in the $\mathrm{C}_{2} \mathrm{H}_{3} \mathrm{NO}$ isomer chemistry and therefore simultaneous identifications in other sources are required. Here, deep ALMA observations of the intermediatemass Class 0 protostar Serpens SMM1-a (hereafter SMM1-a) are presented to derive additional constraints on $\mathrm{CH}_{3} \mathrm{NCO}$ and $\mathrm{HOCH}_{2} \mathrm{CN}$ chemistry.

The Serpens star-forming region contains multiple deeply embedded sources, of which SMM1 is the brightest (Casali et al. 1993). The Serpens region contains multiple outflows and jets, some of which originate from SMM1 (Dionatos et al. 2013; Hull et al. 2016). The chemistry of the SMM1 hot corino, its outflows, and the Serpens core have been characterised in various studies (e.g., White et al. 1995; Hogerheijde et al. 1999; Kristensen et al. 2010; Öberg et al. 2011; Goicoechea et al. 2012; Tychoniec et al. 2019). High-resolution continuum jet observations have shown that SMM1 consists of multiple sources, of which SMM1-a is the main one (Choi 2009; Dionatos et al. 2014; Hull et al. 2017). SMM1-a has SMM1-b as a close neighbor at $\sim 500$ $\mathrm{au}$, while two other sources, SMM1-c and -d, are located further away to its north. Recent distance measurements place the Serpens core, and therefore SMM1, at a distance of $436.0 \pm 10$ pc (Ortiz-León et al. 2017), resulting in a luminosity estimate of the entire SMM1 source of $\sim 100 L_{\odot}$. SMM1-a is considered to 
be an intermediate-mass protostar (Hull et al. 2017; Tychoniec et al. 2019).

In this work, the detection and analysis of the isomers $\mathrm{HOCH}_{2} \mathrm{CN}$ and $\mathrm{CH}_{3} \mathrm{NCO}$ towards SMM1-a are presented and compared with literature results of IRAS $16293 \mathrm{~B}$ and those of other sources. In section 2 the observations towards SMM1 and the analysis method are presented. The detections of $\mathrm{HOCH}_{2} \mathrm{CN}$, $\mathrm{CH}_{3} \mathrm{NCO}$, and various other molecules are presented in section 3. Section 4 discusses these detections and their likely formation pathways. The conclusions of this work are presented in section 5.

\section{Data \& Methods}

\subsection{Observations and spectra of Serpens SMM1}

SMM1 was observed on 27-March-2019 during ALMA cycle 6, as part of project \#2018.1.00836.S (PI: N.F.W. Ligterink). The region was observed using a total of 42 antennae with baselines spanning 15 - 332 meters in configuration C43-5. The on-source integration time was 50 minutes, towards the phase centre $\alpha_{\mathrm{J} 2000}$ $=18: 29: 49.80 \delta_{\mathrm{J} 2000}=+01: 15: 20.6$. Spectra were recorded in select frequency windows between 217.59 and $235.93 \mathrm{GHz}$, at resolutions of $488.21 \mathrm{kHz}\left(0.33 \mathrm{~km} \mathrm{~s}^{-2}\right)$ and $1952.84 \mathrm{kHz}(1.25$ $\mathrm{km} \mathrm{s}^{-2}$ ) for the continuum window, see Table 1 . The data were calibrated and imaged with version 5.4.0-70 of the Common Astronomy Software Applications (CASA). Bandpass and flux calibration was conducted on J2000-1748, while phase calibration was performed on $\mathrm{J} 1851+0035$. The flux uncertainty was $\leq 20 \%$. To reach the desired sensitivity, the measurement sets were cleaned using the Hogbom algorithm (Högbom 1974) and Briggs weighting with a robust parameter of 0.5 . This resulted in an angular resolution of 1 '!32×1',04 and an rms noise of 2.6 $\mathrm{mJy}$ beam ${ }^{-1} \mathrm{~km} \mathrm{~s}^{-1}$ in the final spectral data cubes. The primary beam of the observations was $26^{\prime \prime}$.

Table (1) Frequency settings of ALMA SMM1 observations

\begin{tabular}{cccc}
\hline \hline $\begin{array}{c}\text { Frequency range } \\
(\mathrm{GHz})\end{array}$ & $\begin{array}{c}\text { Bandwidth } \\
(\mathrm{GHz})\end{array}$ & \multicolumn{2}{c}{ Resolution } \\
$(\mathrm{kHz})$ & $\left(\mathrm{km} \mathrm{s}^{-1}\right)$ \\
\hline $217.59-217.70$ & 0.117 & 488.21 & 0.33 \\
$217.97-218.09$ & 0.117 & 488.21 & 0.33 \\
$218.43-218.55$ & 0.117 & 488.21 & 0.33 \\
$218.92-219.03$ & 0.117 & 488.21 & 0.33 \\
$219.71-219.82$ & 0.117 & 488.21 & 0.33 \\
$221.30-221.42$ & 0.117 & 488.21 & 0.33 \\
$221.42-221.53$ & 0.117 & 488.21 & 0.33 \\
$221.53-221.65$ & 0.117 & 488.21 & 0.33 \\
$231.74-231.97$ & 0.234 & 488.21 & 0.33 \\
$233.41-233.65$ & 0.234 & 488.21 & 0.33 \\
$234.06-235.93$ & 1.875 & 1952.84 & 1.25 \\
\hline
\end{tabular}

Due to the line-richness of the source, the following procedure was followed to properly subtract the continuum from the line observations. We imaged all spectral windows without the continuum removed and used the corrected sigma-clipping method of the STATCONT package ${ }^{1}$ (Sánchez-Monge et al. 2018 ) to extract a continuum-subtracted line cube. STATCONT can only subtract zeroth-order polynomials, while in this dataset non-zeroth-order baselines are visible. Furthermore, continuum subtraction in the uv-plane is more desirable since the deconvolution of the line emission is more robust when it is not subjected

\footnotetext{
${ }^{1}$ https://hera.ph1.uni-koeln.de/ sanchez/statcont
}

to the deconvolution errors of the brighter continuum. Therefore, the STATCONT outputs were used to identify the line-free channels in the spectra and the continuum was subtracted in the uv-plane with the uvcontsub task in CASA. Line-free channels are sparse, but for most spectral windows, at least $20 \%$ of the bandwidth was given as input to the uvcontsub task, with the exception of two spectral windows, where only $10 \%$ of the bandwidth was line-free. From the resulting datacube, the SMM1a hot core spectrum was extracted towards the peak continuum position $\alpha_{\mathrm{J} 2000}=18: 29: 49.793, \delta_{\mathrm{J} 2000}=+1.15 .20 .200$. From the average continuum flux density $\left(0.41 \mathrm{mJy} \mathrm{beam}^{-1}\right)$, the background temperature was determined to be $\sim 5.2 \mathrm{~K}$.

\subsection{PILS observations and spectra of IRAS 16293B}

In this work, the column density of $\mathrm{HOCH}_{2} \mathrm{CN}$ is determined independently from the detection presented by (Zeng et al. 2019) by analysing data from the Protostellar Interferometric Line Survey (PILS). Other species relevant to this work are also searched for in the PILS data set. The observational details of the PILS survey have been presented in various other publications (e.g., Jørgensen et al. 2016) and here only the most relevant information is presented. In short, the PILS survey makes use of ALMA band 7 observations, covering a frequency range from 329 to $363 \mathrm{GHz}$ at a spatial resolution of $0 \prime 25$. To investigate the chemical inventory of IRAS 16293B, spectra are extracted at several positions. These positions are on the peak continuum, a halfbeam offset from the peak continuum, and a full-beam offset from the peak continuum. Most PILS analyses of IRAS 16293B make use of the spectrum at the full-beam offset position Jørgensen et al. (e.g., 2016); Coutens et al. (e.g., 2016); Ligterink et al. (e.g., 2017); Coutens et al. (e.g., 2018); Persson et al. (e.g., 2018); Calcutt et al. (e.g., 2018); Jørgensen et al. (e.g., 2018). In this work, this is the main position for which molecular ratios with $\mathrm{HOCH}_{2} \mathrm{CN}$ are determined, but the spectra of other positions are also analysed. The systemic velocity towards these positions is $V_{\mathrm{LSR}}=2.7 \mathrm{~km} \mathrm{~s}^{-1}$ and the line width is approximately $\Delta V=1.0 \mathrm{~km} \mathrm{~s}^{-1}$. Due to the dense dust around IRAS 16293B, the background temperatures $\left(T_{\mathrm{BG}}\right)$ at these positions are higher than the cosmic microwave background radiation temperature of $2.7 \mathrm{~K}$ and couple with the molecular line emission (see Ligterink et al. 2018). At the full-beam offset position $T_{\mathrm{BG}}=21 \mathrm{~K}$, while at the half-beam offset position it is $T_{\mathrm{BG}}=52 \mathrm{~K}$.

\subsection{Analysis method}

The spectra were analyzed with the CASSIS ${ }^{2}$ line analysis software. Spectral line lists were obtained from the JPL database for molecular spectroscopy (Pickett et al. 1998), the Cologne Database for Molecular Spectroscopy (CDMS, Müller et al. 2001, 2005), and from literature. An overview of the spectroscopic line lists used in this work and the laboratory works they are based on is given in Appendix A. Given a spectroscopic line list as input, CASSIS can produce synthetic spectra of a molecule based on parameters such as column density $\left(N_{\mathrm{T}}\right)$, excitation temperature $\left(T_{\text {ex }}\right)$, peak gas velocity $\left(V_{\mathrm{LSR}}\right)$, line width at half maximum $(\Delta V)$, and source size $\left(\theta_{\text {source }}\right)$. These parameters were given as free parameters to a Monte-Carlo Markov Chain (MCMC) algorithm and $\chi^{2}$ minimisation routine. This routine finds the best-fit of a synthetic spectrum to an observed spectrum over a specified parameter space, thereby determining the

${ }^{2}$ CASSIS has been
(http://cassis.irap.omp.eu)



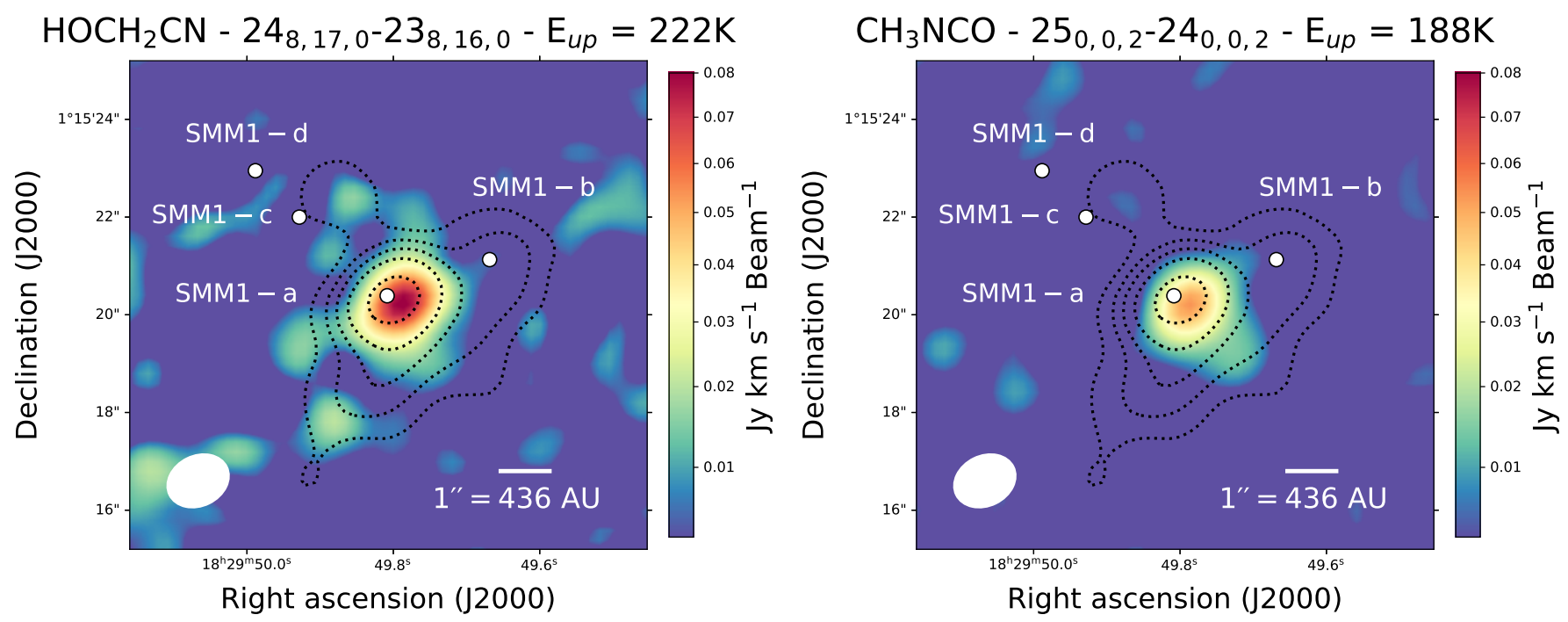

Fig. (2) Moment 0 maps of the $\mathrm{HOCH}_{2} \mathrm{CN} 24_{8,17 / 16}-23_{8,16 / 15}, \mathrm{E}_{\mathrm{up}}=222 \mathrm{~K}$ line and the $\mathrm{CH}_{3} \mathrm{NCO} v=025_{0,0}-24_{0,0}$, $\mathrm{E}_{\text {up }}=188 \mathrm{~K}$ line towards SMM1. Both lines are integrated over 8 velocity bins, centered on the peak frequency of each line as determined towards SMM1-a. Positions of protostars in the SMM1 region are indicated and the beam size $\left(1^{\prime \prime} .32 \times 11^{\prime \prime} .04\right)$ is visualised in the bottom left corner. Dust continuum contours are given by the black dotted line at the levels of $0.02,0.05,0.1,0.2,0.5 \mathrm{Jy}^{\mathrm{Beam}}{ }^{-1}$.

Table (2) Best-fit parameters for molecules detected towards SMM1-a in a 1'!2 beam.

\begin{tabular}{lccccccc}
\hline \hline Molecule & $\begin{array}{c}\text { Lines } \\
\#\end{array}$ & $\begin{array}{c}N_{\mathrm{T}} \\
\left(\mathrm{cm}^{-2}\right)\end{array}$ & $\begin{array}{c}T_{\mathrm{ex}} \\
(\mathrm{K})\end{array}$ & $\begin{array}{c}V_{\mathrm{LSR}} \\
\mathrm{km} \mathrm{s}^{-1}\end{array}$ & $\begin{array}{c}\Delta V \\
\mathrm{~km} \mathrm{~s}^{-1}\end{array}$ & {$[\mathrm{X}] /\left[\mathrm{CH}_{3} \mathrm{OH}\right]$} & {$[\mathrm{X}] /[\mathrm{HNCO}]$} \\
\hline $\mathrm{HOCH}{ }_{2} \mathrm{CN}$ & 18 & $(7.4 \pm 0.9) \times 10^{14}$ & $260 \pm 45$ & $6.8 \pm 0.2$ & $2.5 \pm 0.3$ & $6.2 \times 10^{-4}$ & $7.4 \times 10^{-2}$ \\
$\mathrm{CH}_{3} \mathrm{NCO}$ & 12 & $(6.4 \pm 1.9) \times 10^{14}$ & $240 \pm 60$ & $7.0 \pm 0.4$ & $3.0 \pm 0.6$ & $5.3 \times 10^{-4}$ & $6.4 \times 10^{-2}$ \\
\hline $\mathrm{D}_{2} \mathrm{CO}$ & 3 & $(5.4 \pm 2.5) \times 10^{14}$ & {$[200]$} & $7.4 \pm 0.4$ & $3.9 \pm 0.2$ & $4.5 \times 10^{-4}$ & $5.4 \times 10^{-2}$ \\
$\mathrm{CH}_{3}^{18} \mathrm{OH}$ & 4 & $(2.0 \pm 1.1) \times 10^{15}$ & $250 \pm 60$ & $7.1 \pm 0.2$ & $2.8 \pm 0.3$ & - & - \\
${ }^{12} \mathrm{CH}_{3} \mathrm{OH}^{a}$ & $5^{b}$ & $1.1 \times 10^{18}$ & - & - & - & 1.0 & 110 \\
$\mathrm{CH}_{3} \mathrm{CN}^{c}$ & 6 & $(1.3 \pm 0.3) \times 10^{15}$ & $190 \pm 25$ & $7.5 \pm 0.2$ & $3.4 \pm 0.3$ & $1.1 \times 10^{-3}$ & 0.1 \\
$\mathrm{NH}_{2} \mathrm{CN}$ & 3 & $(5.1 \pm 1.3) \times 10^{13}$ & $190 \pm 40$ & $7.1 \pm 0.2$ & $3.2 \pm 0.4$ & $4.3 \times 10^{-5}$ & $5.1 \times 10^{-3}$ \\
$\mathrm{HN}^{13} \mathrm{CO}$ & 3 & $(1.9 \pm 0.3) \times 10^{14}$ & $190 \pm 30$ & $7.6 \pm 0.2$ & $3.5 \pm 0.3$ & - & - \\
$\mathrm{HN}^{12} \mathrm{CO}$ & $5^{b}$ & $1.0 \times 10^{16}$ & - & - & - & $1.1 \times 10^{-2}$ & 1.0 \\
$\mathrm{CH}_{3} \mathrm{CH}{ }_{2} \mathrm{OH}$ & 14 & $(4.1 \pm 0.9) \times 10^{15}$ & $210 \pm 25$ & $7.3 \pm 0.2$ & $2.8 \pm 0.6$ & $4.1 \times 10^{-3}$ & 0.3 \\
$\mathrm{CH}_{3} \mathrm{OCHO}$ & 24 & $(7.4 \pm 0.7) \times 10^{15}$ & $215 \pm 20$ & $7.3 \pm 0.2$ & $3.1 \pm 0.3$ & $7.4 \times 10^{-3}$ & 0.6 \\
$\mathrm{a}-\left(\mathrm{CH}_{2} \mathrm{OH}\right)_{2}$ & 14 & $(1.7 \pm 0.5) \times 10^{15}$ & $195 \pm 70$ & $7.2 \pm 0.2$ & $2.7 \pm 0.3$ & $1.7 \times 10^{-3}$ & 0.1 \\
\hline $\mathrm{CH}_{3} \mathrm{CNO}$ & 0 & $\leq 1.0 \times 10^{13}$ & {$[200]$} & {$[7.0]$} & {$[3.5]$} & $\leq 9.1 \times 10^{-6}$ & $\leq 1.0 \times 10^{-3}$ \\
$\mathrm{CH}_{3} \mathrm{OCN}$ & 0 & $\leq 5.0 \times 10^{13}$ & {$[200]$} & {$[7.0]$} & {$[3.5]$} & $\leq 4.6 \times 10^{-6}$ & $\leq 5.0 \times 10^{-3}$ \\
$\mathrm{CH}_{2} \mathrm{CNH}$ & 0 & $\leq 1.0 \times 10^{15}$ & {$[200]$} & {$[7.0]$} & {$[3.5]$} & $\leq 8.3 \times 10^{-4}$ & 0.1 \\
$\mathrm{CH}(\mathrm{O}) \mathrm{CN}$ & 0 & $\leq 2.0 \times 10^{14}$ & {$[200]$} & {$[7.0]$} & {$[3.5]$} & $\leq 1.7 \times 10^{-4}$ & $\leq 2.0 \times 10^{-2}$ \\
$\mathrm{NH}_{2} \mathrm{CH}{ }_{2} \mathrm{CN}$ & 0 & $\leq 1.0 \times 10^{14}$ & {$[200]$} & {$[7.0]$} & {$[3.5]$} & $\leq 8.3 \times 10^{-5}$ & $\leq 1.0 \times 10^{-2}$ \\
\hline
\end{tabular}

Notes. Values in brackets are assumed. ${ }^{a}$ Main isotopologue column densities are determined by applying the ratios ${ }^{16} \mathrm{O} /{ }^{18} \mathrm{O}=560$ and ${ }^{12} \mathrm{C} /{ }^{13} \mathrm{C}=$ 52.5 to the minor isotopologue column densities. ${ }^{b}$ The number of lines identified of the main isotopologue in this data set. ${ }^{c} \mathrm{The} \mathrm{CH}_{3} \mathrm{CN}$ best-fit parameters are determined from its vibrationally excited state $v_{8}=1$.

best-fit parameters and thus column density and excitation temperature of a molecule. For the analysis, optically thin lines $(\tau \ll$ $1.0)$ were used. The $\tau$-value was approximated from the by-eye synthetic fit (see below) of the observed rotational lines with the CASSIS software. The molecules were assumed to be in local thermodynamic equilibrium (LTE). Errors on physical parameters take the uncertainty of the fit and the flux uncertainty as input and are calculated from the spread in $\chi^{2}$ values around the minimum to a $3 \sigma$ confidence level.

In this work, spectral lines of a molecule were identified in the observed spectra and a by-eye synthetic fit of the lines was made. For the by-eye fit, line width and peak velocity are determined from prominent spectral lines of molecules such as
$\mathrm{HNCO}$ and $\mathrm{CH}_{3} \mathrm{OH}$ and used as a first approximation for other molecules. An excitation temperature of $200 \mathrm{~K}$ is taken as an initial guess and followed by a round of adjusting column density and rotational temperature until a reasonable by-eye fit was found. The by-eye fit results were given as starting parameters for the MCMC $\chi^{2}$ minimisation routine. The $\chi^{2}$ minimisation was performed on lines that are not blended and have minimal contributions from the wings of neighboring lines. Blending species were identified by checking the line position for other lines of known hot core / corino species with $A_{i j}>1 \times 10^{-6}$ and $\mathrm{E}_{\mathrm{up}}$ of $0-1000 \mathrm{~K}$. The column density was given as a free parameter over two orders of magnitude centered on the by-eye fit column density and the excitation temperature was a free parameter 
Table (3) Best-fit parameters of $\mathrm{HOCH}_{2} \mathrm{CN}$ and related species towards IRAS $16923 \mathrm{~B}$ in the PILS data set in a $0{ }^{\prime \prime} .5$ beam

\begin{tabular}{|c|c|c|c|c|}
\hline Molecule & $\begin{array}{c}N_{\mathrm{T}} \\
\left(\mathrm{cm}^{-2}\right)\end{array}$ & $\begin{array}{l}T_{\mathrm{ex}} \\
(\mathrm{K})\end{array}$ & {$[\mathrm{X}] /\left[\mathrm{CH}_{3} \mathrm{OH}\right]^{a}$} & {$[\mathrm{X}] /[\mathrm{HNCO}]^{a}$} \\
\hline $\mathrm{HOCH}_{2} \mathrm{CN}$ & $\leq 1.0 \times 10^{15}$ & [150] & $\leq 1.0 \times 10^{-4}$ & $\leq 3.3 \times 10^{-2}$ \\
\hline $\mathrm{HOCH}_{2} \mathrm{CN}$ & $\leq 1.0 \times 10^{15}$ & [300] & $\leq 1.0 \times 10^{-4}$ & $\leq 3.3 \times 10^{-2}$ \\
\hline $\mathrm{CH}_{2} \mathrm{CNH}$ & $\leq 1.0 \times 10^{15}$ & [100] & $\leq 1.0 \times 10^{-4}$ & $\leq 3.3 \times 10^{-2}$ \\
\hline $\mathrm{CH}_{2} \mathrm{CNH}$ & $\leq 2.0 \times 10^{15}$ & [300] & $\leq 2.0 \times 10^{-4}$ & $\leq 6.7 \times 10^{-2}$ \\
\hline $\mathrm{CH}(\mathrm{O}) \mathrm{CN}$ & $\leq 5.0 \times 10^{14}$ & [100] & $\leq 5.0 \times 10^{-5}$ & $\leq 1.7 \times 10^{-2}$ \\
\hline $\mathrm{CH}(\mathrm{O}) \mathrm{CN}$ & $\leq 5.0 \times 10^{14}$ & [300] & $\leq 5.0 \times 10^{-5}$ & $\leq 1.7 \times 10^{-2}$ \\
\hline $\mathrm{NH}_{2} \mathrm{CH}_{2} \mathrm{CN}$ & $\leq 1.0 \times 10^{15}$ & [100] & $\leq 1.0 \times 10^{-4}$ & $\leq 3.3 \times 10^{-2}$ \\
\hline $\mathrm{NH}_{2} \mathrm{CH}_{2} \mathrm{CN}$ & $\leq 5.0 \times 10^{14}$ & [300] & $\leq 5.0 \times 10^{-5}$ & $\leq 1.7 \times 10^{-2}$ \\
\hline
\end{tabular}

Notes. Values in brackets are assumed. $V_{\mathrm{LSR}}=2.7 \mathrm{~km} \mathrm{~s}^{-1}$ and $\Delta V=1.0 \mathrm{~km} \mathrm{~s}^{-1}$. Note that some upper limit column densities are similar because the upper state energies of the lines cover only a narrow range of energies. ${ }^{a} \mathrm{CH}_{3} \mathrm{OH}$ and $\mathrm{HNCO}$ column densities were adopted from Jørgensen et al. (2018) and Coutens et al. (2016), respectively.

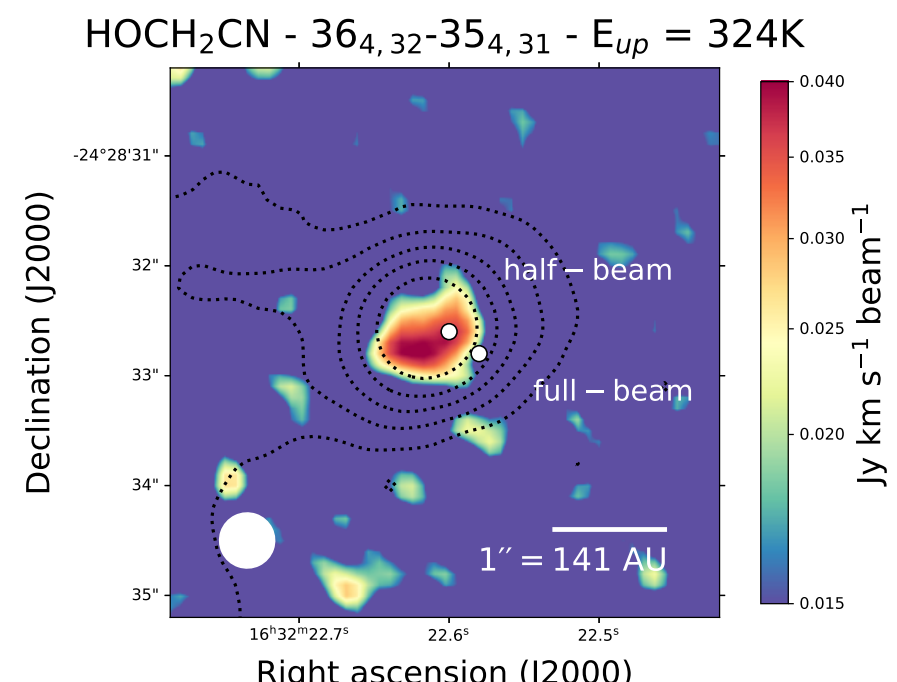

Fig. (3) Moment 0 map of the $\mathrm{HOCH}_{2} \mathrm{CN} 36_{4,32}-35_{4,31}, \mathrm{E}_{\mathrm{up}}=$ $324 \mathrm{~K}$ line towards IRAS 16293B. The line is integrated over 8 velocity bins, centered on the peak frequency of the line. The positions of the half-beam and full-beam offset positions around IRAS $16293 \mathrm{~B}$ are indicated and the beam size $\left(0{ }^{\prime \prime} .5 \times 00^{\prime \prime} .5\right)$ is visualised in the bottom left corner. Dust continuum contours are given by the black dotted line at the levels of $0.02,0.05,0.1,0.2$, $0.5 \mathrm{Jy} \mathrm{Beam}^{-1}$.

from $50-350 \mathrm{~K}$. For SMM1-a, $\Delta V$ was a free parameter from $1.0-4.0 \mathrm{~km} \mathrm{~s}^{-1}$, and the source velocity was a free parameter between $6.0-9.0 \mathrm{~km} \mathrm{~s}^{-1}$. The source size was assumed to be equal to the beam size and taken to be 1 '!2, resulting in a beam filling factor of 0.5 . A background continuum temperature $\left(T_{\mathrm{bg}}\right)$ of $5.2 \mathrm{~K}$ was used.

For the analysis of IRAS 16293B, $\Delta V$ and $V_{\text {LSR }}$ were fixed to $1.0 \mathrm{~km} \mathrm{~s}^{-1}$ and $2.7 \mathrm{~km} \mathrm{~s}^{-1}$, respectively. The source size was assumed to be equal to the beam size at 0 '.5, while a background continuum temperature of $T_{\mathrm{bg}}=21 \mathrm{~K}$ was used.

\section{Results}

\subsection{SMM1}

In the spectra of SMM1-a, multiple unblended rotational lines of the isomers $\mathrm{HOCH}_{2} \mathrm{CN}$ and $\mathrm{CH}_{3} \mathrm{NCO} v=0$ are found. Moment 0 maps (the spatial mapping of the integrated line intensity of a single rotational line) of both species show that most emission originates from SMM1-a, see Fig. 2. The identified lines towards SMM1-a are presented in Figs. 4 and 5. For $\mathrm{HOCH}_{2} \mathrm{CN}$, this is the second independent interstellar detection of this molecule (the first detection of $\mathrm{HOCH}_{2} \mathrm{CN}$ was presented towards IRAS 16293B by Zeng et al. 2019), while the first detection of $\mathrm{CH}_{3} \mathrm{NCO}$ towards SMM1-a is part of only a handful of detections of this species towards other interstellar sources.

Several other species are identified in the SMM1-a spectra as well. Rotational lines of acetonitrile $\left(\mathrm{CH}_{3} \mathrm{CN} v_{8}=1\right)$, cyanamide $\left(\mathrm{NH}_{2} \mathrm{CN}\right)$, ethanol $\left(\mathrm{CH}_{3} \mathrm{CH}_{2} \mathrm{OH}\right)$, the anti-conformer of ethylene glycol $\left(\mathrm{a}-\left(\mathrm{CH}_{2} \mathrm{OH}\right)_{2}\right)$, deuterated formaldehyde $\left(\mathrm{D}_{2} \mathrm{CO}\right)$, isocyanic acid $\left(\mathrm{HN}^{12} \mathrm{CO}\right.$ and $\left.\mathrm{HN}^{13} \mathrm{CO}\right)$, methylformate $\left(\mathrm{CH}_{3} \mathrm{OCHO}\right)$, and methanol $\left({ }^{12} \mathrm{CH}_{3} \mathrm{OH}\right.$ and $\left.\mathrm{CH}_{3}^{18} \mathrm{OH}\right)$ are detected. Rotational lines of the $\mathrm{C}_{2} \mathrm{H}_{3} \mathrm{NO}$ isomers methyl fulmiate $\left(\mathrm{CH}_{3} \mathrm{CNO}\right)$ and methyl cyanate $\left(\mathrm{CH}_{3} \mathrm{OCN}\right)$ were not identified in the spectra. The molecules aminoacetonitrile $\left(\mathrm{NH}_{2} \mathrm{CH}_{2} \mathrm{CN}\right)$, ketenimine $\left(\mathrm{CH}_{2} \mathrm{CNH}\right)$, and formylcyanide $(\mathrm{HC}(\mathrm{O}) \mathrm{CN})$ are searched for, but not identified. Spectra are presented in Appendix B and spectroscopic parameters of transitions are provided in Table 5. Following the procedure detailed in Sect. 2.3, the best-fit parameters of these species are determined. For undetected species, upper limit column densities are determined by assuming $T_{\mathrm{ex}}=200 \mathrm{~K}$, which is chosen as a representative excitation temperature from the molecules that are detected. The fit parameters are presented in Table 2. The main isotopologues of $\mathrm{CH}_{3} \mathrm{OH}$ and $\mathrm{HNCO}$ are optically thick and their column densities are therefore determined from minor isotopologues. This is done by multiplying with the local interstellar ${ }^{12} \mathrm{C} /{ }^{13} \mathrm{C}$ ratio of $52.5 \pm 15.4$ (Yan et al. 2019) and ${ }^{16} \mathrm{O} /{ }^{18} \mathrm{O}$ ratio of 560 (Wilson 1999).

\subsection{IRAS $16293 B$}

Because the chemical inventory of IRAS $16293 \mathrm{~B}$ is well characterised with results from the PILS survey, this data set is used to search for $\mathrm{HOCH}_{2} \mathrm{CN}$ and related species to make an unbiased chemical comparison with SMM1-a. While $\mathrm{HOCH}_{2} \mathrm{CN}$ was identified towards IRAS 16293B by Zeng et al. (2019), this detection cannot be confirmed in the PILS spectrum at the fullbeam offset position (the position commonly used for the molecular analysis of IRAS 16293B with PILS data, see Fig.3). Figure 6 shows the $\mathrm{HOCH}_{2} \mathrm{CN}$ a-type transitions $\left(J_{0, J^{\prime}}^{\prime}-J_{0, J^{\prime \prime}}^{\prime \prime}\right)$ at this position covered by the PILS spectral range with a synthetic glycolonitrile spectrum at $N_{\mathrm{T}}=1.0 \times 10^{15} \mathrm{~cm}^{-2}$ and $T_{\mathrm{ex}}$ $=150$ and $300 \mathrm{~K}$. A synthetic spectrum of the previously identified molecules towards IRAS 16293B at the full-beam offset 
$\mathrm{HOCH}_{2} \mathrm{CN}$ - Serpens SMM1-a
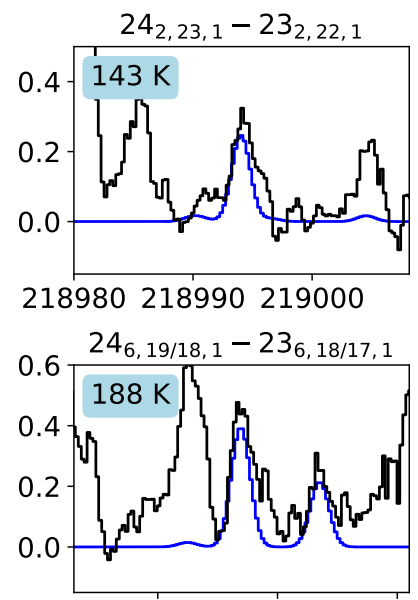

22140022141022142

$24_{8,17 / 16,0}-23_{8,16 / 15,0}$

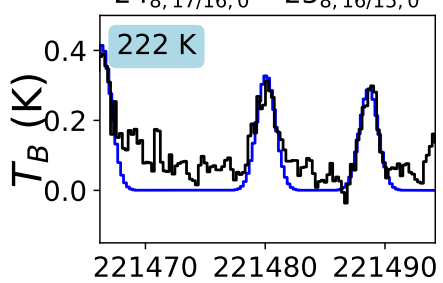

$0.624_{13,12 / 11,1}-23_{13,11 / 10,1}$

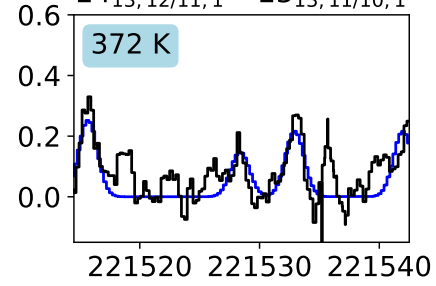

221520221530221540

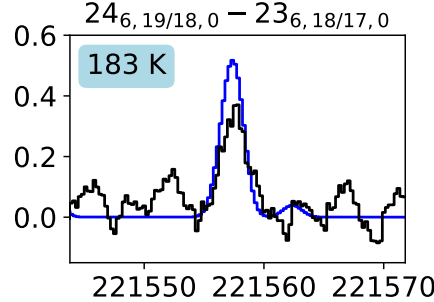

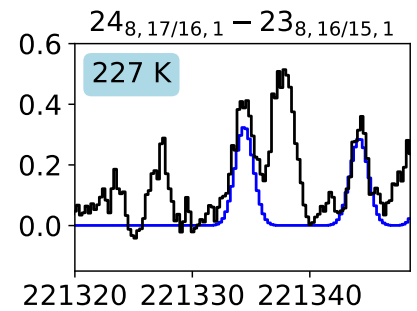

$24_{11,14 / 13,1}-23_{11,13 / 12,1}$
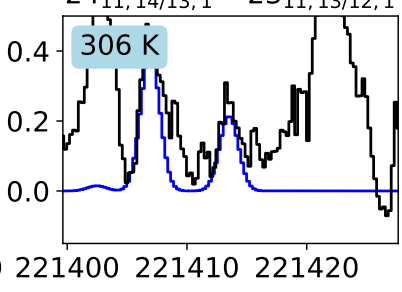

$0.624_{9,16 / 15,0}-23_{9,15 / 14,0}$

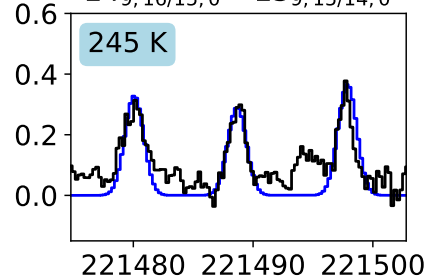

$24_{5,20,1}-23_{5,19,1}$

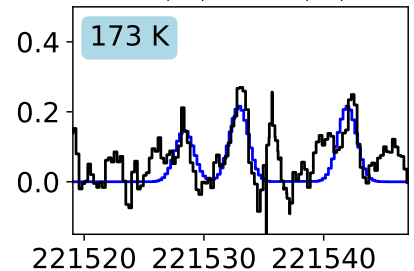

$24_{12,13 / 12,0}-23_{12,12 / 11,0}$

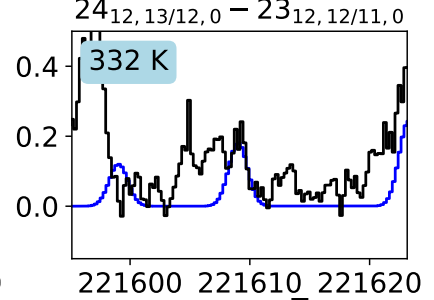

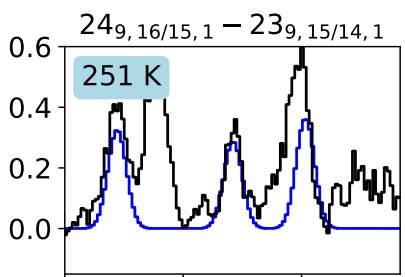

221330221340221350

$0.624_{12,13 / 12,1}-23_{12,12 / 11,1}$

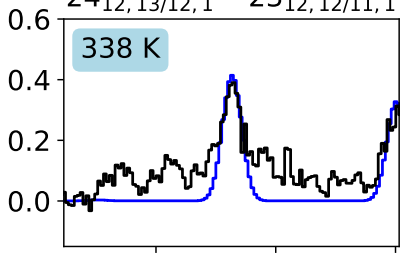

221460221470221480
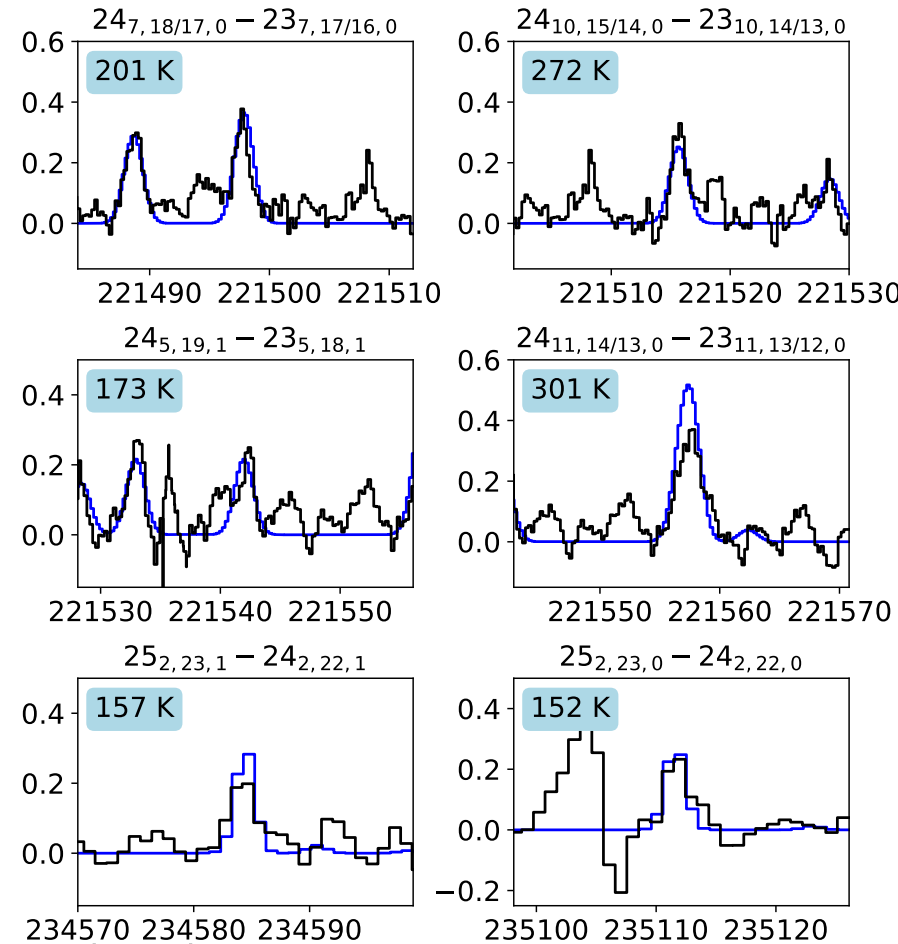
Frequency $(\mathrm{MHz})$

Fig. (4) Identified lines of $\mathrm{HOCH}_{2} \mathrm{CN}$ towards SMM1. The observed spectrum is plotted in black, with the best-fit synthetic spectrum overplotted in blue $\left(N_{\mathrm{T}}=(7.4 \pm 0.9) \times 10^{14} \mathrm{~cm}^{-2}, T_{\mathrm{ex}}=260 \pm 45 \mathrm{~K}\right)$. The transition is indicated at the top of each panel and the upper state energy is given in the top left of each panel.

position is added in green. Note that this synthetic spectrum only includes molecules listed in previous publications and does not include $\mathrm{HOCH}_{2} \mathrm{CN}$. The molecules and parameters used in this fit are listed in Table 5. When a rotational spectrum is experimentally measured, a-type transitions are usually the first and most accurately determined transitions. The assignment of these a-type transitions, therefore, is key to claim an unambiguous identification. However, of the seven a-type transitions covered by the PILS survey, only the $39_{0,39,1}-38_{0,38,1}$ transition at $344625 \mathrm{MHz}$ is possibly detected, although this feature has a contribution of a $\mathrm{HONO}$ and $\mathrm{CH}_{2} \mathrm{DOH}$ transition (Jørgensen et al. 2016, 2018; Coutens et al. 2019), which also can fully reproduce this line. Appendix $\mathrm{C}$ presents all the $\mathrm{HOCH}_{2} \mathrm{CN}$ transitions at the full-beam offset position that are largely unblended and have $A_{\mathrm{ij}} \geq 1 \times 10^{-3} \mathrm{~s}^{-1}$. At the full-beam offset position, a large number $(\sim 40)$ of glycolonitrile transitions that are present in the synthetic spectrum are not seen in the observed spectrum. We note that due to the line-richness of the source the baseline subtraction is challenging and in some cases, it can be oversubtracted. This can explain why certain $\mathrm{HOCH}_{2} \mathrm{CN}$ lines are not clearly observed, as the baseline at these positions dips. Furthermore, some transitions seem to be better reproduced with low excitation temperatures, whereas others require warmer temperatures. This could indicate that two gas components are traced, as also shown by Zeng et al. (2019), but at this position these components are hard to distinguish. Therefore, $\mathrm{HOCH}_{2} \mathrm{CN}$ can only tentatively be identified towards the full-beam offset posi- 


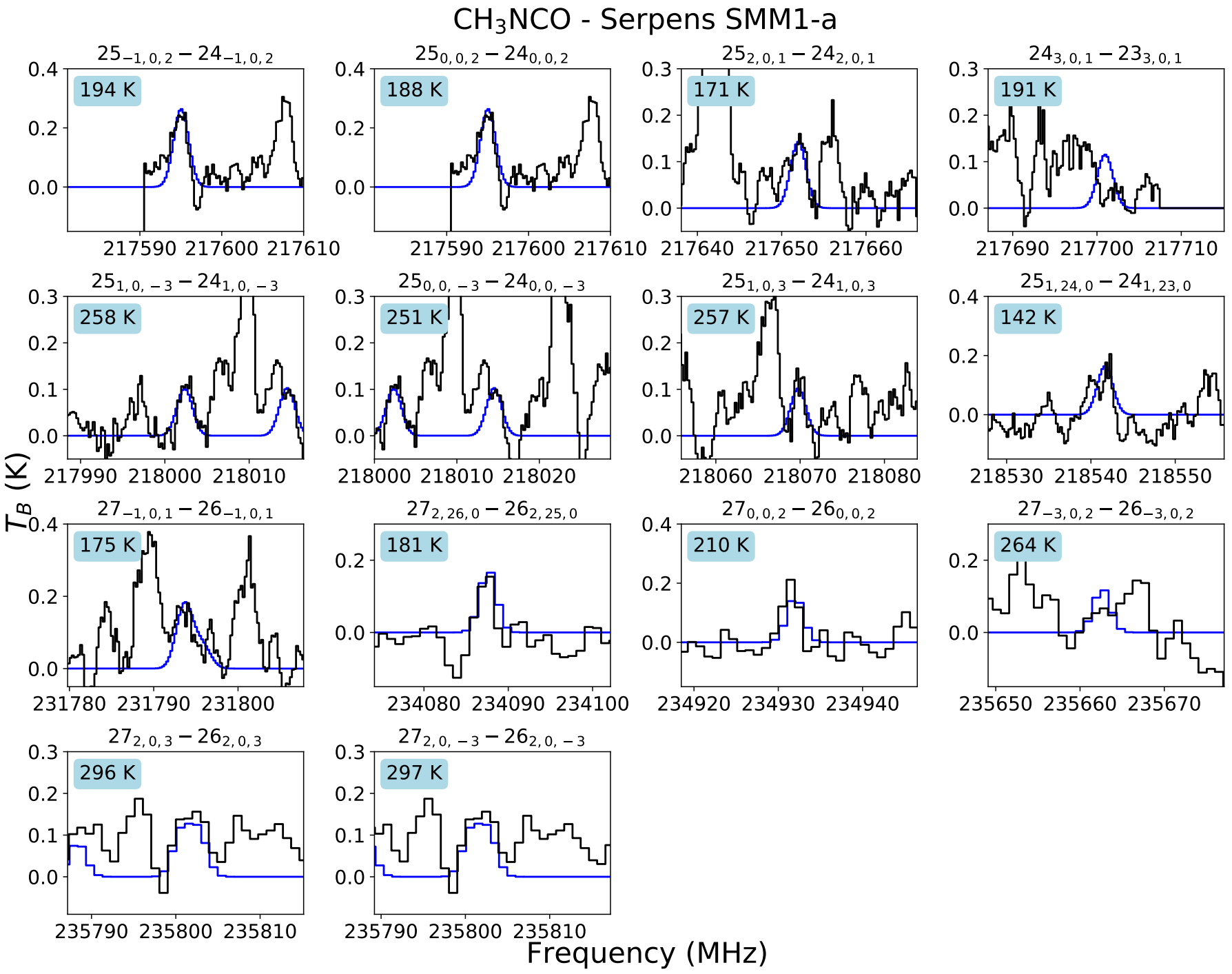

Fig. (5) Identified lines of $\mathrm{CH}_{3} \mathrm{NCO}, v=0$ towards SMM1. The observed spectrum is plotted in black, with the best-fit synthetic spectrum overplotted in blue $\left(N_{\mathrm{T}}=(6.4 \pm 1.9) \times 10^{14} \mathrm{~cm}^{-2}, T_{\mathrm{ex}}=240 \pm 60 \mathrm{~K}\right)$. The transition is indicated at the top of each panel and the upper state energy is given in the top left of each panel.

tion, with a column density of $\sim 1.0 \times 10^{15} \mathrm{~cm}^{-2}$ at $T_{\mathrm{ex}}=150$ and $300 \mathrm{~K}$.

At the half-beam offset position (see Fig. 3), which is closer to the continuum peak of IRAS $16293 \mathrm{~B}, \mathrm{HOCH}_{2} \mathrm{CN}$ can be identified. At this position, at least four a-type transitions are clearly detected, while the three other lines suffer from line blending or absorption features, see Fig. 7. These lines can approximately be fitted with synthetic spectra of $N_{\mathrm{T}}=3.0 \times 10^{15} \mathrm{~cm}^{-2}$ for $T_{\mathrm{ex}}=$ 150 and $300 \mathrm{~K}$. In appendix $\mathrm{C}$ the remaining $\mathrm{HOCH}_{2} \mathrm{CN}$ transitions at the half-beam offset position are shown, with the same selection criteria for the full-beam offset position.

In Fig. 3 the moment 0 map of the $\mathrm{HOCH}_{2} \mathrm{CN} 36_{4,32}-$ $35_{4,31}$ transition towards IRAS 16293B is shown. This map shows that $\mathrm{HOCH}_{2} \mathrm{CN}$ emission towards IRAS 16293B is compact. This explains the non-detection of glycolonitrile towards the full-beam offset position, as this position misses most of the $\mathrm{HOCH}_{2} \mathrm{CN}$ emission. At the same time, this map demonstrates why Zeng et al. (2019) could detect $\mathrm{HOCH}_{2} \mathrm{CN}$ towards IRAS $16293 \mathrm{~B}$, since these authors use a larger observational beam of 1 !'6 beam (with an assumed source size of 0 ".5), which covers the entire emitting area.
Because the chemical inventory at the full-beam offset position of the PILS data is best characterised, the tentative detection of $\mathrm{HOCH}_{2} \mathrm{CN}$ towards this position, with a column density of $\sim 1.0 \times 10^{15} \mathrm{~cm}^{-2}$ ), is used for further analysis in this paper. However, the identification of $\mathrm{HOCH}_{2} \mathrm{CN}$ towards the half-beam offset position in combination with the moment 0 map support the detection of $\mathrm{HOCH}_{2} \mathrm{CN}$ towards IRAS 16923B by Zeng et al. (2019).

The related species $\mathrm{CH}_{2} \mathrm{CNH}, \mathrm{CH}(\mathrm{O}) \mathrm{CN}$, and $\mathrm{NH}_{2} \mathrm{CH}_{2} \mathrm{CN}$ are also searched for in the PILS dataset, but clear and unblended lines are not identified. For these species upper limit column densities are determined at the full-beam offset position at excitation temperatures of 100 and $300 \mathrm{~K}$. The upper limit column densities and abundances of all species are presented in Table 3 .

\section{Discussion}

In this work, several molecules are detected towards SMM1-a and analysed. Most notable are the detection of the $\mathrm{C}_{2} \mathrm{H}_{3} \mathrm{NO}$ isomers $\mathrm{CH}_{3} \mathrm{NCO}$ (methyl isocyanate) and $\mathrm{HOCH}_{2} \mathrm{CN}$ (glycolonitrile). For $\mathrm{HOCH}_{2} \mathrm{CN}$, this is only its second interstellar detec- 


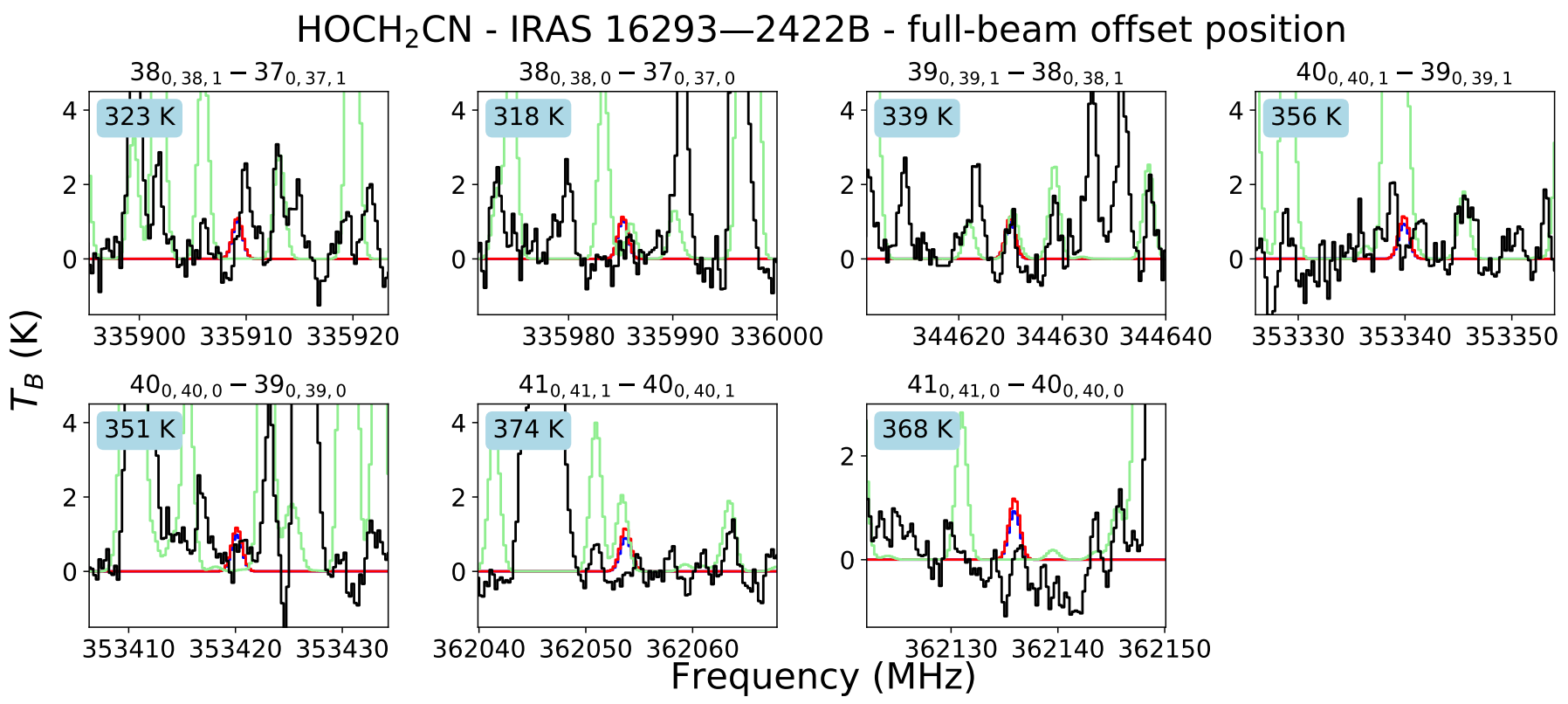

Fig. (6) Overview of a-type $\left(J_{0, J^{\prime}}^{\prime}-J_{0, J^{\prime \prime}}^{\prime \prime}\right) \mathrm{HOCH}_{2} \mathrm{CN}$ transitions covered by the PILS spectrum towards the full-beam offset position of IRAS 16293B, illustrating the non-detection of these lines in this spectrum. The observed spectrum is plotted in black and synthetic spectra for a column density of $1.0 \times 10^{15} \mathrm{~cm}^{-2}$ and excitation temperatures of 150 (blue) and $300 \mathrm{~K}$ (red) are overplotted. The synthetic spectrum of the entire molecular inventory determined with PILS data towards this position is plotted in green. The quantum numbers of the transition are indicated at the top of each panel and the upper state energy is given in the top left of each panel.

$\mathrm{HOCH}_{2} \mathrm{CN}$ - IRAS 16293-2422B - half-beam offset position
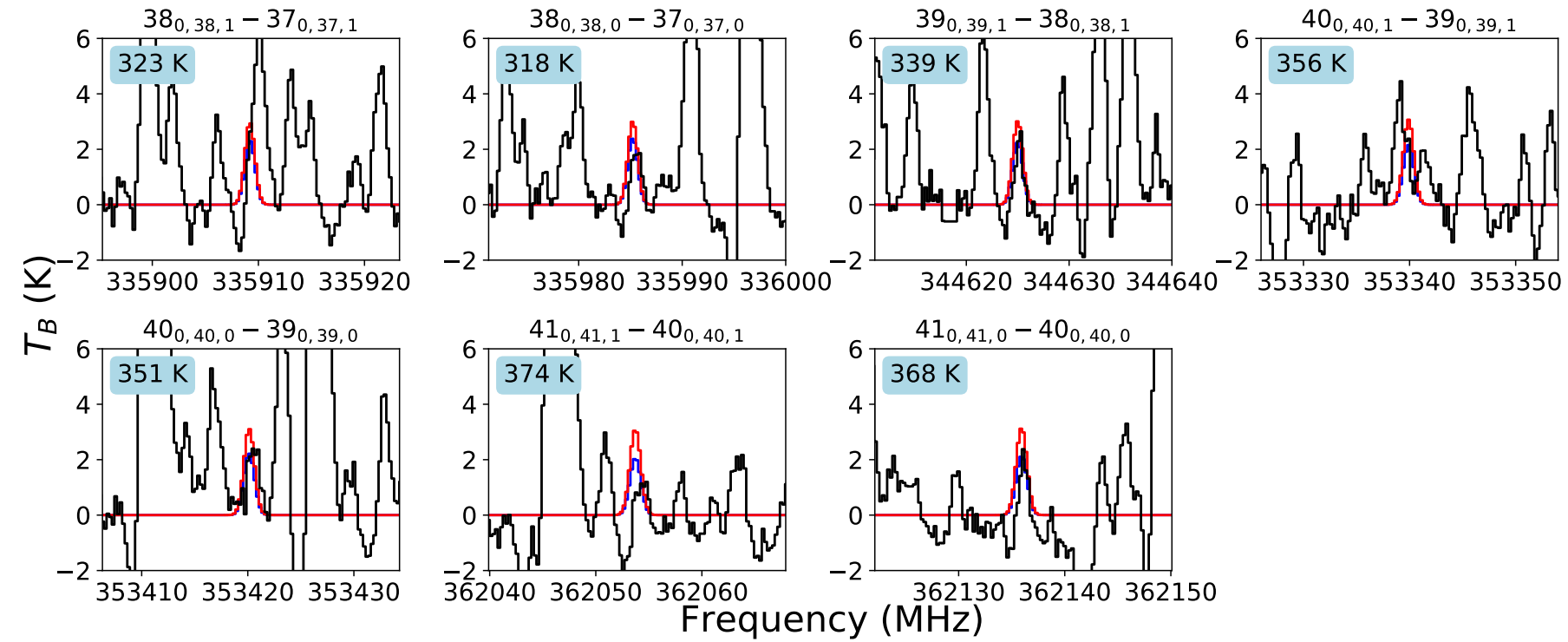

Fig. (7) Overview of a-type $\left(J_{0, J^{\prime}}^{\prime}-J_{0, J^{\prime \prime}}^{\prime \prime}\right) \mathrm{HOCH}_{2} \mathrm{CN}$ transitions covered by the PILS spectrum towards the half-beam offset position of IRAS 16293B, illustrating the detection of a number of these lines. The observed spectrum is plotted in black and synthetic spectra for a column density of $3.0 \times 10^{15} \mathrm{~cm}^{-2}$ and excitation temperatures of 150 (blue) and $300 \mathrm{~K}$ (red) are overplotted. The quantum numbers of the transition are indicated at the top of each panel and the upper state energy is given in the top left of each panel.

tion. $\mathrm{CH}_{3} \mathrm{NCO}$ has been detected in multiple interstellar sources, but this is the first detection towards SMM1 and therefore also the first detection towards an intermediate-mass source. These new detections serve as additional evidence for a large and diverse reservoir of prebiotic molecules in star- and planet-forming regions, which can contribute to the emergence of biomolecules on planetary bodies. Of the $\mathrm{C}_{2} \mathrm{H}_{3} \mathrm{NO}$ isomers, $\mathrm{CH}_{3} \mathrm{NCO}$ is en- ergetically the most favorable, followed by $\mathrm{HOCH}_{2} \mathrm{CN}$, which has a higher relative energy of $12.1-18.6 \mathrm{kcal} \mathrm{mol}^{-1}(0.5-0.8$ $\mathrm{eV}$ molecule ${ }^{-1}$ or $5800-9300 \mathrm{~K}$ molecule $^{-1}$ ), depending on the level of theory used (Fourré et al. 2020). In a thermodynamic equilibrium, lower energy or more stable products are favored and in such a scenario, $\mathrm{CH}_{3} \mathrm{NCO}$ is expected to be more abundant than $\mathrm{HOCH}_{2} \mathrm{CN}$ by a factor of at least $1 \times 10^{9}$ (assuming a 
temperature of $300 \mathrm{~K}$ ). The fact that $\mathrm{CH}_{3} \mathrm{NCO}$ and $\mathrm{HOCH}_{2} \mathrm{CN}$ are found to be equally abundant is, therefore, evidence that the formation of these molecules is rather driven by kinetics.

To better understand the interstellar chemistry of $\mathrm{HOCH}_{2} \mathrm{CN}$ and $\mathrm{CH}_{3} \mathrm{NCO}$, their abundances and those of several other species are compared for SMM1-a, IRAS 16293B, and several other sources for which at least some of these species are detected. For this comparison, it is important to emphasise observational differences. For example, SMM1 ( $\mathrm{D} \approx 436 \mathrm{pc}$ ) is located further away than IRAS 16293 (D $\approx 141$ pc, Dzib et al. $2018)$ and the beam size used in this work $\left(11^{\prime \prime} 2\right)$ is larger than that of the PILS survey $\left(0^{\prime \prime} .5\right)$. Therefore, the chemical inventory of SMM1-a and the involved chemical processes are investigated on a much larger spatial scale of roughly $500 \mathrm{au}$, compared to about 70 au for IRAS 16293B. The SMM1-a observations can cover a larger range of physical environments (e.g. also the envelope or outflow), and potentially a larger temperature gradient. At the same time, the higher luminosity of SMM1 results in a larger area where hot core conditions are present, thus compensating for the lower spatial resolution. Furthermore, the SMM1-a spectrum is extracted towards the continuum peak, but for IRAS 16293B a full-beam offset position from the continuum peak is used. Therefore, when comparing molecular ratios between the two sources, they may not only be affected by different physical conditions but also due to the way the sources were observed. Observational parameters of SMM1-a, IRAS 16293B, and other sources used for comparisons are listed in Table D.1.

$\mathrm{HOCH}_{2} \mathrm{CN}$ is thus far only detected in two sources, SMM1a and IRAS 16293B (Zeng et al. 2019), and therefore a chemical comparison is limited to these two objects. To use molecular ratios that are unbiased by observational parameters, only data of the chemical inventory of IRAS 16293B obtained with PILS survey data at the full-beam offset position is used for the source comparison. This means that the tentative column density of $\mathrm{HOCH}_{2} \mathrm{CN}$ in IRAS $16293 \mathrm{~B}$ is used. Figure 8 shows the abundances of molecules detected in this work to $\mathrm{CH}_{3} \mathrm{OH}$ and HNCO in SMM1-a and IRAS 16293B. For IRAS 16293B, the analysis performed in this work is combined with results from Jørgensen et al. (2016); Coutens et al. (2016); Ligterink et al. (2017); Coutens et al. (2018); Persson et al. (2018); Calcutt et al. (2018); Jørgensen et al. (2018). For both the $[\mathrm{X}] /\left[\mathrm{CH}_{3} \mathrm{OH}\right]$ and $[\mathrm{X}] /[\mathrm{HNCO}]$ ratios, all the oxygen-bearing molecules, $\mathrm{CH}_{3} \mathrm{CN}$, and $\mathrm{NH}_{2} \mathrm{CN}$ are found to be more abundant in IRAS 16293B than in SMM1-a. For $[\mathrm{X}] /\left[\mathrm{CH}_{3} \mathrm{OH}\right]$ its ratios are generally a factor of a few lower in SMM1-a, while for the $[\mathrm{X}] /[\mathrm{HNCO}]$ ratios the difference is usually more than a factor of ten.

\subsection{SMM1-a: $\mathrm{AHOCH}_{2} \mathrm{CN}$-rich source}

While general trends are found in the $[\mathrm{X}] /\left[\mathrm{CH}_{3} \mathrm{OH}\right]$ and $[\mathrm{X}] /[\mathrm{HNCO}]$ ratios displayed in Fig. 8, three molecules deviate from the general trend. The abundance of $\mathrm{CH}_{3} \mathrm{NCO}$ is found to be approximately equal in both sources, while $\mathrm{HOCH}_{2} \mathrm{CN}$ and HNCO are more abundant in SMM1-a compared to IRAS 16293B. In particular, for $\mathrm{HOCH}_{2} \mathrm{CN}$ a large difference is seen in its ratios to $\mathrm{CH}_{3} \mathrm{OH}$, which can be more than an order of magnitude different between the two sources.

To gain further insight in how the chemical compositions of SMM1-a and IRAS 16293B differ, the statistical distance of molecular ratios are plotted in Fig. 9. The statistical distance indicates how significant the difference in a molecular ratio between SMM1-a and IRAS 16293B is (see Manigand et al. 2020, and Appendix E). Greater values indicate a greater difference in the molecular ratios between the two sources. A positive value indicates that the ratio of SMM1-a is greater than that of IRAS 16293B and vice versa. Fig. 9 highlights that $\mathrm{HOCH}_{2} \mathrm{CN}$ and $\mathrm{HNCO}$ are more abundant in SMM1-a ( $\sigma$ ranging from 3 6) and $\mathrm{CH}_{3} \mathrm{NCO}$ is moderately more abundant in SMM1-a $(\sigma \geq$ 2).

The statistical distance results have several implications. Since the abundances of both $\mathrm{HOCH}_{2} \mathrm{CN}$ and $\mathrm{HNCO}$ are enhanced in SMM1-a, this may indicate a relationship between these two species. For $\mathrm{CH}_{3} \mathrm{NCO}$ a much less significant enhancement is seen, which can imply that both $\mathrm{C}_{2} \mathrm{H}_{3} \mathrm{NO}$ isomers form via different chemical reactions or under different physical conditions. However, it is important to stress that an abundance correlation does not always imply a formational link between species (Belloche et al. 2020).

The statistical distances of ratios involving $\mathrm{CH}_{3} \mathrm{CN}, \mathrm{NH}_{2} \mathrm{CN}$, a- $\left(\mathrm{CH}_{2} \mathrm{OH}\right)$, and $\mathrm{CH}_{3} \mathrm{CH}_{2} \mathrm{OH}$ show that there is almost no variation in these molecules between SMM1-a and IRAS 16293B. This is interesting because some of these molecules can form in reactions involving radicals from which $\mathrm{HOCH}_{2} \mathrm{CN}$ also can be formed, such as $\mathrm{CN}, \mathrm{CH}_{2} \mathrm{OH}$, and $\mathrm{CH}_{2} \mathrm{CN}$. This hints that either $\mathrm{HOCH}_{2} \mathrm{CN}$ is not formed from these radicals, is not linked to the reaction networks that form the four aforementioned species, or $\mathrm{HOCH}_{2} \mathrm{CN}$ forms from the same radicals, but under different physical conditions.

Finally, it is interesting to note that ratios of $\mathrm{D}_{2} \mathrm{CO}$ and $\mathrm{CH}_{3} \mathrm{OCHO}$ to $\mathrm{NH}_{2} \mathrm{CN}, \mathrm{CH}_{3} \mathrm{CH}_{2} \mathrm{OH}$, and a- $\left(\mathrm{CH}_{2} \mathrm{OH}\right)_{2}$ seem to be a bit more abundant in SMM1-a than in IRAS 16293B. This is particularly significant for the case of $\mathrm{D}_{2} \mathrm{CO}$ since $\mathrm{H}_{2} \mathrm{CO}$ is involved in the Strecker-like formation of $\mathrm{HOCH}_{2} \mathrm{CN}$, see reaction 2. A higher abundance of $\mathrm{H}_{2} \mathrm{CO}$ may indicate that the Strecker-like reaction can more efficiently take place. However, care needs to be taken with this interpretation, since the $\mathrm{D}_{2} \mathrm{CO}$ spectral lines in the SMM1-a spectrum are blended and thus there is a large uncertainty on its column density. At the same time, the $\mathrm{D} / \mathrm{H}$ ratio of $\mathrm{H}_{2} \mathrm{CO}$ is not known in SMM1-a, which introduces another source of uncertainty. To investigate if there is a correlation between $\mathrm{HOCH}_{2} \mathrm{CN}$ and $\mathrm{H}_{2} \mathrm{CO}$, both species should be identified towards more sources and $\mathrm{H}_{2} \mathrm{CO}$ should be observed through its minor ${ }^{13} \mathrm{C}$ and ${ }^{18} \mathrm{O}$ isotopes instead of the deuterated species. For now, however, the Strecker-like synthesis of $\mathrm{HOCH}_{2} \mathrm{CN}$ in the ISM can neither be confirmed nor ruled out.

\subsection{Interstellar formation of $\mathrm{CH}_{3} \mathrm{NCO}$}

Since its first detection in the ISM, the formation of $\mathrm{CH}_{3} \mathrm{NCO}$ has been hypothesised to be linked to that of HNCO, see Eq. 1. To investigate the interstellar chemical relationship between these two species, their gas-phase ratios towards interstellar sources are plotted in Fig. 10. The result of the SMM1a analysis is complemented by data from the low-mass protostar IRAS 16239B (Ligterink et al. 2017), the quiescent giant molecular cloud G+0.693 (Zeng et al. 2018), the high-mass starforming region Orion KL (Cernicharo et al. 2016), the high-mass hot molecular core G10.47+0.03 (Gorai et al. 2020), and the galactic center source Sagittarius B2(N) (Sgr B2(N), Belloche et al. 2013; Cernicharo et al. 2016; Belloche et al. 2017). The majority of these sources is categorised as hot cores or corinos. In these sources, thermal desorption of molecules from ice mantles plays an important role to chemically enrich the gas surrounding the protostar, in particular around the desorption temperature of water ice $(\sim 100 \mathrm{~K})$. The exception is the source $\mathrm{G}+0.693$, which is a molecular cloud. Molecules observed in the gas of this cloud are assumed to be the result of gas-phase 
$[\mathrm{X}] /\left[\mathrm{CH}_{3} \mathrm{OH}\right](\%)$

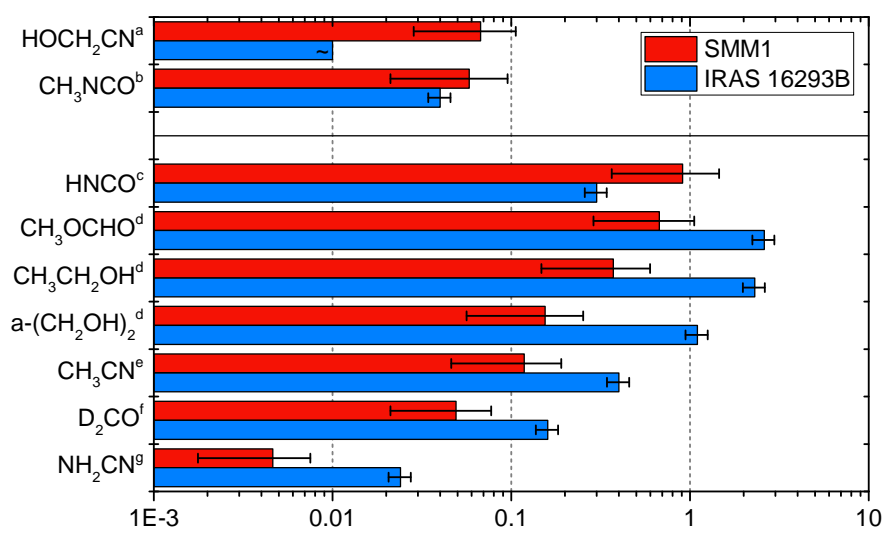

(\%)

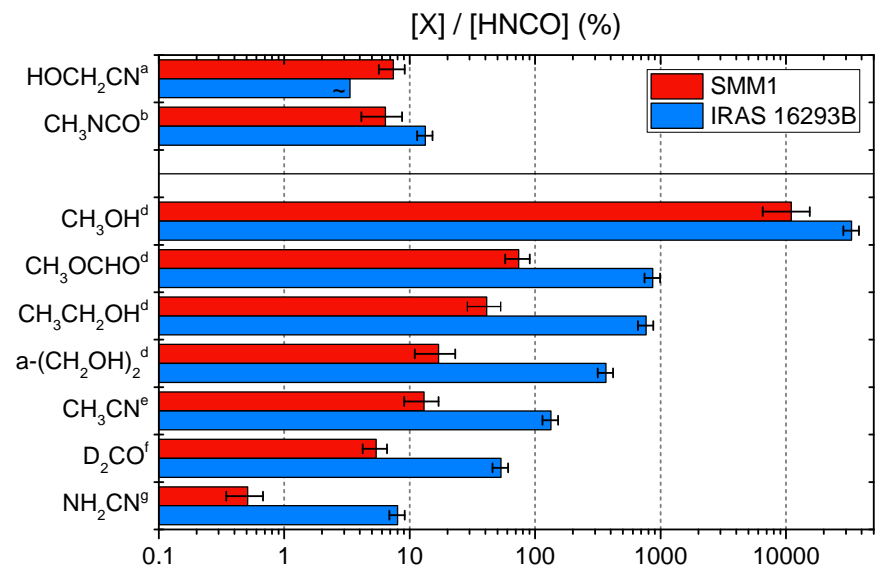

(\%)

Fig. (8) Ratios of $[\mathrm{X}] /\left[\mathrm{CH}_{3} \mathrm{OH}\right]$ towards SMM1-a (red) and IRAS 16293B (blue) in decreasing order of SMM1-a abundance. The " " symbol indicates that these $\mathrm{HOCH}_{2} \mathrm{CN}$ ratios have been determined with the column density of the tentative $\mathrm{HOCH} \mathrm{CN}^{-}$ detection towards the IRAS 16293B full-beam offset position. For IRAS 16293B, column densities derived towards the full-beam offset position from the following PILS publications are used: ${ }^{a}$ This work, ${ }^{b}$ Ligterink et al. (2017), ${ }^{c}$ Coutens et al. (2016), ${ }^{d}$ Jørgensen et al. (2016, 2018), ${ }^{e}$ Calcutt et al. (2018), ${ }^{f}$ Persson et al. (2018), ${ }^{g}$ Coutens et al. (2018).

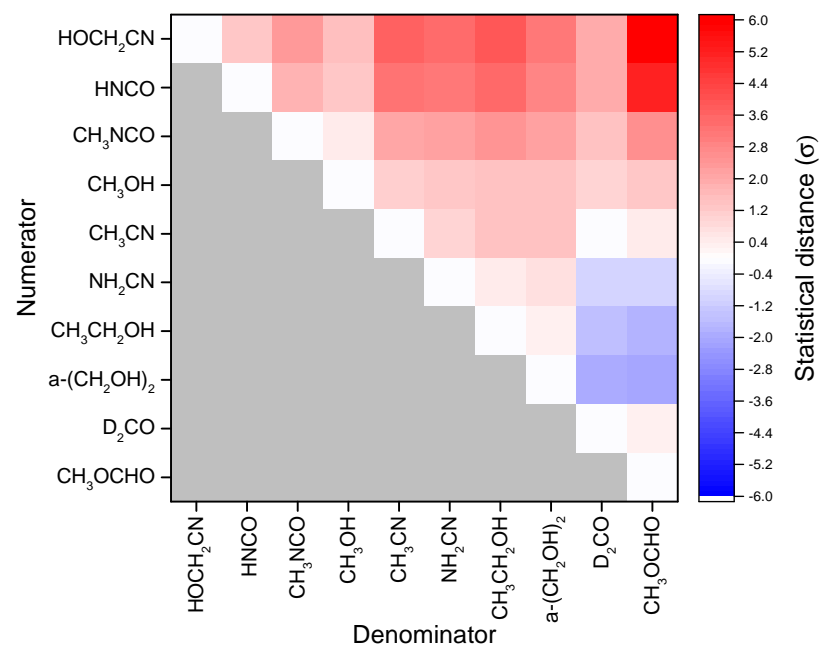

Fig. (9) Statistical distance between molecular ratios in SMM1 and IRAS 16293B, given in $\sigma$. Larger $\sigma$ values indicate a larger difference between the two sources for a given ratio. Positive values indicate that a ratio is higher in SMM1-a, while negative values indicate that a ratio is lower in SMM1-a. In particular, all ratios of $\mathrm{HOCH}_{2} \mathrm{CN}$ are found to be higher in SMM1-a than in IRAS 16239B.

formation reactions or non-thermal desorption from ice mantles of dust grains.

The ratios of $\mathrm{CH}_{3} \mathrm{NCO}$ and $\mathrm{HNCO}$ are generally similar at $\left[\mathrm{CH}_{3} \mathrm{NCO}\right] /[\mathrm{HNCO}]=\sim 10 \%$ and vary only by a factor of a few, in particular when the lowest and highest ratio are omitted. The lowest ratio, found towards $\mathrm{G}+0.693$, arises in a source with a very different physical structure and can therefore not directly be compared with the hot core and corino sources. The highest ratio is found towards $\mathrm{G} 10.47+0.03$, but the analysis of $\mathrm{HNCO}$ in this source is likely performed on optically thick HNCO lines and the analysis seems to underestimate the HNCO column density in this source (see Fig. 4 in Gorai et al. 2020). Removing these results from the analysis, a correlation between $\mathrm{CH}_{3} \mathrm{NCO}$

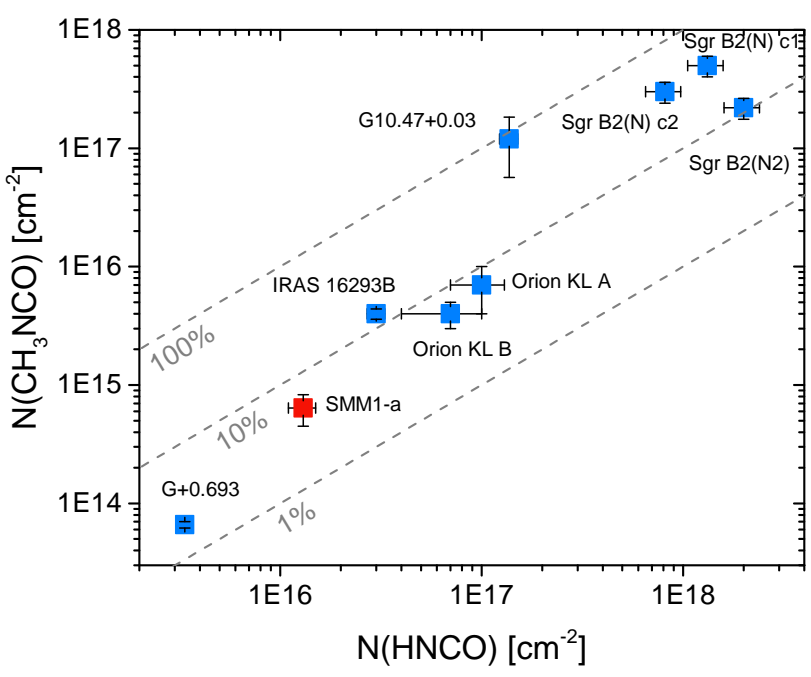

Fig. (10) Ratios of $\left[\mathrm{CH}_{3} \mathrm{NCO}\right] /[\mathrm{HNCO}]$ ratios towards SMM1-a and various other sources. Column densities from the following publications are used: Belloche et al. (2013), Cernicharo et al. (2016), Ligterink et al. (2017), Belloche et al. (2017), Zeng et al. (2018), Gorai et al. (2020), and this work.

and $\mathrm{HNCO}$ is found, which may indicate a chemical link between $\mathrm{CH}_{3} \mathrm{NCO}$ and $\mathrm{HNCO}$. Furthermore, this correlation spans a variety of sources of different masses and over four order of magnitude in luminosities. This results in different physical conditions, such as gas and dust temperature and radiation fields for each source. Therefore, the lack of source-to-source variation in $\left[\mathrm{CH}_{3} \mathrm{NCO}\right] /[\mathrm{HNCO}]$ ratio hints that the abundances of these species are set at an early stage of star formation. Formation of $\mathrm{CH}_{3} \mathrm{NCO}$ via reaction 1 in the ice mantles of dust grains during the dark cloud stage or while the ice mantles are warmed up in the hot core/corino stage are a plausible scenario. 


\subsection{On the formation of $-\mathrm{CN}$ and $-\mathrm{NCO}$ molecules}

Figure 9 shows that $\mathrm{HOCH}_{2} \mathrm{CN}$ and $\mathrm{HNCO}$ abundances are enhanced in SMM1-a compared to IRAS 16293B. At the same time, $\mathrm{CH}_{3} \mathrm{NCO}$ is only marginally enhanced and $\mathrm{CH}_{3} \mathrm{CN}$ and $\mathrm{NH}_{2} \mathrm{CN}$ abundances show little difference between the two sources. Why the abundances of $\mathrm{HOCH}_{2} \mathrm{CN}$ and $\mathrm{HNCO}$ are enhanced in SMM1-a and those of $\mathrm{CH}_{3} \mathrm{NCO}, \mathrm{CH}_{3} \mathrm{CN}$, and $\mathrm{NH}_{2} \mathrm{CN}$ are not is not straightforward to explain. However, it is likely that the various - $\mathrm{CN}$ and -NCO molecules form in different chemical reactions and physical conditions.

As this work shows, $\mathrm{CH}_{3} \mathrm{NCO}$ probably forms at an early stage of star-formation, as do $\mathrm{CH}_{3} \mathrm{CN}$ and $\mathrm{NH}_{2} \mathrm{CN}$. All three species are suggested to form in radical-radical addition reactions in ice mantles. These reactions take place during the dark cloud stage in cold $(\sim 10 \mathrm{~K})$ ice mantles and significantly speed up when the ice mantle temperature increases to $\sim 30 \mathrm{~K}$ and radicals become mobile (Garrod et al. 2008; Coutens et al. 2018). Some reactions can compete for the same radical, such as $\mathrm{CH}_{3} \mathrm{CN}$ and $\mathrm{NH}_{2} \mathrm{CN}$, which both compete for the $-\mathrm{CN}$ radical.

The fact that $\mathrm{HOCH}_{2} \mathrm{CN}$ and $\mathrm{HNCO}$ are enhanced in abundance in SMM1-a, can indicate a link between these species. Both molecules can be formed from $\mathrm{HCN}$ in ice mantles of interstellar dust grains. $\mathrm{HOCH}_{2} \mathrm{CN}$ can be formed in the Strecker-like reaction when $\mathrm{HCN}$ is converted to $\mathrm{CN}^{-}$. $\mathrm{HNCO}$ and the related anion $\mathrm{OCN}^{-}$are formed when $\mathrm{HCN}: \mathrm{H}_{2} \mathrm{O}$ mixtures are processed with energetic UV photons or protons (Gerakines et al. 2004). These reactions are aided by high grain temperatures $(\gg 30 \mathrm{~K}$, but below the water sublimation temperature) for a prolonged time and high fluxes of photons and energetic particles. If these conditions are met in SMM1, they can explain the higher abundances of $\mathrm{HOCH}_{2} \mathrm{CN}$ and $\mathrm{HNCO}$ compared to IRAS 16239B and present a formational link between some $-\mathrm{CN}$ and $-\mathrm{NCO}$ molecules. However, only circumstantial evidence can be presented for such conditions in SMM1, which is based on the fact that SMM1 hosts multiple protostellar sources and outflows, which can warm and irradiate the cloud (e.g. Choi 2009; Dionatos et al. 2014; Hull et al. 2017; Tychoniec et al. 2019).

To gain further insight into the reactions that form - $\mathrm{CN}$ and NCO molecules, unbiased observations of these species towards a multitude of sources spanning different physical conditions are needed. Not only the isomers $\mathrm{HOCH}_{2} \mathrm{CN}$ and $\mathrm{CH}_{3} \mathrm{NCO}$ should be targeted for these observations, but also species like $\mathrm{CH}_{3} \mathrm{CN}$, $\mathrm{HNCO}, \mathrm{NH}_{2} \mathrm{CN}, \mathrm{C}_{2} \mathrm{H}_{3} \mathrm{CN}$, and $\mathrm{C}_{2} \mathrm{H}_{5} \mathrm{CN}$. Laboratory, theoretical and modeling efforts should be focused on understanding the formation of these species. In particular, the formation of $\mathrm{HOCH}_{2} \mathrm{CN}$ via pathways other than the thermal Strecker-like synthesis needs to be studied and a better understanding of the formation of $\mathrm{CH}_{3} \mathrm{CN}$ is required.

\section{Conclusions}

This publication presents the simultaneous detection of the $\mathrm{C}_{2} \mathrm{H}_{3} \mathrm{NO}$ isomers methyl isocyanate $\left(\mathrm{CH}_{3} \mathrm{NCO}\right)$ and glycolonitrile $\left(\mathrm{HOCH}_{2} \mathrm{CN}\right)$. Both species are identified towards the intermediate-mass Class 0 protostar Serpens SMM1-a. This is only the second interstellar detection of glycolonitrile, while for methyl isocyanate it is the first detection towards an intermediate-mass protostar. Additionally, $\mathrm{CH}_{3} \mathrm{OH}$, $\mathrm{HNCO}$, $\mathrm{CH}_{3} \mathrm{OCHO}, \mathrm{CH}_{3} \mathrm{CH}_{2} \mathrm{OH}$, a- $\left(\mathrm{CH}_{2} \mathrm{OH}\right)_{2}, \mathrm{D}_{2} \mathrm{CO}$, and $\mathrm{NH}_{2} \mathrm{CN}$ are detected. $\mathrm{CH}_{2} \mathrm{CNH}, \mathrm{CH}(\mathrm{O}) \mathrm{CN}$, and $\mathrm{NH}_{2} \mathrm{CH}_{2} \mathrm{CN}$, molecules that are related to $\mathrm{HOCH}_{2} \mathrm{CN}$, are searched for but not identified. Data from the PILS survey towards IRAS 16293B are analysed in search for $\mathrm{HOCH}_{2} \mathrm{CN}$ and this molecule is identified in a spec- trum extracted at a half-beam offset position from the continuum peak of IRAS 16239B. The molecules $\mathrm{CH}_{2} \mathrm{CNH}, \mathrm{CH}(\mathrm{O}) \mathrm{CN}$, and $\mathrm{NH}_{2} \mathrm{CH}_{2} \mathrm{CN}$ are not identified towards this source.

The detection of $\mathrm{CH}_{3} \mathrm{NCO}$ and $\mathrm{HOCH}_{2} \mathrm{CN}$ towards SMM1$\mathrm{a}$ is additional evidence of a large interstellar reservoir of prebiotic molecules. Delivery of these molecules to planetary surfaces may contribute to the formation of biomolecules on these objects. The column densities and abundances of $\mathrm{CH}_{3} \mathrm{NCO}\left(N_{\mathrm{T}}\right.$ $=6.4 \times 10^{14} \mathrm{~cm}^{-2}$ and $\left.\left[\mathrm{CH}_{3} \mathrm{NCO}\right] /\left[\mathrm{CH}_{3} \mathrm{OH}\right]=5.3 \times 10^{-4}\right)$ and $\mathrm{HOCH}_{2} \mathrm{CN}\left(N_{\mathrm{T}}=7.4 \times 10^{14} \mathrm{~cm}^{-2}\right.$ and $\left[\mathrm{HOCH}_{2} \mathrm{CN}\right] /\left[\mathrm{CH}_{3} \mathrm{OH}\right]$ $=6.2 \times 10^{-4}$ ) are found to be equal within their error bars. Since $\mathrm{HOCH}_{2} \mathrm{CN}$ is the least energetically favorable of the two isomers, thermodynamics predicts that $\mathrm{CH}_{3} \mathrm{NCO}$ should be more abundant. The equal ratio between both molecules is therefore evidence that the formation of these molecules is driven by kinetics.

The comparison of molecular ratios between SMM1-a and IRAS $16293 \mathrm{~B}$ show that $\mathrm{HOCH}_{2} \mathrm{CN}$ and $\mathrm{HNCO}$ are significantly more abundant in the former source. The molecular ratios of $\mathrm{HOCH}_{2} \mathrm{CN}$ hint that the formation of this molecule does not heavily depend on solid-state radical-radical addition reactions, such as $\mathrm{HOCH}_{2}+\mathrm{CN}$ and $\mathrm{HO}+\mathrm{CH}_{2} \mathrm{CN}$. Formation via the thermal Strecker-like reaction $\left[\mathrm{X}^{+} \mathrm{CN}^{-}\right]+\mathrm{H}_{2} \mathrm{CO}$ in ice mantles cannot be confirmed nor ruled out based on the current data but may be a prominent formation pathway.

To investigate the possibility that $\mathrm{CH}_{3} \mathrm{NCO}$ formation is related to HNCO, the ratios of these molecules in SMM1-a and other sources are analysed. These ratios are found to be uniform throughout all sources at $\left[\mathrm{CH}_{3} \mathrm{NCO}\right] /[\mathrm{HNCO}]=\sim 10 \%$. This indicates that there is a chemical link between both species, but also that its ratios is already set at an early stage of starformation. Presumably $\mathrm{CH}_{3} \mathrm{NCO}$ forms via the radical-radical reaction $\mathrm{CH}_{3}+\mathrm{NCO}$ in ice mantles during the dark cloud stage.

It is difficult to establish a chemical link between - $\mathrm{CN}$ and -NCO molecules. Some may be related, such as $\mathrm{HOCH}_{2} \mathrm{CN}$ and $\mathrm{HNCO}$, which can both form from $\mathrm{HCN}$ at elevated $(\gg 30 \mathrm{~K}$ ) grain temperatures and in relatively high radiation fields. Continued observational, laboratory, and theoretical studies of - $\mathrm{CN}$ and -NCO molecules are required to gain further insight into their formation and links in their chemistry.

Acknowledgements. We thank E.G. Bøgelund, S.F. Wampfler, M.N. Drozdovskaya, B. Kulterer, and B.A. McGuire for helpful discussions on the observations, spectroscopy, and the chemistry of the $\mathrm{C}_{2} \mathrm{H}_{3} \mathrm{NO}$ isomers. The authors acknowledge assistance from Allegro, the European ALMA Regional Center node in the Netherlands. We thank the anonymous referee for their thorough review of this manuscript and helpful comments. This paper makes use of the following ALMA data: ADS/JAO.ALMA\#2018.1.00836.S and ADS/JAO.ALMA\#2013.1.00278.S. ALMA is a partnership of ESO (representing its member states), NSF (USA) and NINS (Japan), together with NRC (Canada), MOST and ASIAA (Taiwan), and KASI (Republic of Korea), in cooperation with the Republic of Chile. The Joint ALMA Observatory is operated by ESO, AUI/NRAO and NAOJ. NFWL is supported by the Swiss National Science Foundation (SNSF) Ambizione grant 193453. JKJ is supported by the European Research Council (ERC) under the European Union's Horizon 2020 research and innovation programme through ERC Consolidator Grant "S4F" (grant agreement No 646908). AC acknowledges financial support from the Agence Nationale de la Recherche (grant ANR-19-ERC7-0001-01).

\section{References}

Allamandola, L., Sandford, S., \& Valero, G. 1988, Icarus, 76, 225 Belloche, A., Garrod, R. T., Müller, H. S. P., et al. 2019, A\&A, 628, A10 Belloche, A., Maury, A., Maret, S., et al. 2020, Astronomy \& Astrophysics Belloche, A., Menten, K., Comito, C., et al. 2008, Astronomy \& Astrophysics, 482, 179

Belloche, A., Meshcheryakov, A. A., Garrod, R. T., et al. 2017, A\&A, 601, A49 
Belloche, A., Müller, H. S., Menten, K. M., Schilke, P., \& Comito, C. 2013 , Astronomy \& Astrophysics, 559, A47

Bocquet, R., Demaison, J., Cosléou, J., et al. 1999, Journal of molecular spectroscopy, 195, 345

Bøgelund, E. G., McGuire, B. A., Hogerheijde, M. R., van Dishoeck, E. F., \& Ligterink, N. F. W. 2019, A\&A, 624, A82

Boogert, A. A., Gerakines, P. A., \& Whittet, D. C. 2015, Annual Review of Astronomy and Astrophysics, 53

Bossa, J., Theule, P., Duvernay, F., \& Chiavassa, T. 2009, The Astrophysical Journal, 707, 1524

Bulak, M., Paardekooper, D., Fedoseev, G., \& Linnartz, H. 2020, Astronomy \& Astrophysics, 636, A32

Calcutt, H., Jørgensen, J. K., Müller, H., et al. 2018, Astronomy \& Astrophysics, 616, A90

Casali, M., Eiroa, C., \& Duncan, W. 1993, Astronomy and Astrophysics, 275, 195

Cernicharo, J., Kisiel, Z., Tercero, B., et al. 2016, Astronomy \& Astrophysics, $587, \mathrm{~L} 4$

Choi, M. 2009, The Astrophysical Journal, 705, 1730

Christen, D., Coudert, L., Suenram, R. D., \& Lovas, F. J. 1995, Journal of Molecular Spectroscopy, 172, 57

Christen, D. \& Müller, H. S. 2003, Physical Chemistry Chemical Physics, 5, 3600

Coutens, A., Jørgensen, J. K., Van der Wiel, M. H. D., et al. 2016, Astronomy \& Astrophysics, 590, L6

Coutens, A., Ligterink, N. F. W., Loison, J.-C., et al. 2019, Astronomy \& Astrophysics, 623, L13

Coutens, A., Willis, E., Garrod, R., et al. 2018, Astronomy \& Astrophysics, 612, A 107

Danger, G., Borget, F., Chomat, M., et al. 2011, Astronomy \& Astrophysics, 535, A47

Danger, G., Duvernay, F., Theulé, P., Borget, F., \& Chiavassa, T. 2012, The Astrophysical Journal, 756, 11

Danger, G., Rimola, A., Mrad, N. A., et al. 2014, Physical Chemistry Chemical Physics, 16, 3360

Dionatos, O., Jørgensen, J. K., Green, J. D., et al. 2013, Astronomy \& Astrophysics, 558, A88

Dionatos, O., Jørgensen, J. K., Teixeira, P., Güdel, M., \& Bergin, E. 2014, Astronomy \& Astrophysics, 563, A28

Dzib, S., Ortiz-León, G., Hernández-Gómez, A., et al. 2018, Astronomy \& Astrophysics, 614, A20

Fisher, J., Paciga, G., Xu, L.-H., et al. 2007, Journal of Molecular Spectroscopy, 245,7

Fourré, I., Matz, O., Ellinger, Y., \& Guillemin, J. 2020, Astronomy \& Astrophysics, 639, A16

Garrod, R. T., Weaver, S. L. W., \& Herbst, E. 2008, The Astrophysical Journal, 682,283

Gerakines, P., Moore, M., \& Hudson, R. 2004, Icarus, 170, 202

Goicoechea, J. R., Cernicharo, J., Karska, A., et al. 2012, Astronomy \& Astrophysics, 548, A77

Gorai, P., Bhat, B., Sil, M., et al. 2020, The Astrophysical Journal, 895, 86

Halfen, D., Ilyushin, V. V., \& Ziurys, L. M. 2015, The Astrophysical Journal Letters, 812, L5

Halfen, D. T., Ilyushin, V., \& Ziurys, L. M. 2011, ApJ, 743, 60

Hocking, W., Gerry, M., \& Winnewisser, G. 1975, Canadian Journal of Physics, 53,1869

Högbom, J. A. 1974, A\&AS, 15, 417

Hogerheijde, M. R., Van Dishoeck, E. F., Salverda, J. M., \& Blake, G. A. 1999, The Astrophysical Journal, 513, 350

Hollis, J. M., Lovas, F. J., \& Jewell, P. R. 2000, The Astrophysical Journal Letters, 540, L107

Hollis, J. M., Lovas, F. J., Remijan, A. J., et al. 2006, ApJ, 643, L25

Holtom, P. D., Bennett, C. J., Osamura, Y., Mason, N. J., \& Kaiser, R. I. 2005, ApJ, 626, 940

Hudson, R. \& Moore, M. 2004, Icarus, 172, 466

Hull, C. L., Girart, J. M., Kristensen, L. E., et al. 2016, The Astrophysical Journal Letters, 823, L27

Hull, C. L., Girart, J. M., Tychoniec, Ł., et al. 2017, The Astrophysical Journal, 847,92

Ilyushin, V., Kryvda, A., \& Alekseev, E. 2009, Journal of Molecular Spectroscopy, 255, 32

Jacobsen, S., Jørgensen, J., Van der Wiel, M., et al. 2018, Astronomy \& Astrophysics, 612, A72

Jørgensen, J., Müller, H., Calcutt, H., et al. 2018, Astronomy \& Astrophysics, $620, \mathrm{~A} 170$

Jørgensen, J. K., Favre, C., Bisschop, S. E., et al. 2012, The Astrophysical Journal Letters, 757, L4

Jørgensen, J. K., Van der Wiel, M. H. D., Coutens, A., et al. 2016, Astronomy \& Astrophysics, 595, A117
Kaifu, N., Morimoto, M., Nagane, K., et al. 1974, ApJ, 191, L135

Koivusaari, M., Horneman, V., \& Anttila, R. 1992, Journal of Molecular Spectroscopy, 152, 377

Kristensen, L., Van Dishoeck, E., Van Kempen, T., et al. 2010, Astronomy \& Astrophysics, 516, A57

Kukolich, S. G., Nelson, A., \& Yamanashi, B. 1971, Journal of the American Chemical Society, 93, 6769

Lapinov, A., Golubiatnikov, G. Y., Markov, V., \& Guarnieri, A. 2007, Astronomy Letters, 33, 121

Lee, C.-W., Kim, J.-K., Moon, E.-S., Minh, Y. C., \& Kang, H. 2009, ApJ, 697

Ligterink, N., Coutens, A., Kofman, V., et al. 2017, Monthly Notices of the Royal Astronomical Society, 469, 2219

Ligterink, N. F., El-Abd, S. J., Brogan, C. L., et al. 2020, The Astrophysical Journal, 901, 37

Ligterink, N. F. W., Calcutt, H., Coutens, A., et al. 2018, Astronomy \& Astrophysics, 619, A28

Majumdar, L., Loison, J.-C., Ruaud, M., et al. 2018, Monthly Notices of the Royal Astronomical Society: Letters, 473, L59

Manigand, S., Jørgensen, J., Calcutt, H., et al. 2020, Astronomy \& Astrophysics, $635, \mathrm{~A} 48$

Margulès, L., McGuire, B., Senent, M. L., et al. 2017, Astronomy \& Astrophysics, 601, A50

Martín-Doménech, R., Rivilla, V., Jiménez-Serra, I., et al. 2017, Monthly Notices of the Royal Astronomical Society, 469, 2230

Maté, B., Molpeceres, G., Tanarro, I., et al. 2018, The Astrophysical Journal, 861,61

McGuire, B. A., Carroll, P. B., Loomis, R. A., et al. 2016, Science, 352, 1449

Müller, H. S., Belloche, A., Xu, L.-H., et al. 2016, Astronomy \& Astrophysics, 587, A92

Müller, H. S., Brown, L. R., Drouin, B. J., et al. 2015, Journal of Molecular Spectroscopy, 312, 22

Müller, H. S., Schlöder, F., Stutzki, J., \& Winnewisser, G. 2005, Journal of Molecular Structure, 742, 215

Müller, H. S., Thorwirth, S., Roth, D., \& Winnewisser, G. 2001, Astronomy \& Astrophysics, 370, L49

Niedenhoff, M., Yamada, K., Belov, S., \& Winnewisser, G. 1995, Journal of Molecular Spectroscopy, 174, 151

Öberg, K. I., Van der Marel, N., Kristensen, L. E., \& Van Dishoeck, E. F. 2011, The Astrophysical Journal, 740, 14

Ortiz-León, G. N., Dzib, S. A., Kounkel, M. A., et al. 2017, The Astrophysica Journal, 834, 143

Pearson, J. C., Brauer, C. S., \& Drouin, B. J. 2008, Journal of Molecular Spectroscopy, 251, 394

Persson, M. V., Jørgensen, J. K., Müller, H., et al. 2018, Astronomy \& Astrophysics, 610, A54

Pickett, H., Poynter, R., Cohen, E., et al. 1998, Journal of Quantitative Spectroscopy and Radiative Transfer, 60, 883

Quénard, D., Jiménez-Serra, I., Viti, S., Holdship, J., \& Coutens, A. 2018 Monthly Notices of the Royal Astronomical Society, 474, 2796

Read, W. G., Cohen, E. A., \& Pickett, H. M. 1986, Journal of Molecular Spectroscopy, 115,316

Rivilla, V., Martín-Pintado, J., Jiménez-Serra, I., et al. 2019, Monthly Notices of the Royal Astronomical Society: Letters, 483, L114

Rivilla, V. M., Martín-Pintado, J., Jiménez-Serra, I., et al. 2020, The Astrophysical Journal Letters, 899, L28

Rubin, R. H., Swenson, G. W., J., Benson, R. C., Tigelaar, H. L., \& Flygare, W. H. 1971, ApJ, 169, L39

Saladino, R., Crestini, C., Pino, S., Costanzo, G., \& Di Mauro, E. 2012, Physics of Life Reviews, 9, 84

Sánchez-Monge, Á., Schilke, P., Ginsburg, A., Cesaroni, R., \& Schmiedeke, A. 2018, Astronomy \& Astrophysics, 609, A101

Sandford, S. A., Nuevo, M., Bera, P. P., \& Lee, T. J. 2020, Chemical Reviews

Schwartz, A. W. \& Goverde, M. 1982, Journal of molecular evolution, 18, 351

Schwartz, A. W., Joosten, H., \& Voet, A. 1982, Biosystems, 15, 191

Turner, B. E., Liszt, H. S., Kaifu, N., \& Kisliakov, A. G. 1975, ApJ, 201, L149

Tychoniec, Ł., Hull, C. L. H., Kristensen, L. E., et al. 2019, A\&A, 632, A101

White, G. J., Casali, M. M., \& Eiroa, C. 1995, Astronomy \& Astrophysics, 298, 594

Wilson, T. 1999, Reports on Progress in Physics, 62, 143

Woon, D. E. 2001, Icarus, 149, 277

Xu, L.-H., Fisher, J., Lees, R., et al. 2008, Journal of Molecular Spectroscopy, 251,305

Yan, Y., Zhang, J., Henkel, C., et al. 2019, The Astrophysical Journal, 877, 154

Zakharenko, O., Motiyenko, R. A., Margulès, L., \& Huet, T. R. 2015, Journal of Molecular Spectroscopy, 317, 41

Zaleski, D. P., Seifert, N. A., Steber, A. L., et al. 2013, The Astrophysical Journal Letters, 765, L10

Zeng, S., Jiménez-Serra, I., Rivilla, V., et al. 2018, Monthly Notices of the Royal Astronomical Society, 478, 2962

Zeng, S., Quénard, D., Jiménez-Serra, I., et al. 2019, Monthly Notices of the Royal Astronomical Society: Letters, 484, L43 


\section{Appendix A: Spectroscopic data}

In this paper, the CDMS and JPL spectroscopic databases are the primary sources of molecular line lists. In the following table, an overview of the analysed molecules, their identifier and catalog, and the most important publications in literature on which these entries are based is given.

\section{Appendix B: Supporting information for the SMM1-a analysis}

\section{Appendix C: Analysis of PILS data}

\section{Appendix D: Source parameters}

\section{Appendix E: Statistical distance}

The statistical distance of molecular ratios between SMM1-a and IRAS $16293 \mathrm{~B}$ is calculated according to the following equation:

$S_{\mathrm{X} / \mathrm{Y}}=\frac{\left(\frac{N_{\mathrm{X}}}{N_{\mathrm{Y}}}\right)_{\text {SMM1-a }}-\left(\frac{N_{\mathrm{X}}}{N_{\mathrm{Y}}}\right)_{\text {IRAS 16293B }}}{\sqrt{\sigma_{\text {SMM1-a }}^{2}+\sigma_{\text {IRAS 16293B }}^{2}}}$,

where $N_{\mathrm{x}}$ and $N_{\mathrm{y}}$ are the column densities of two different molecules and $\sigma$ is the uncertainty on the column density ratio $\left(\frac{N_{\mathrm{X}}}{N_{\mathrm{Y}}}\right)$. The value of $S_{\mathrm{X} / \mathrm{Y}}$ is given in $\sigma$ and indicates the significance of the difference, with greater values implying that there is a more significant difference between the two sources. In this equation, positive values indicate that $\left(\frac{N_{X}}{N_{Y}}\right)$ is more abundant in SMM1-a than in IRAS 16293B, while negative values indicate the opposite. 
Table (A.1)

\begin{tabular}{|c|c|c|c|c|}
\hline Molecule & ID & catalog & entry date & reference \\
\hline $\mathrm{D}_{2} \mathrm{CO}$ & 32502 & CDMS & Jan 2016 & $\begin{array}{c}\text { Bocquet et al. (1999) } \\
\text { Zakharenko et al. (2015) }\end{array}$ \\
\hline${ }^{12} \mathrm{CH}_{3} \mathrm{OH}$ & 32504 & CDMS & May 2016 & Xu et al. (2008) \\
\hline $\mathrm{CH}_{3}^{18} \mathrm{OH}$ & 34504 & CDMS & Sep 2020 & Fisher et al. (2007) \\
\hline $\mathrm{CH}_{3}^{3} \mathrm{CN}, v_{8}=1$ & 41509 & CDMS & Nov 2016 & $\begin{array}{l}\text { Müller et al. (2015) } \\
\text { Koivusaari et al. (1992) }\end{array}$ \\
\hline $\mathrm{NH}_{2} \mathrm{CN}$ & 42003 & JPL & Jan 1991 & Read et al. (1986) \\
\hline $\mathrm{HN}^{12} \mathrm{CO}$ & 43511 & CDMS & May 2009 & $\begin{array}{l}\text { Kukolich et al. (1971) } \\
\text { Hocking et al. (1975) } \\
\text { Niedenhoff et al. (1995) } \\
\text { Lapinov et al. (2007) }\end{array}$ \\
\hline $\mathrm{HN}^{13} \mathrm{CO}$ & 44008 & JPL & Jul 1987 & Hocking et al. (1975) \\
\hline $\mathrm{CH}_{3} \mathrm{CH}_{2} \mathrm{OH}$ & 46524 & CDMS & Nov 2016 & $\begin{array}{l}\text { Pearson et al. (2008) } \\
\text { Müller et al. (2016) }\end{array}$ \\
\hline $\mathrm{CH}_{3} \mathrm{NCO}, v=0$ & 57505 & CDMS & Mar 2016 & Cernicharo et al. (2016) \\
\hline $\mathrm{CH}_{3} \mathrm{NCO}, v=1$ & 57506 & CDMS & Mar 2016 & Cernicharo et al. (2016) \\
\hline $\mathrm{HOCH}_{2} \mathrm{CN}$ & 57512 & CDMS & Mar 2017 & Margulès et al. (2017) \\
\hline $\mathrm{CH}_{3} \mathrm{OCHO}$ & 60003 & JPL & Apr 2009 & Ilyushin et al. (2009) \\
\hline $\mathrm{a}-\left(\mathrm{CH}_{2} \mathrm{OH}\right)_{2}$ & 62503 & CDMS & Sep 2003 & $\begin{array}{l}\text { Christen et al. (1995) } \\
\text { Christen \& Müller (2003) }\end{array}$ \\
\hline
\end{tabular}

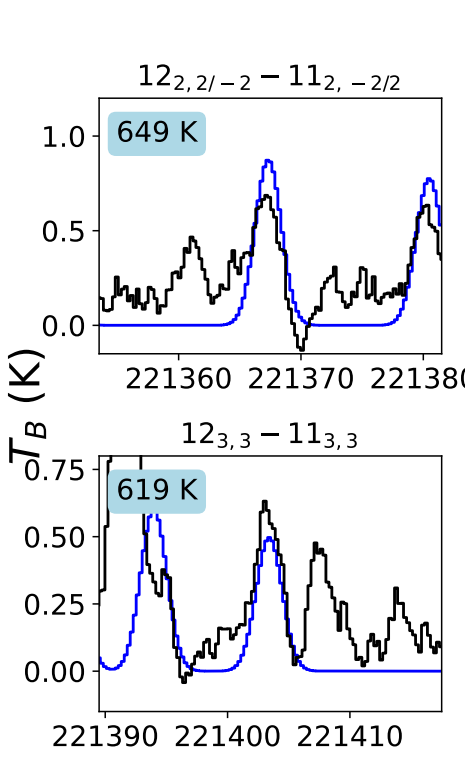

$\mathrm{CH}_{3} \mathrm{CN} \quad v_{8}=1$ - Serpens SMM1-a
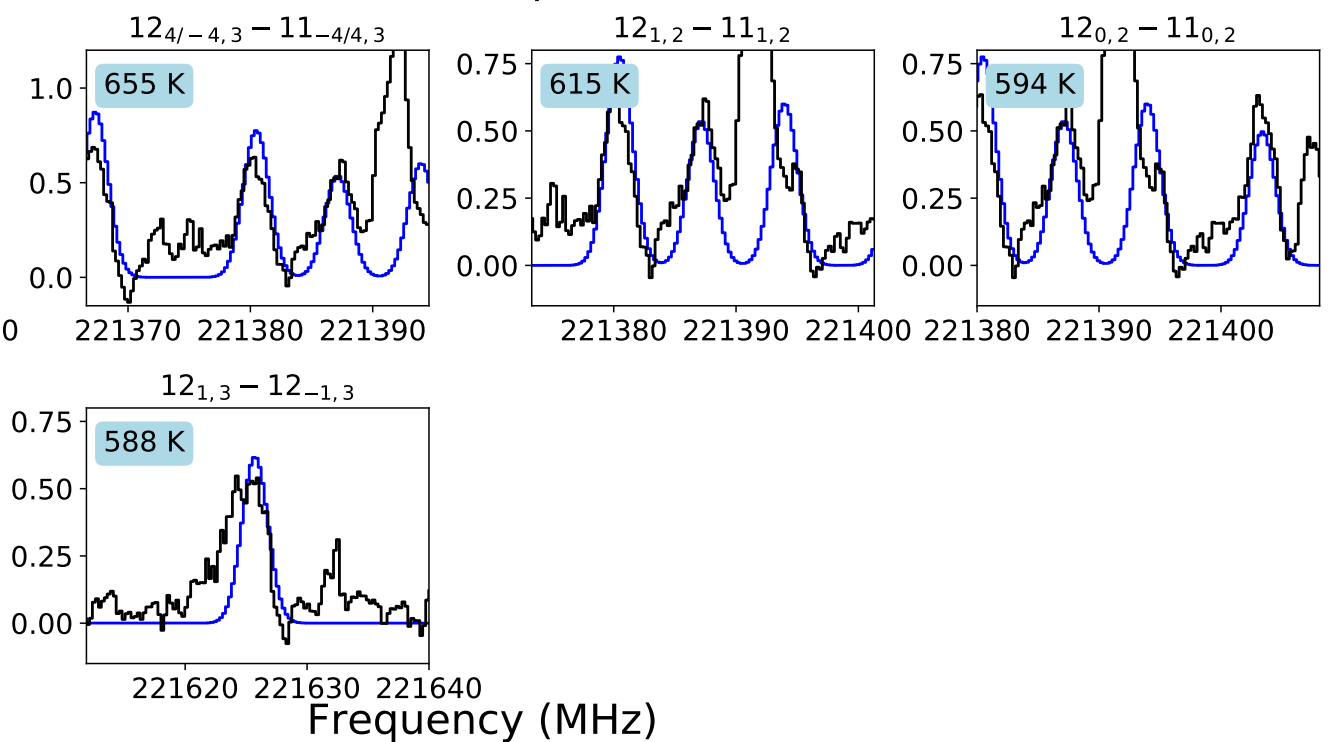

Fig. (B.1) Identified lines of $\mathrm{CH}_{3} \mathrm{CN} v_{8}=1$ towards SMM1. The observed spectrum is plotted in black, with the best-fit synthetic spectrum overplotted in blue $\left(N_{\mathrm{T}}=(1.3 \pm 0.3) \times 10^{15} \mathrm{~cm}^{-2}, T_{\mathrm{ex}}=190 \pm 25 \mathrm{~K}\right)$. The transition is indicated at the top of each panel and the upper state energy is given in the top left of each panel.

Table (D.1) Physical parameters of interstellar sources used for abundance comparison.

\begin{tabular}{ccccccc}
\hline \hline Source & Telescope & $\begin{array}{c}\text { Distance } \\
(\mathrm{pc})\end{array}$ & $\begin{array}{c}\text { Luminosity } \\
L_{\odot}\end{array}$ & $\begin{array}{c}\text { Beam size } \\
\left({ }^{\prime \prime} \times{ }^{\prime \prime}\right)\end{array}$ & $\begin{array}{c}\text { physical size } \\
\text { au }\end{array}$ & Reference \\
\hline IRAS 16293-2422B & ALMA & 141 & $3^{a}$ & $0.5 \times 0.5$ & 70 & Jørgensen et al. (2016) \\
Serpens SMM1-a & ALMA & 436 & $100^{b}$ & $1.3 \times 1.0$ & 500 & this work \\
Orion KL & ALMA & 414 & $1 \times 10^{5}$ & $1.8 \times 1.8$ & 750 Cernicharo et al. (2016) \\
Sgr B2(N2) & ALMA & 8300 & $4.7 \times 10^{6}$ & $1.6 \times 1.2-2.9 \times 1.5$ & $1.3 \times 10^{4}$ & Belloche et al. $(2017)$ \\
G10.47+0.03 & ALMA & 8550 & $5 \times 10^{5}$ & $2.0 \times 1.4-2.4 \times 1.6$ & $1.6 \times 10^{4}$ & Gorai et al. $(2020)$ \\
Sgr B2(N) & IRAM 30m & 8300 & $4.7 \times 10^{6}$ & $3.2 \times 2.8-12.2 \times 4.4$ & $3.0 \times 10^{4}$ & Cernicharo et al. $(2016)$ \\
G+0.693 & IRAM 30m \& GBT & $8300^{c}$ & - & $9 \times 9-55 \times 55$ & $\geq 7.5 \times 10^{4}$ & Zeng et al. $(2019)$ \\
\hline
\end{tabular}

Notes. ${ }^{a}$ Luminosity determined from a modeling investigation by Jacobsen et al. (2018). ${ }^{b}$ Luminosity for the entire SMM1 source. ${ }^{c}$ The distance to $\mathrm{G}+0.693$ is assumed to be the same as Sgr B2. 


\section{$\mathrm{NH}_{2} \mathrm{CN}$ - Serpens SMM1-a}
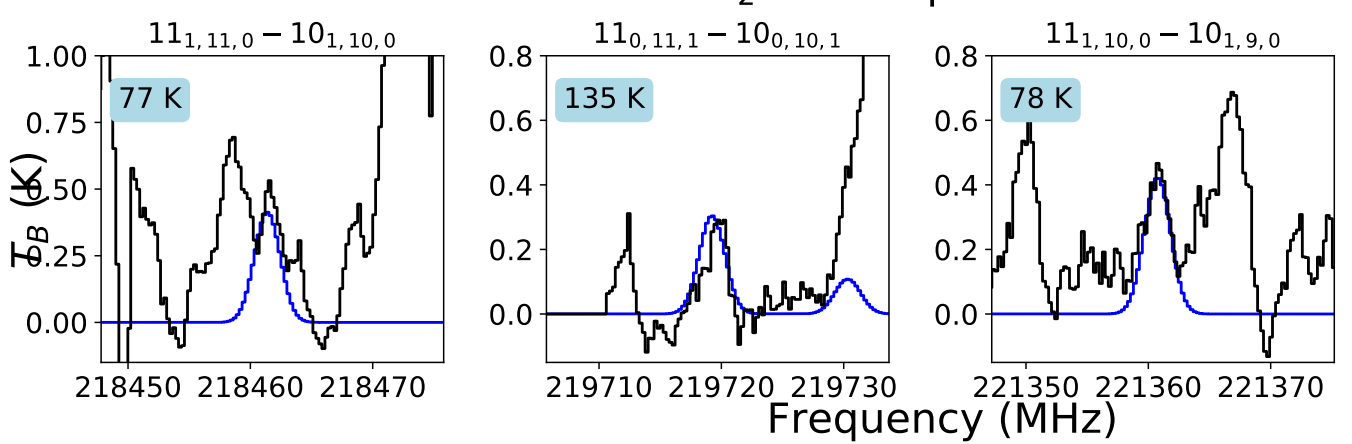

Fig. (B.2) Identified lines of $\mathrm{NH}_{2} \mathrm{CN}$ towards SMM1. The observed spectrum is plotted in black, with the best-fit synthetic spectrum overplotted in blue $\left(N_{\mathrm{T}}=(5.1 \pm 1.3) \times 10^{13} \mathrm{~cm}^{-2}, T_{\mathrm{ex}}=190 \pm 40 \mathrm{~K}\right)$. The transition is indicated at the top of each panel and the upper state energy is given in the top left of each panel.

\section{a- $\left(\mathrm{CH}_{2} \mathrm{OH}\right)_{2}$ - Serpens SMM1-a}
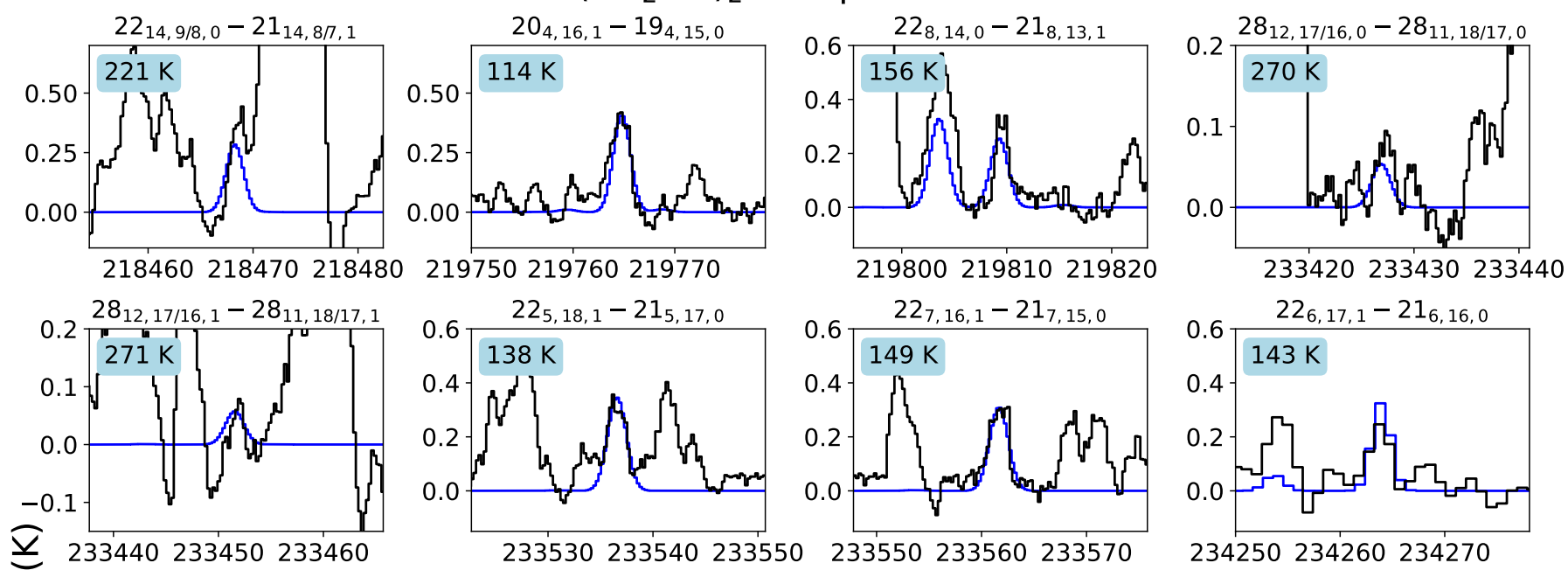

$\stackrel{5}{\infty} \quad 51_{13,39,1}-51_{12,40,1}$
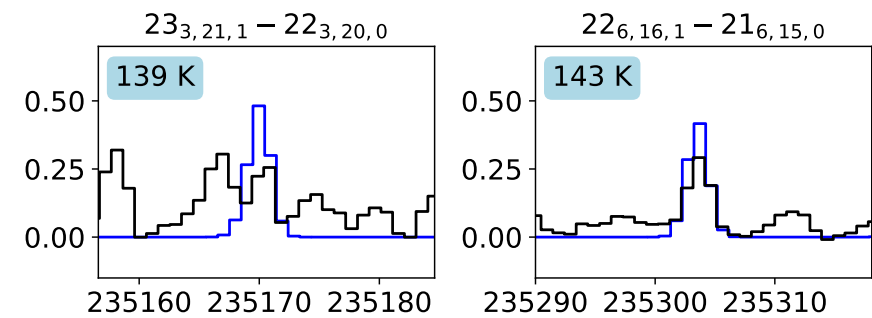

$145,9,1-134,10,1$
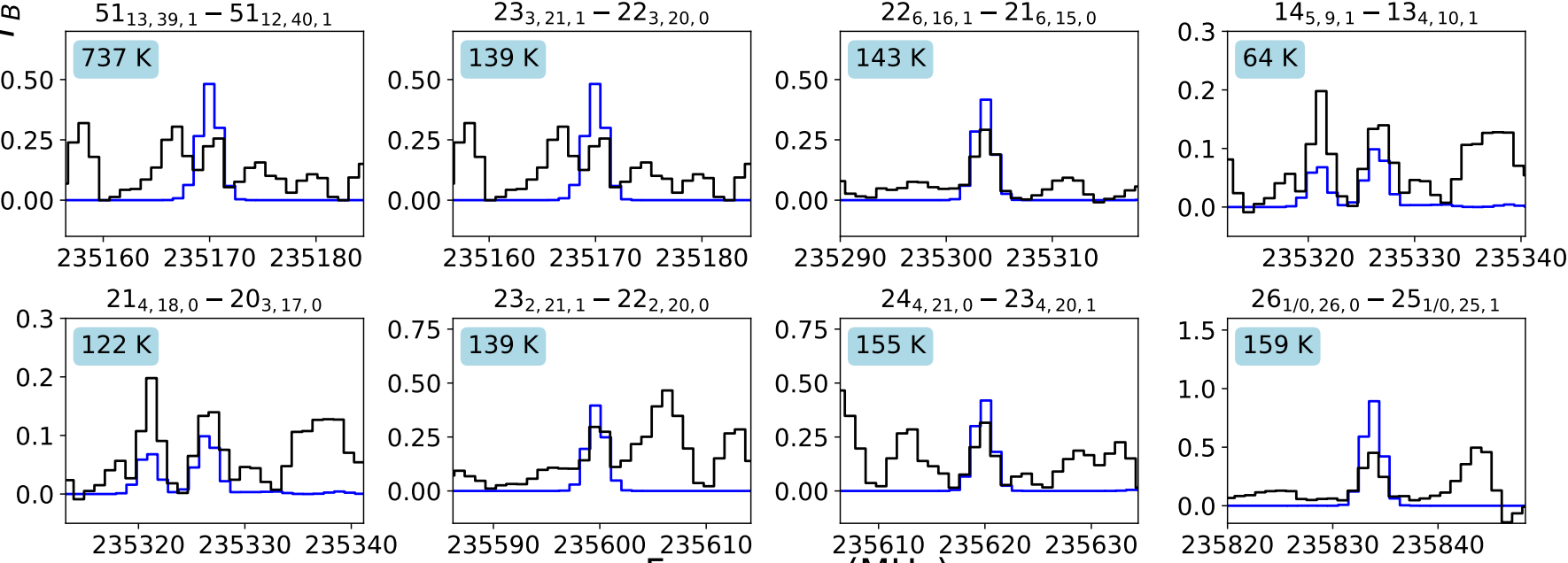

Frequency $(\mathrm{MHz})$
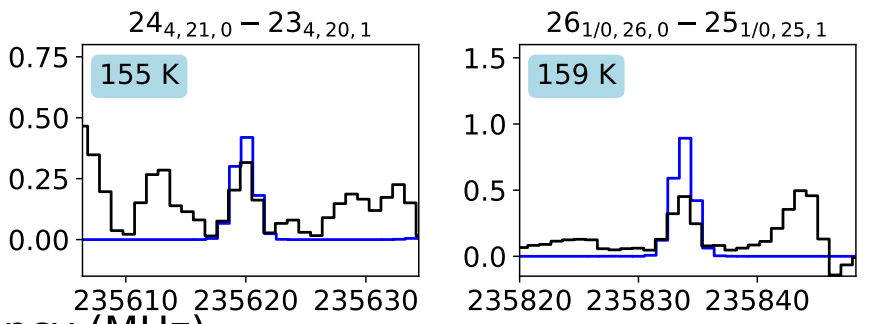

Fig. (B.3) Identified lines of a- $\left(\mathrm{CH}_{2} \mathrm{OH}\right)_{2}$ towards SMM1. The observed spectrum is plotted in black, with the best-fit synthetic spectrum overplotted in blue $\left(N_{\mathrm{T}}=(1.7 \pm 0.5) \times 10^{15} \mathrm{~cm}^{-2}, T_{\mathrm{ex}}=195 \pm 70 \mathrm{~K}\right)$. The transition is indicated at the top of each panel and the upper state energy is given in the top left of each panel. 


\section{$\mathrm{CH}_{3} \mathrm{CH}_{2} \mathrm{OH}$ - Serpens SMM1-a}

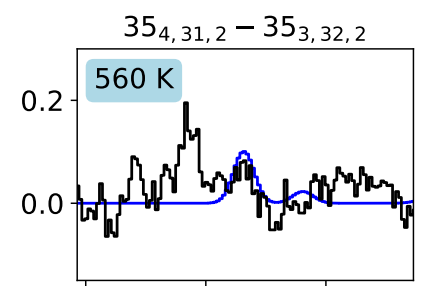

218930218940218950

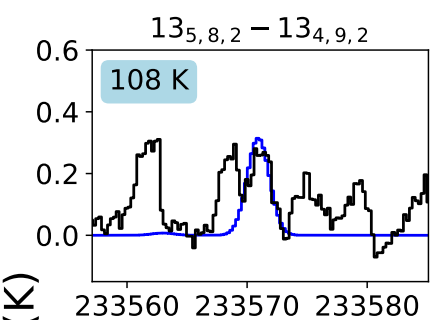

$105,5,2-10_{4,6,2}$

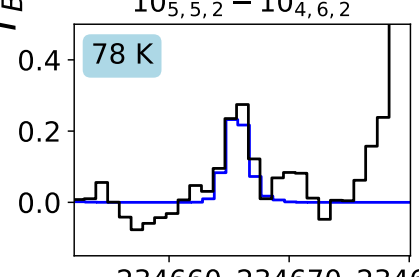

234660234670234680234700234710234720

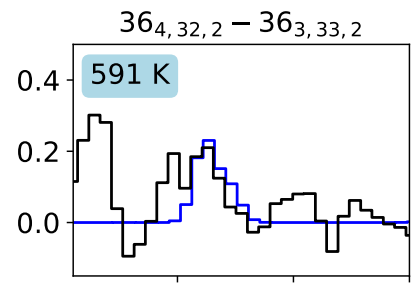

234850234860234870234860234870234880

$10_{5,6,2}-10_{4,7,2}$
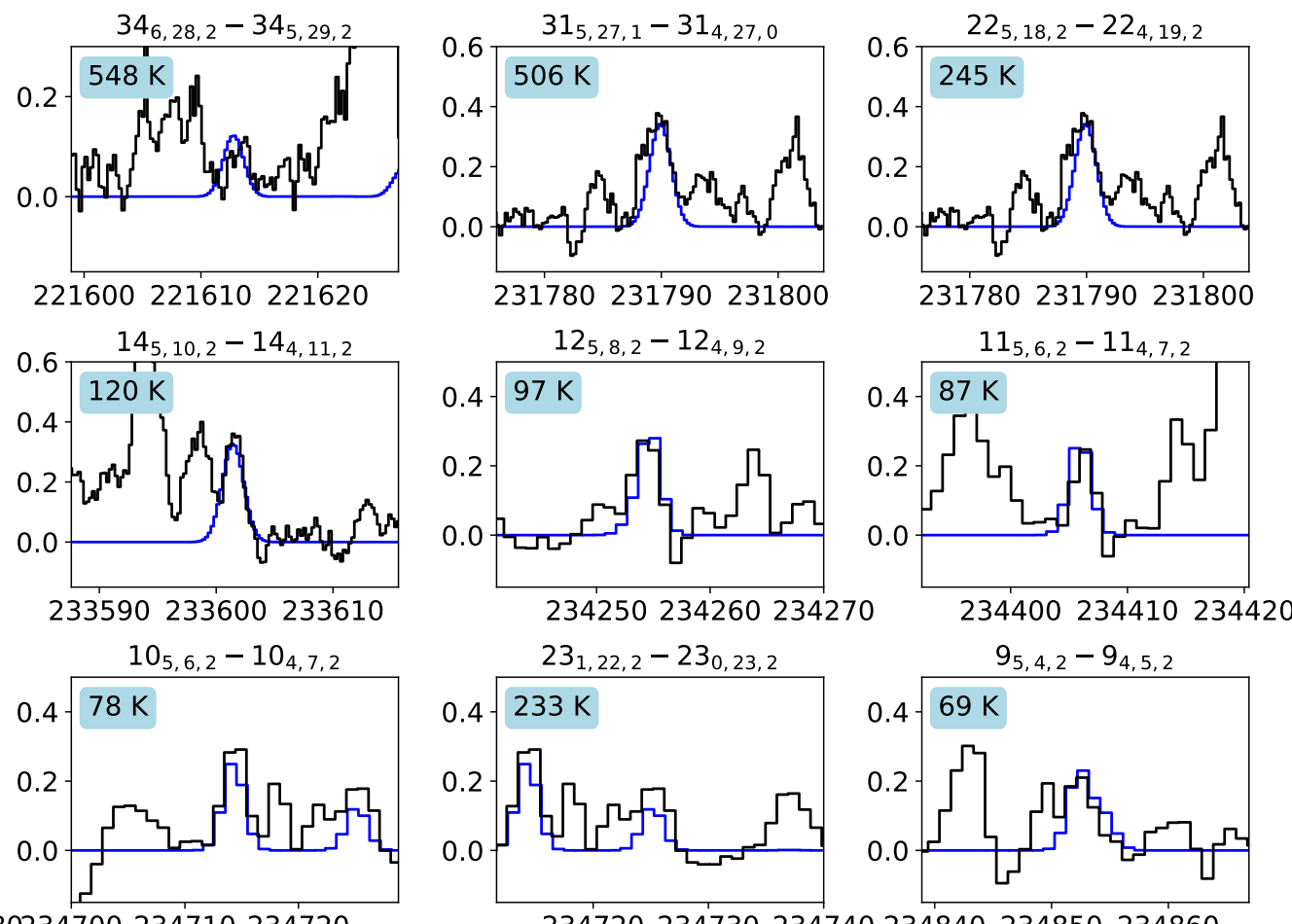

234720234730234740234840234850234860

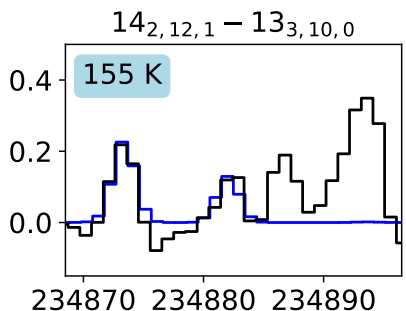

234870234880234890

( $\mathrm{MHz})$

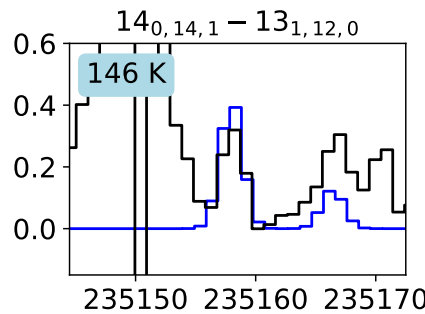

Fig. (B.4) Identified lines of $\mathrm{CH}_{3} \mathrm{CH}_{2} \mathrm{OH}$ towards SMM1. The observed spectrum is plotted in black, with the best-fit synthetic spectrum overplotted in blue $\left(N_{\mathrm{T}}=(4.1 \pm 0.9) \times 10^{15} \mathrm{~cm}^{-2}, T_{\mathrm{ex}}=210 \pm 25 \mathrm{~K}\right)$. The transition is indicated at the top of each panel and the upper state energy is given in the top left of each panel. 


\section{$\mathrm{CH}_{3} \mathrm{OCHO}$ - Serpens SMM1-a}
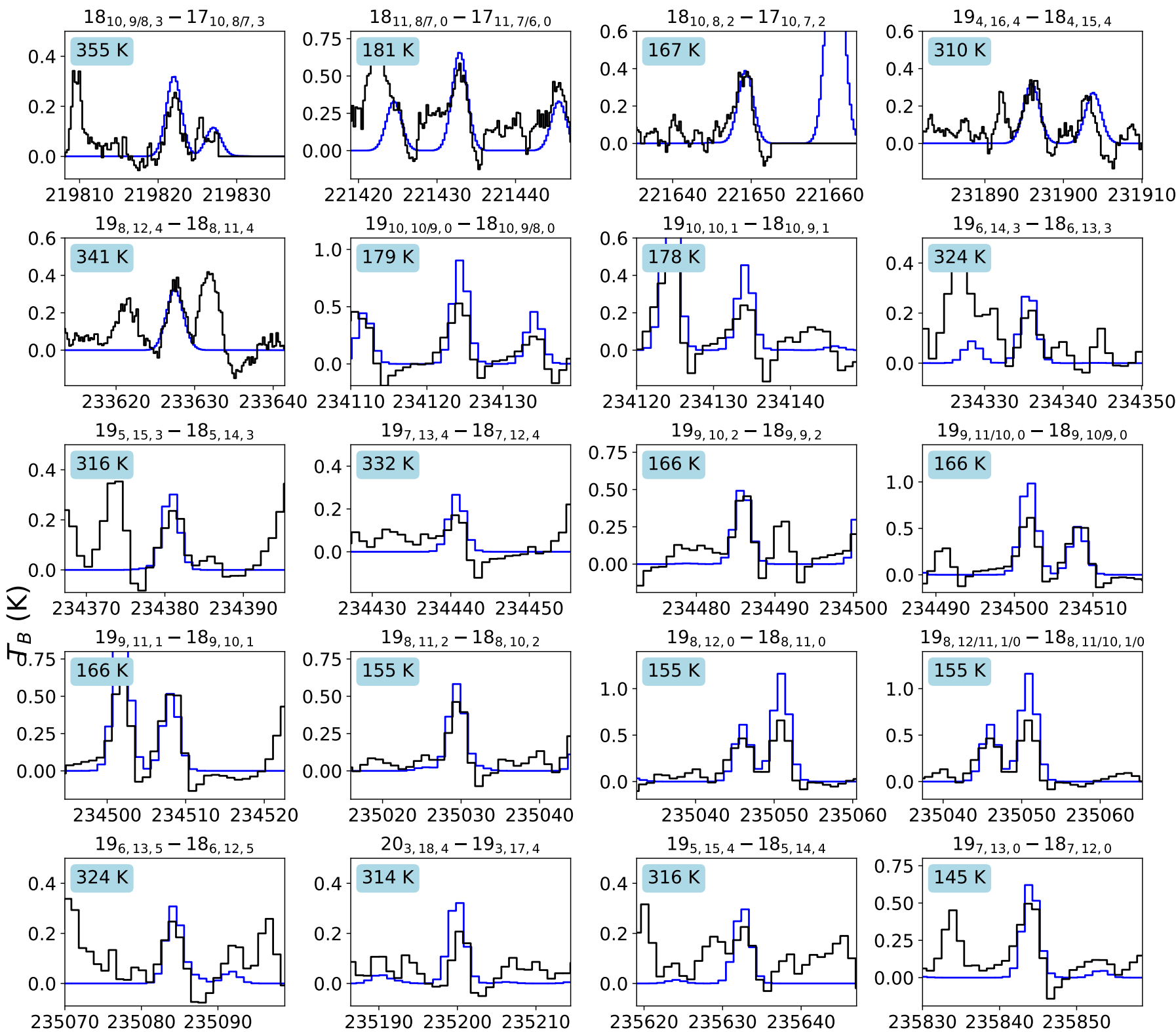

235070235080235090
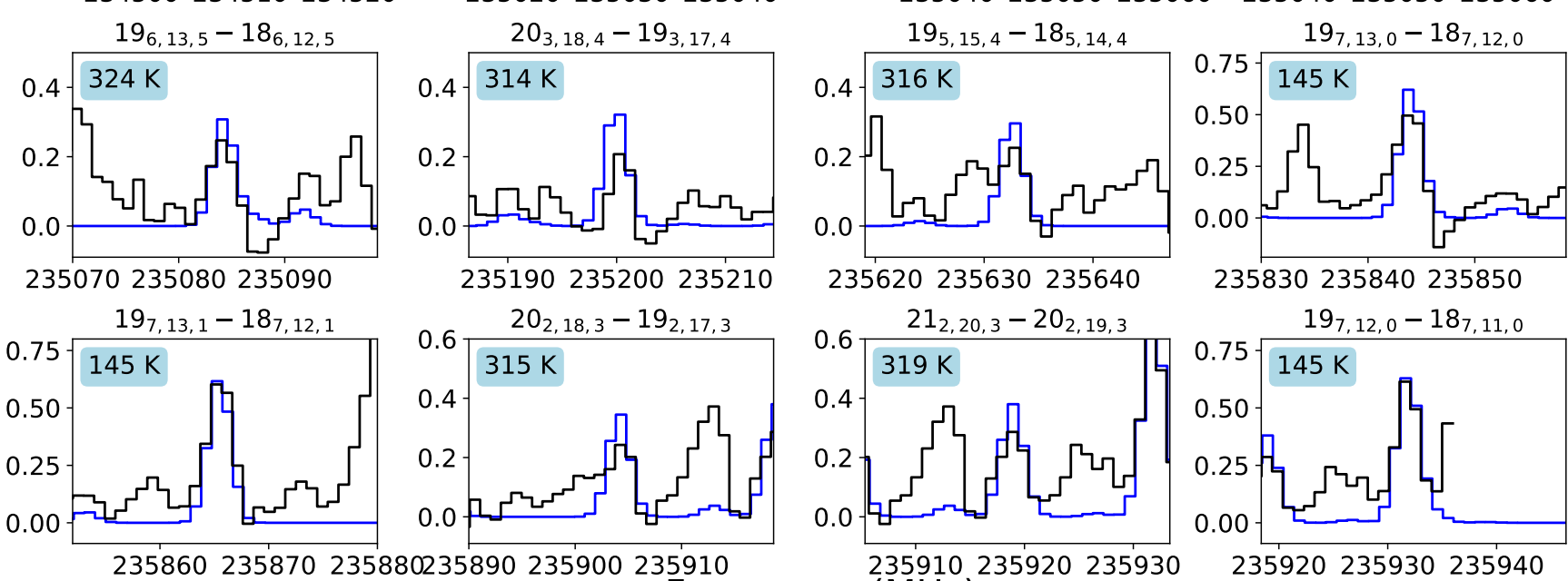

235830235840235850

235860235870235880235890235900235910

Frequency $(\mathrm{MHz})$

Fig. (B.5) Identified lines of $\mathrm{CH}_{3} \mathrm{OCHO}$ towards SMM1. The observed spectrum is plotted in black, with the best-fit synthetic spectrum overplotted in blue $\left(N_{\mathrm{T}}=(7.4 \pm 0.7) \times 10^{15} \mathrm{~cm}^{-2}, T_{\mathrm{ex}}=215 \pm 20 \mathrm{~K}\right)$. The transition is indicated at the top of each panel and the upper state energy is given in the top left of each panel. 


\section{$\mathrm{D}_{2} \mathrm{CO}$ - Serpens SMM1-a}
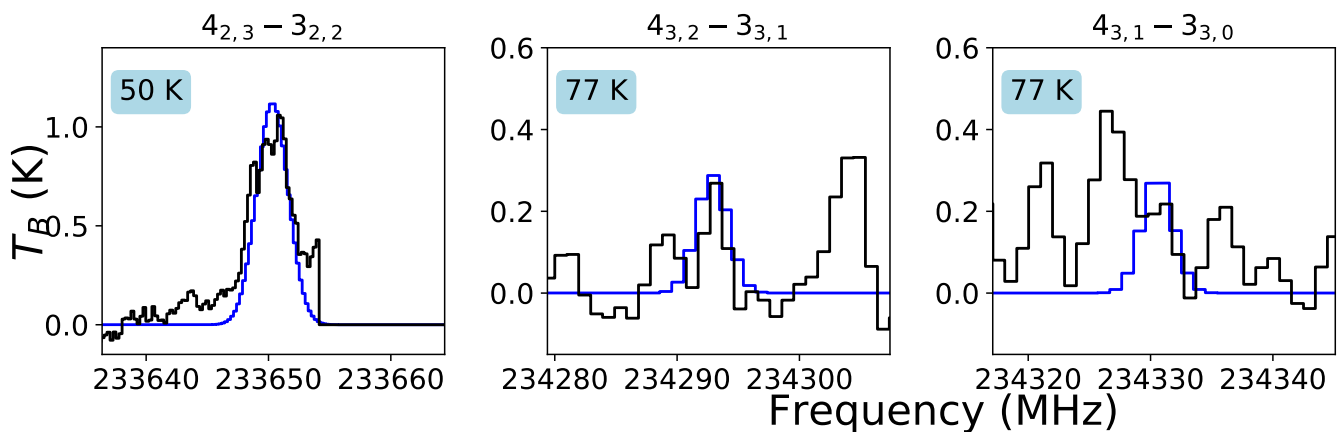

Fig. (B.6) Identified lines of $\mathrm{D}_{2} \mathrm{CO}$ towards SMM1. The observed spectrum is plotted in black, with the best-fit synthetic spectrum overplotted in blue $\left(N_{\mathrm{T}}=(5.4 \pm 0.5) \times 10^{14} \mathrm{~cm}^{-2}, T_{\mathrm{ex}}=[200] \mathrm{K}\right)$. The transition is indicated at the top of each panel and the upper state energy is given in the top left of each panel.
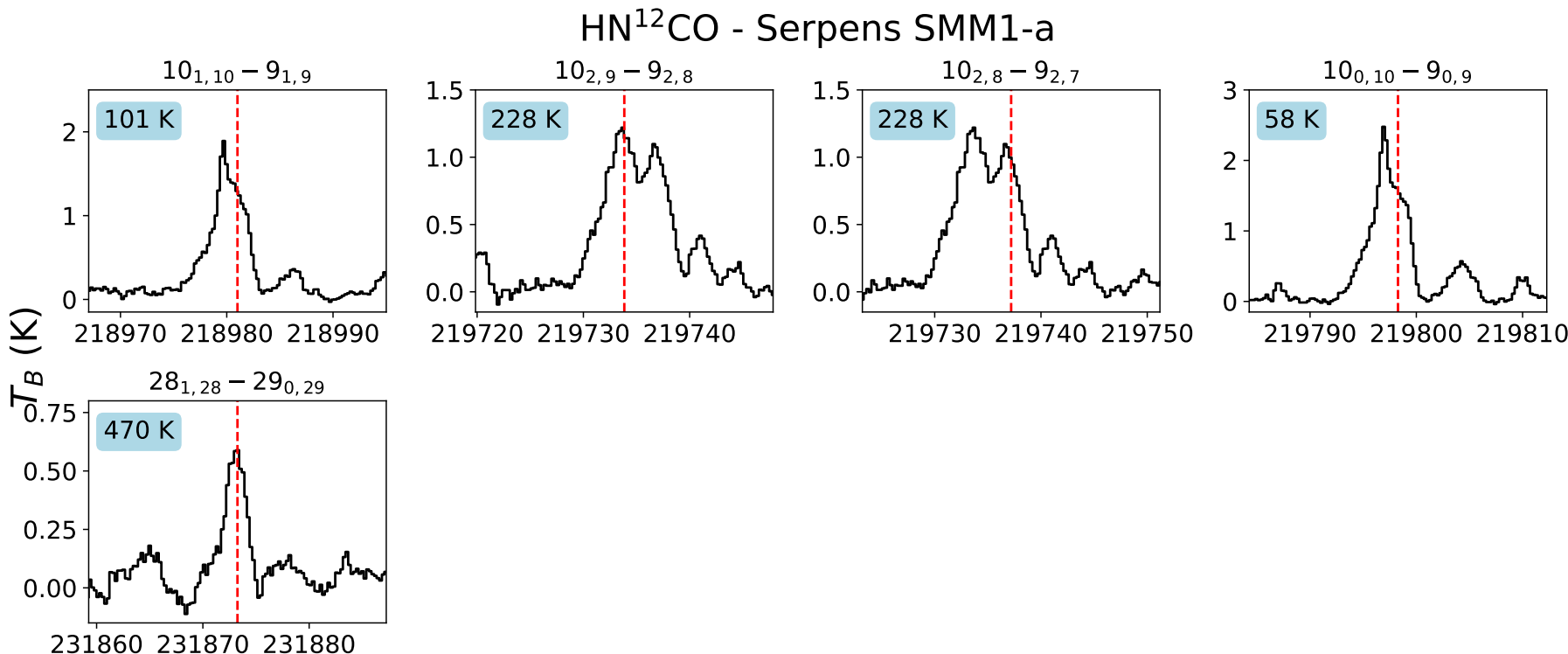

\section{Frequency $(\mathrm{MHz})$}

Fig. (B.7) Identified lines of $\mathrm{HN}^{12} \mathrm{CO}$ towards SMM1. The observed spectrum is plotted in black and the line position is indicated by the red dotted line. Because these lines are optically thick, not synthetic fit is given. The transition is indicated at the top of each panel and the upper state energy is given in the top left of each panel.

$\mathrm{HN}^{13} \mathrm{CO}$ - Serpens SMM1-a

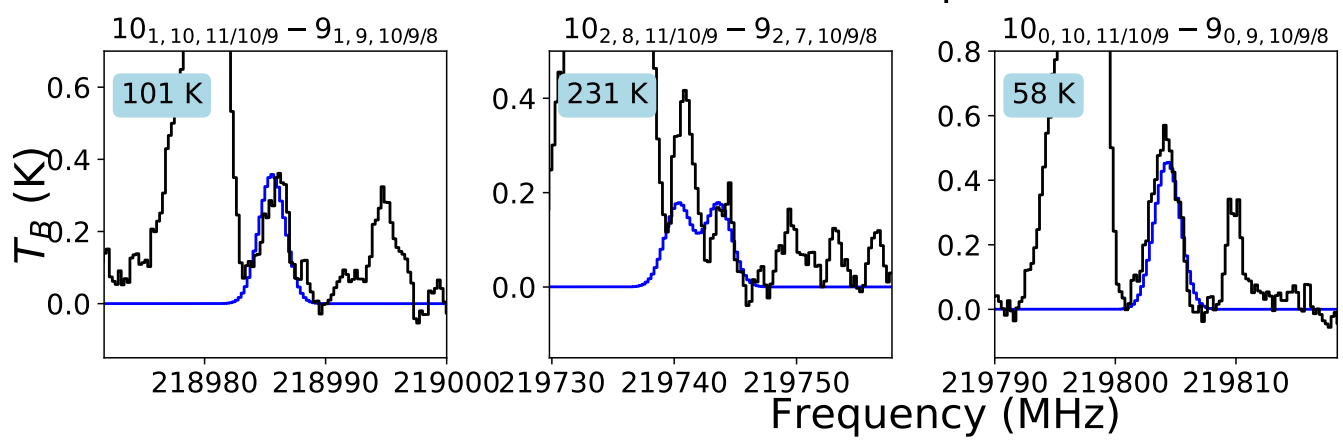

Fig. (B.8) Identified lines of $\mathrm{HN}^{13} \mathrm{CO}$ towards SMM1. The observed spectrum is plotted in black, with the best-fit synthetic spectrum overplotted in blue $\left(N_{\mathrm{T}}=(1.9 \pm 0.3) \times 10^{14} \mathrm{~cm}^{-2}, T_{\mathrm{ex}}=190 \pm 30 \mathrm{~K}\right)$. The transition is indicated at the top of each panel and the upper state energy is given in the top left of each panel. 

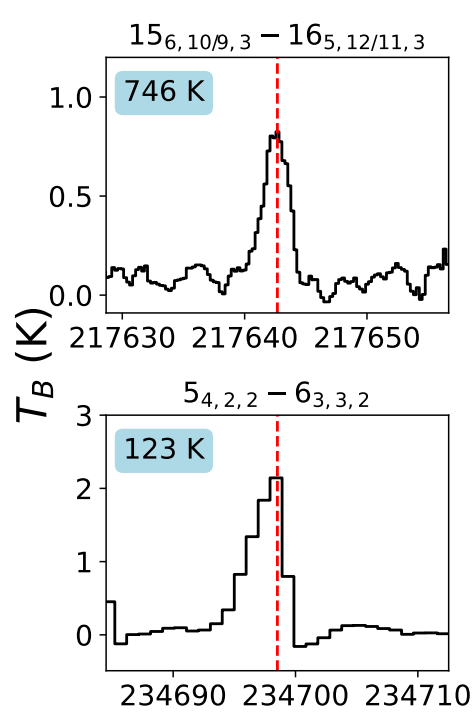

${ }^{12} \mathrm{CH}_{3} \mathrm{OH}$ - Serpens SMM1-a
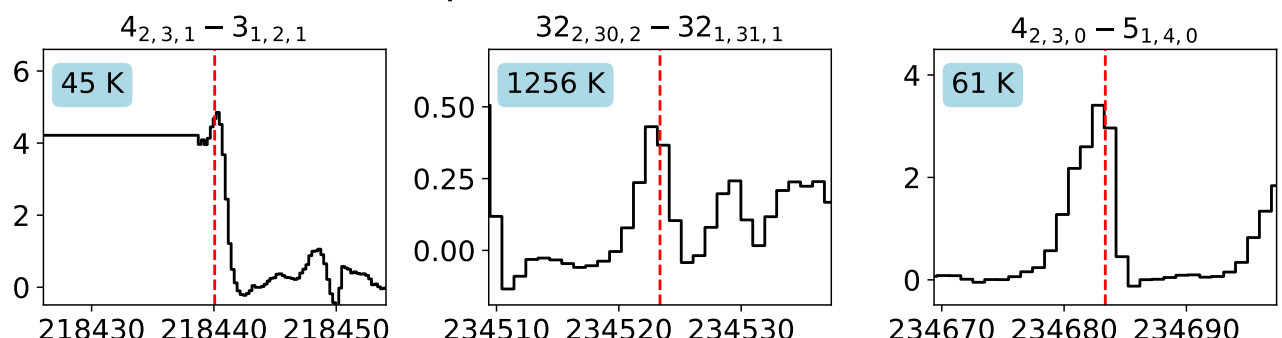

234670234680234690

\section{Frequency $(\mathrm{MHz})$}

Fig. (B.9) Identified lines of ${ }^{12} \mathrm{CH}_{3} \mathrm{OH}$ towards SMM1. The observed spectrum is plotted in black and the line position is indicated by the red dotted line. Because these lines are optically thick, not synthetic fit is given. The transition is indicated at the top of each panel and the upper state energy is given in the top left of each panel.

\section{$\mathrm{CH}_{3}^{18} \mathrm{OH}$ - Serpens SMM1-a}
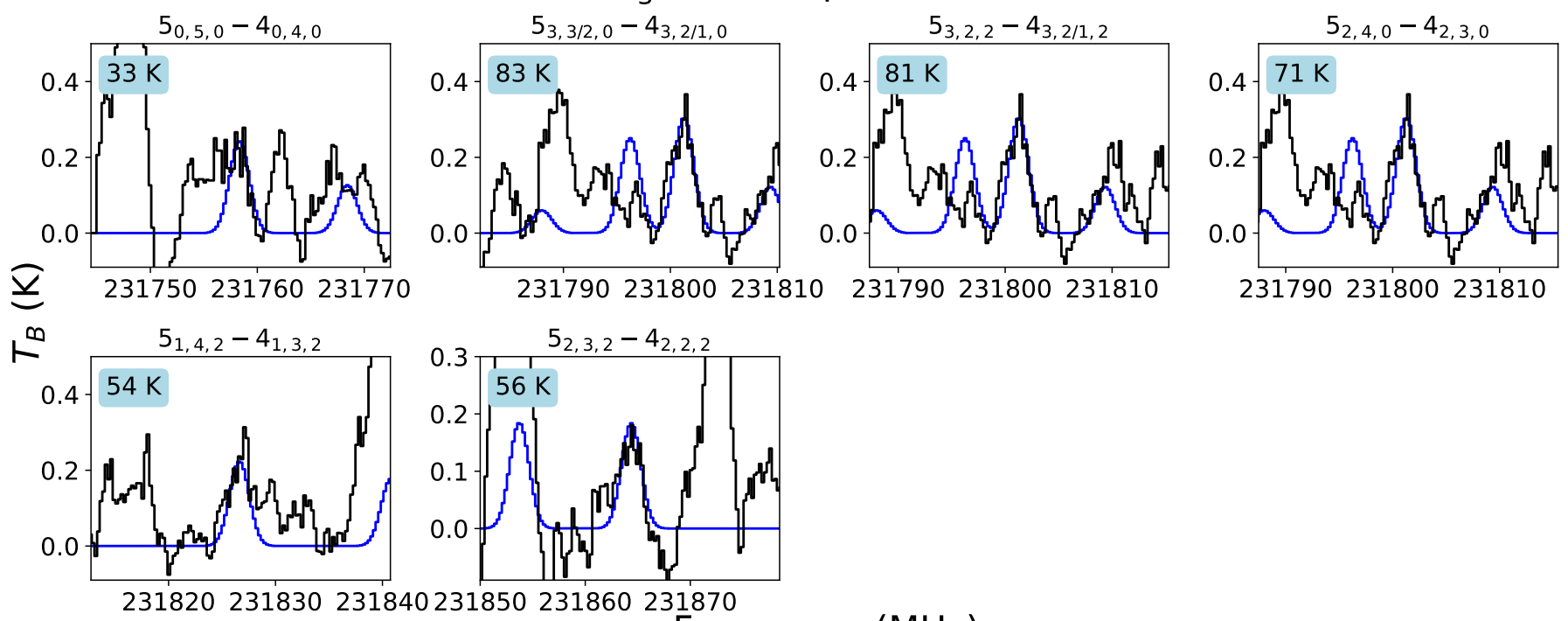

Frequency (MHz)

Fig. (B.10) Identified lines of $\mathrm{CH}_{3}^{18} \mathrm{OH}$ towards SMM1. The observed spectrum is plotted in black, with the best-fit synthetic spectrum overplotted in blue $\left(N_{\mathrm{T}}=(2.0 \pm 0.7) \times 10^{15} \mathrm{~cm}^{-2}, T_{\mathrm{ex}}=250 \pm 60 \mathrm{~K}\right)$. The transition is indicated at the top of each panel and the upper state energy is given in the top left of each panel. 
$\mathrm{HOCH}_{2} \mathrm{CN}$ - IRAS 16293-2422B - full-beam offset position
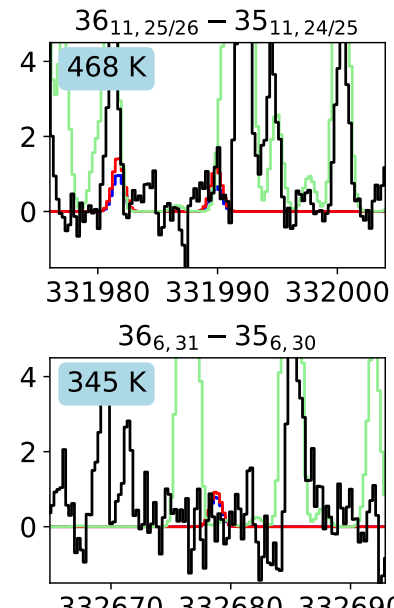

$37_{2,36}-36_{2,35}$

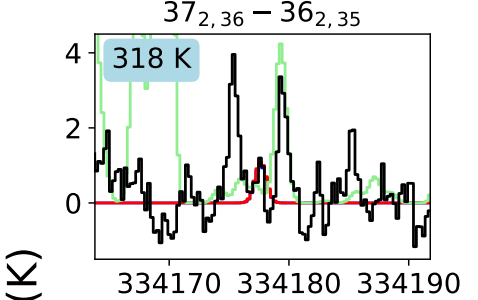

冓
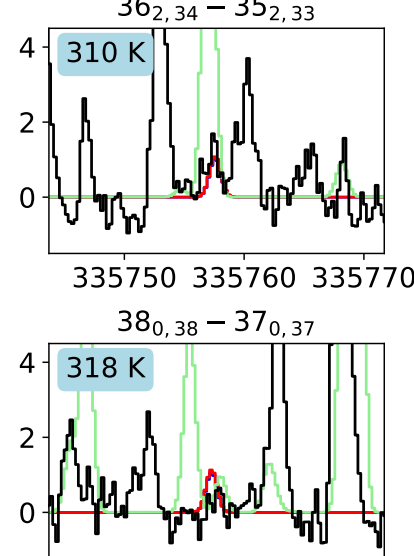

335980335990336000338250338260338270

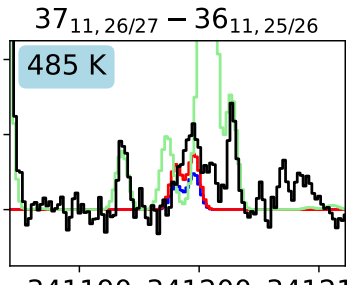

$36_{4,32}-35_{4,31}$
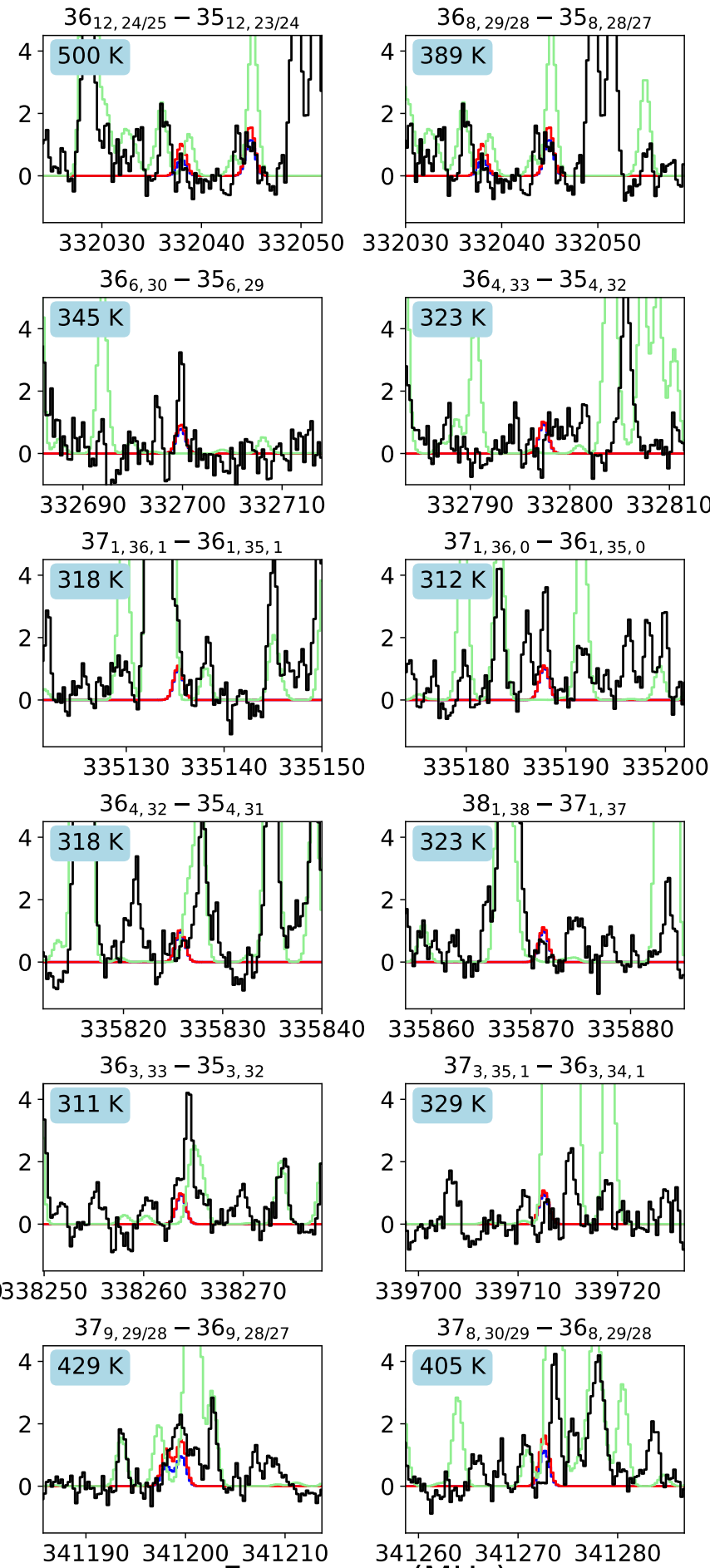
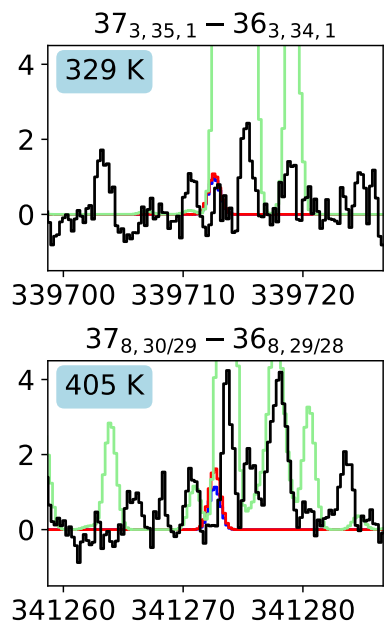

341260341270341280

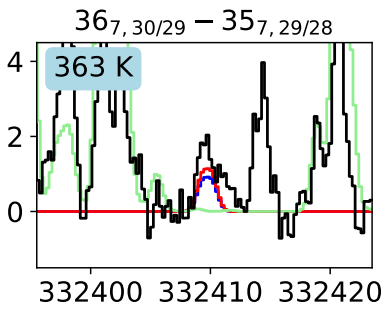

332400332410332420
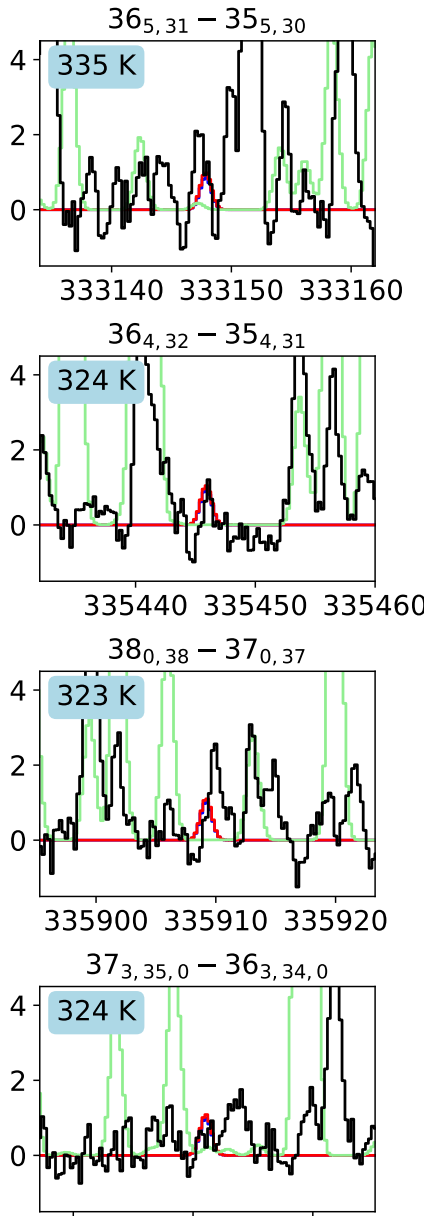

339760339770339780

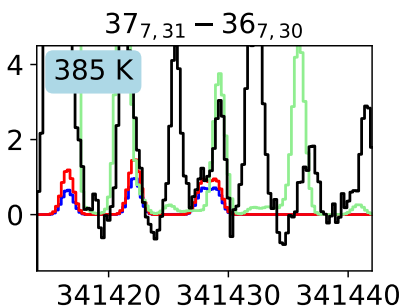

Fig. (C.1) Spectral lines of $\mathrm{HOCH}_{2} \mathrm{CN}$ in the PILS spectrum towards IRAS 16293B at the full-beam offset position. The observed spectrum is plotted in black, with synthetic spectra overplotted $\left(N_{\mathrm{T}}=\left[1.0 \times 10^{15}\right] \mathrm{cm}^{-2}, T_{\mathrm{ex}}=150\right.$, blue, and $300 \mathrm{~K}$, red). The synthetic spectrum of the entire molecular inventory determined with PILS data towards this position is plotted in green. All covered transitions with $A_{\mathrm{ij}} \geq 1.0 \times 10^{-3} \mathrm{~s}^{-1}$ that are not blended are shown. The transition is indicated at the top of each panel and the upper state energy is given in the top left of each panel. $\mathrm{HOCH}_{2} \mathrm{CN}$ is not detected in the full-beam offset position spectrum towards IRAS 16293B. 
$\mathrm{HOCH}_{2} \mathrm{CN}$ - IRAS 16293-2422B - full-beam offset position
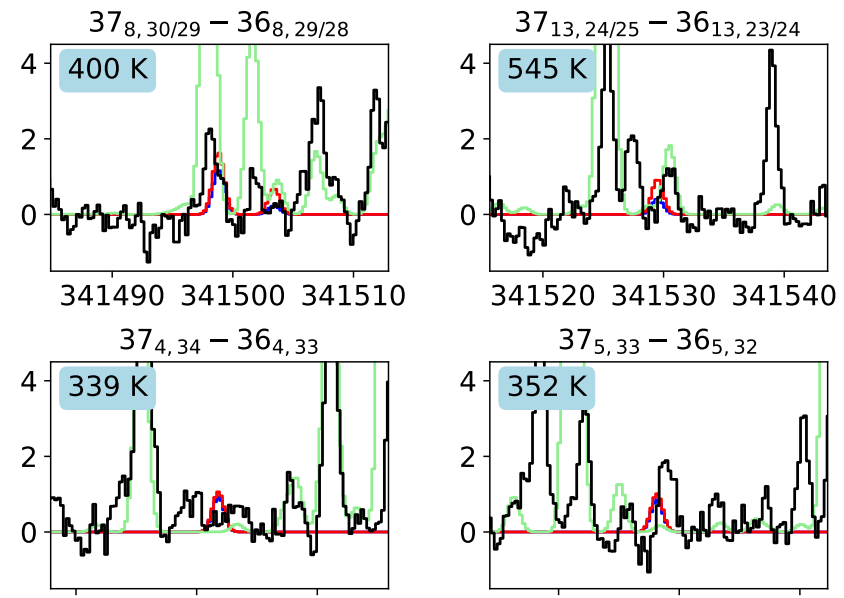

341990342000342010
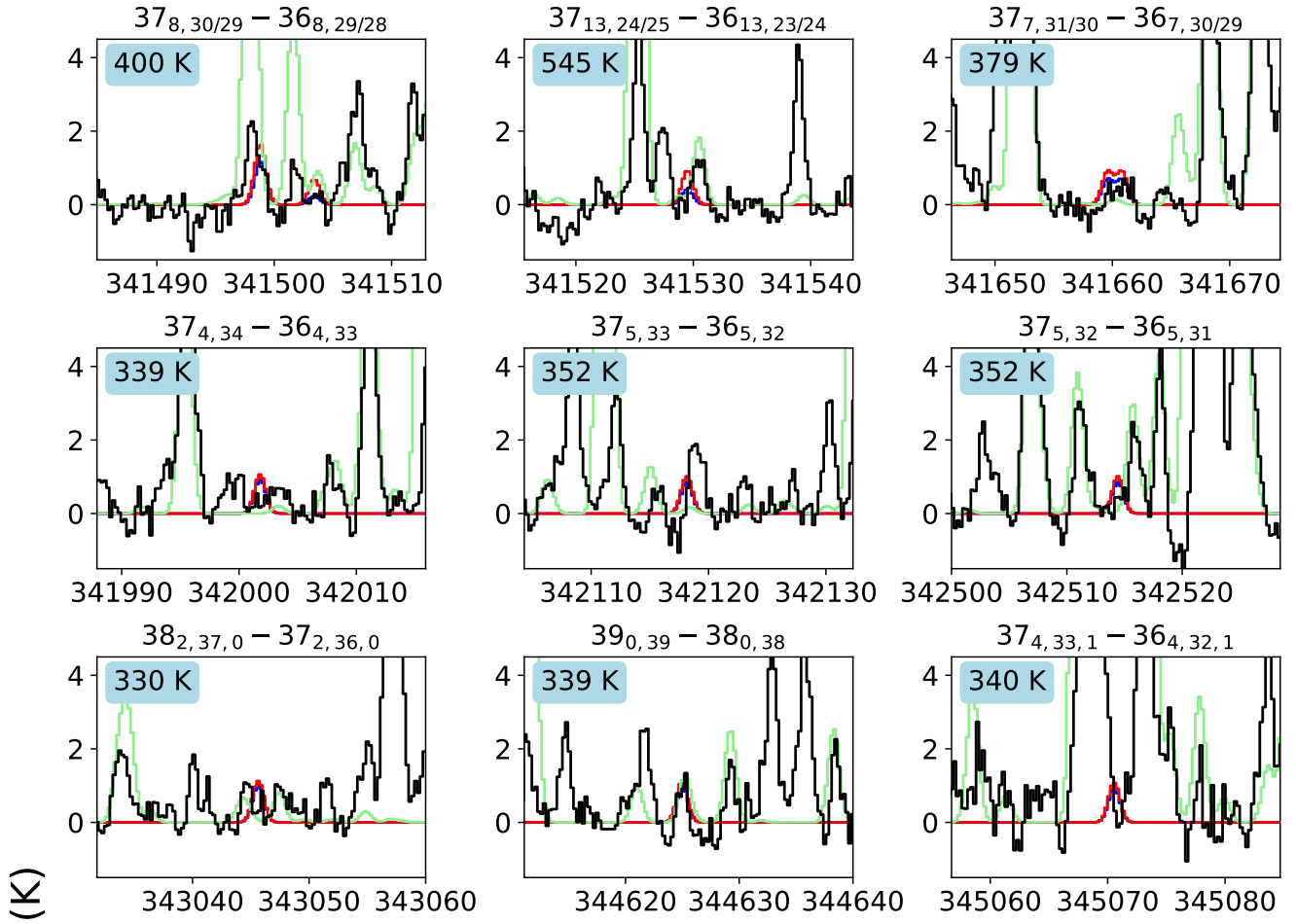

344620344630344640

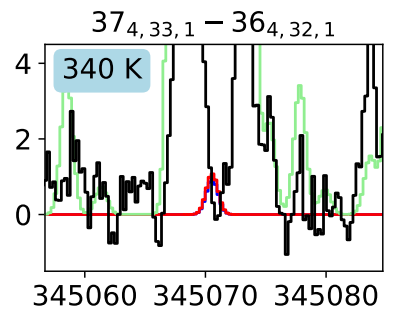

$\stackrel{\infty}{1}$
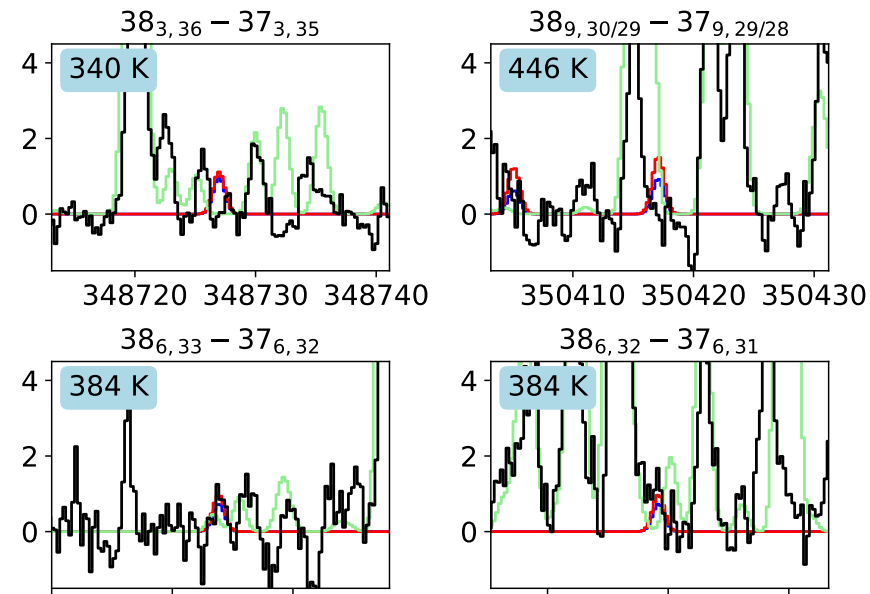

350970350980350990

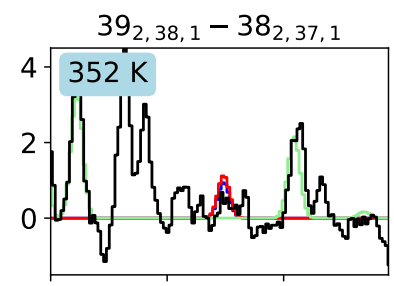

351690351700351710
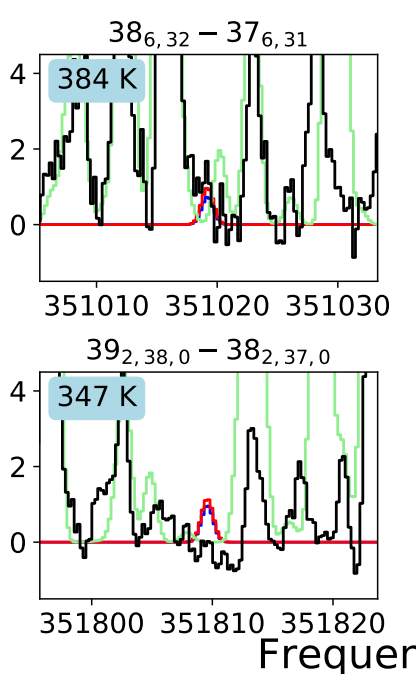

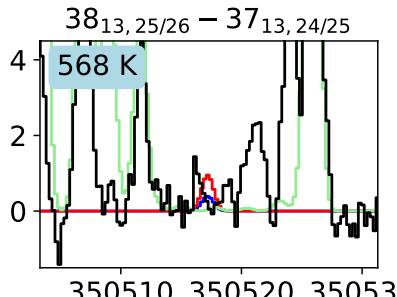

$38_{6,32}-37_{6,31}$

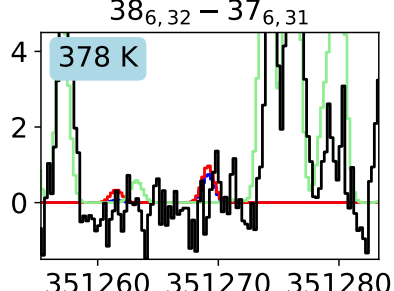

$38_{5,33,1}-37_{5,32,1}$

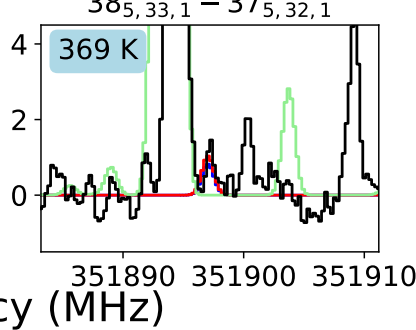

Fig. (C.2) Same as Fig. C.1
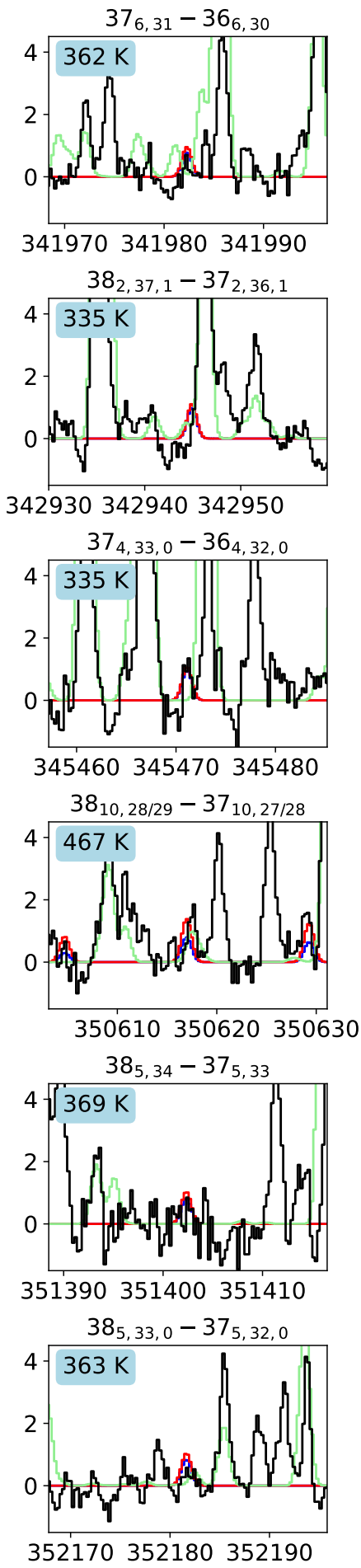
$\mathrm{HOCH}_{2} \mathrm{CN}$ - IRAS 16293-2422B - full-beam offset position
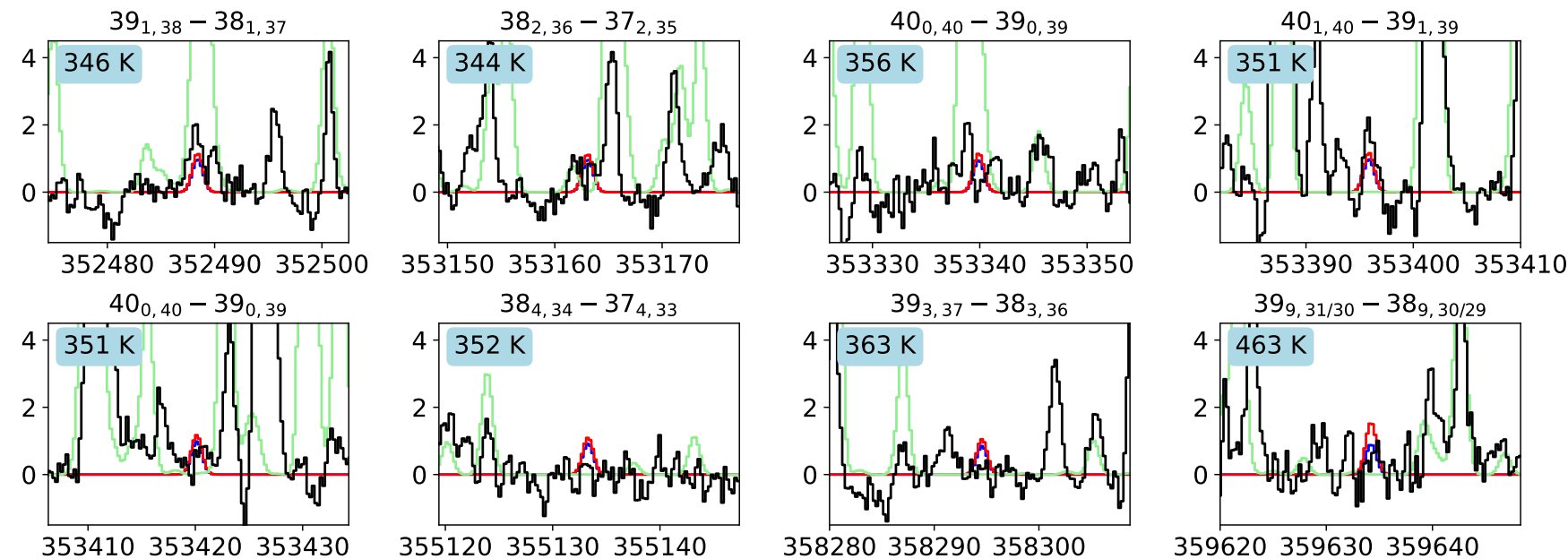

353410353420353430
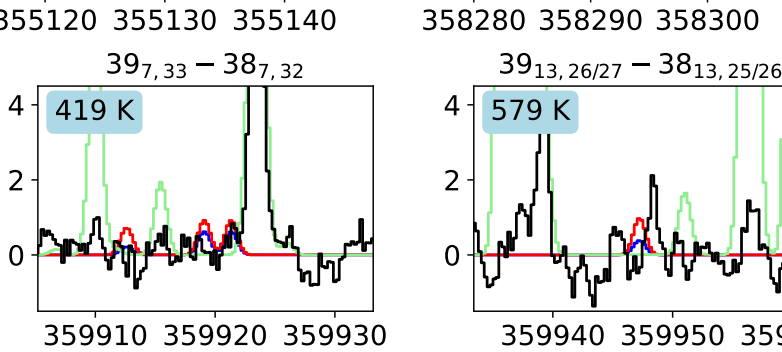

359620359630359640
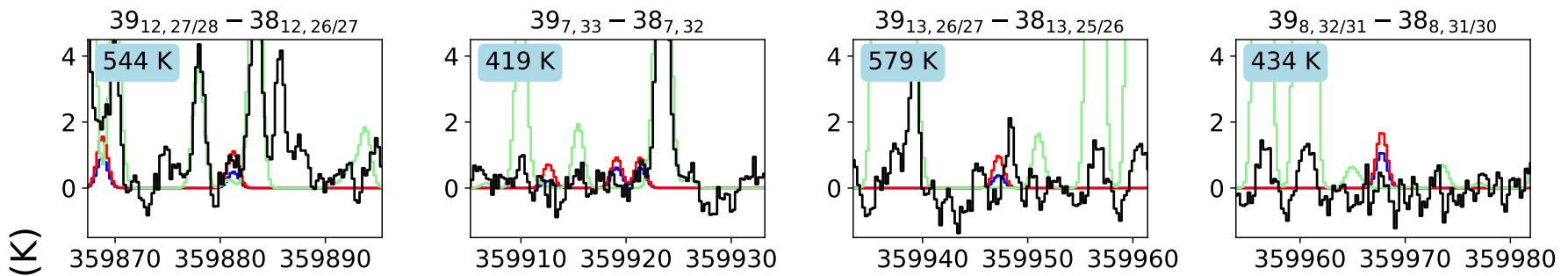

œ $39_{16,23 / 24}-38_{16,22 / 23}$
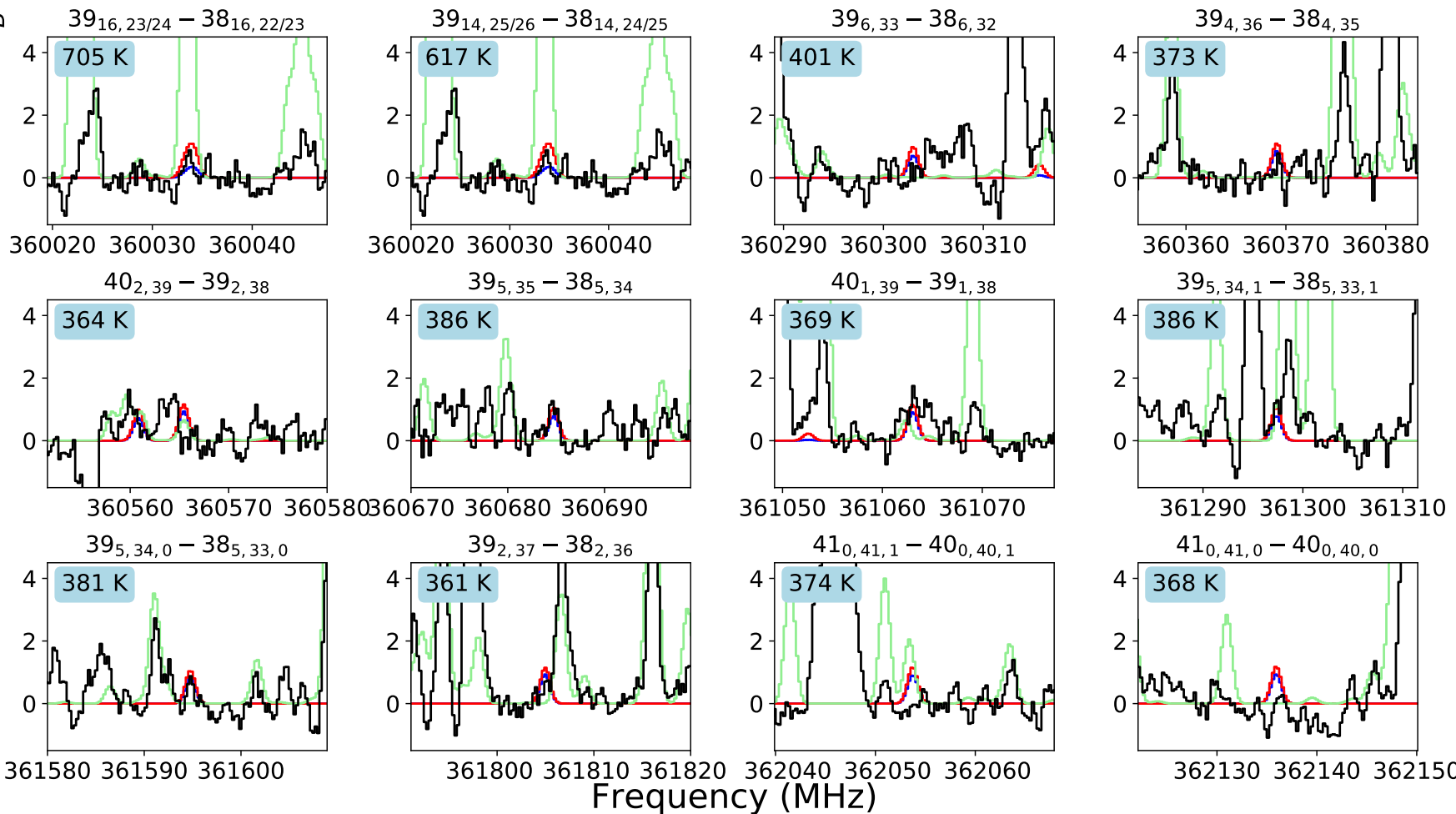

361580361590361600

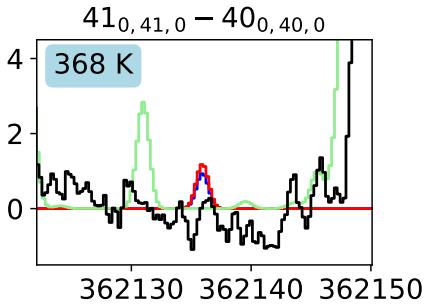

Fig. (C.3) Same as Fig. C.1 
$\mathrm{HOCH}_{2} \mathrm{CN}$ - IRAS 16293-2422B - half-beam offset position
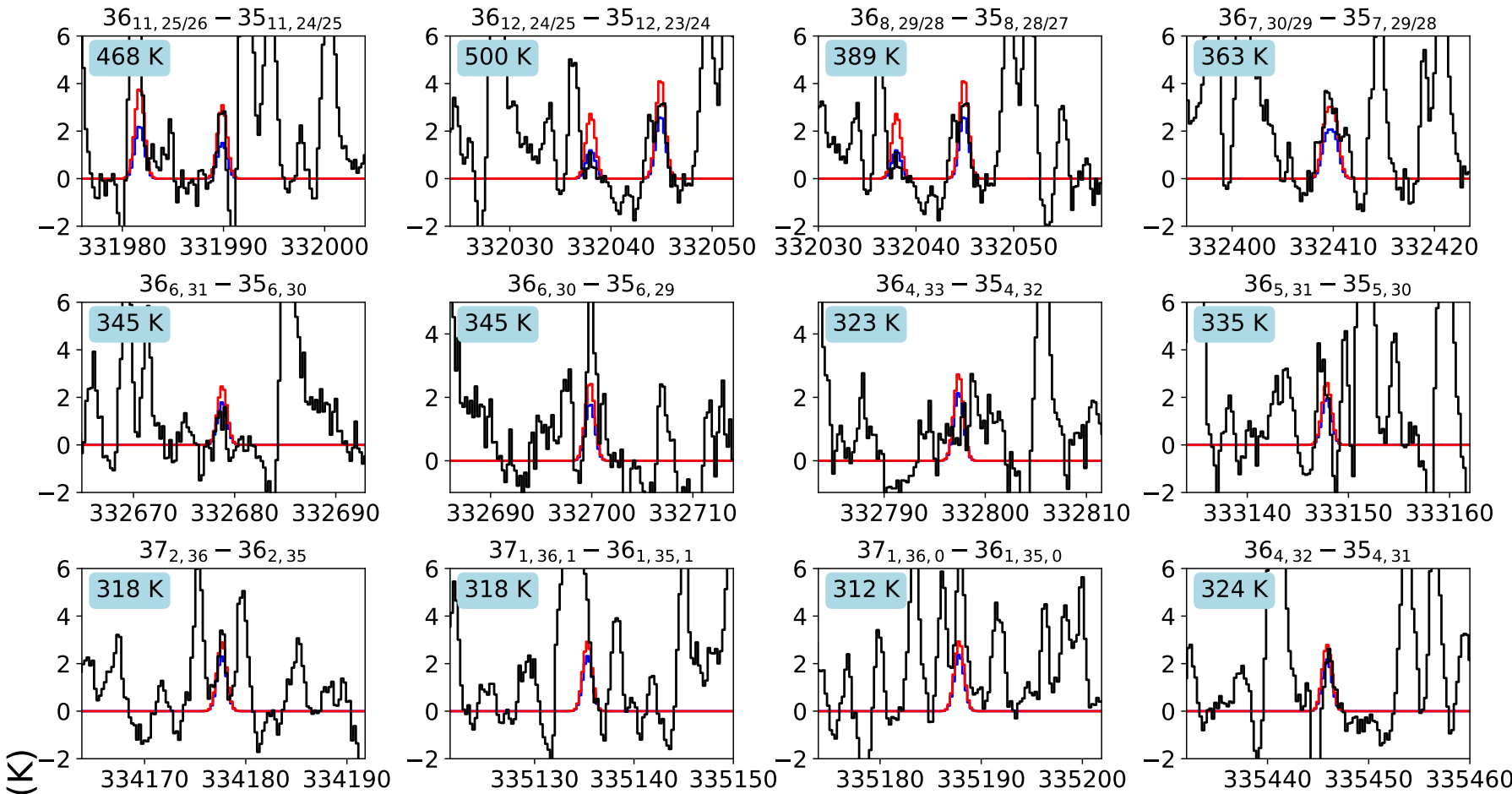

$r^{\infty}$
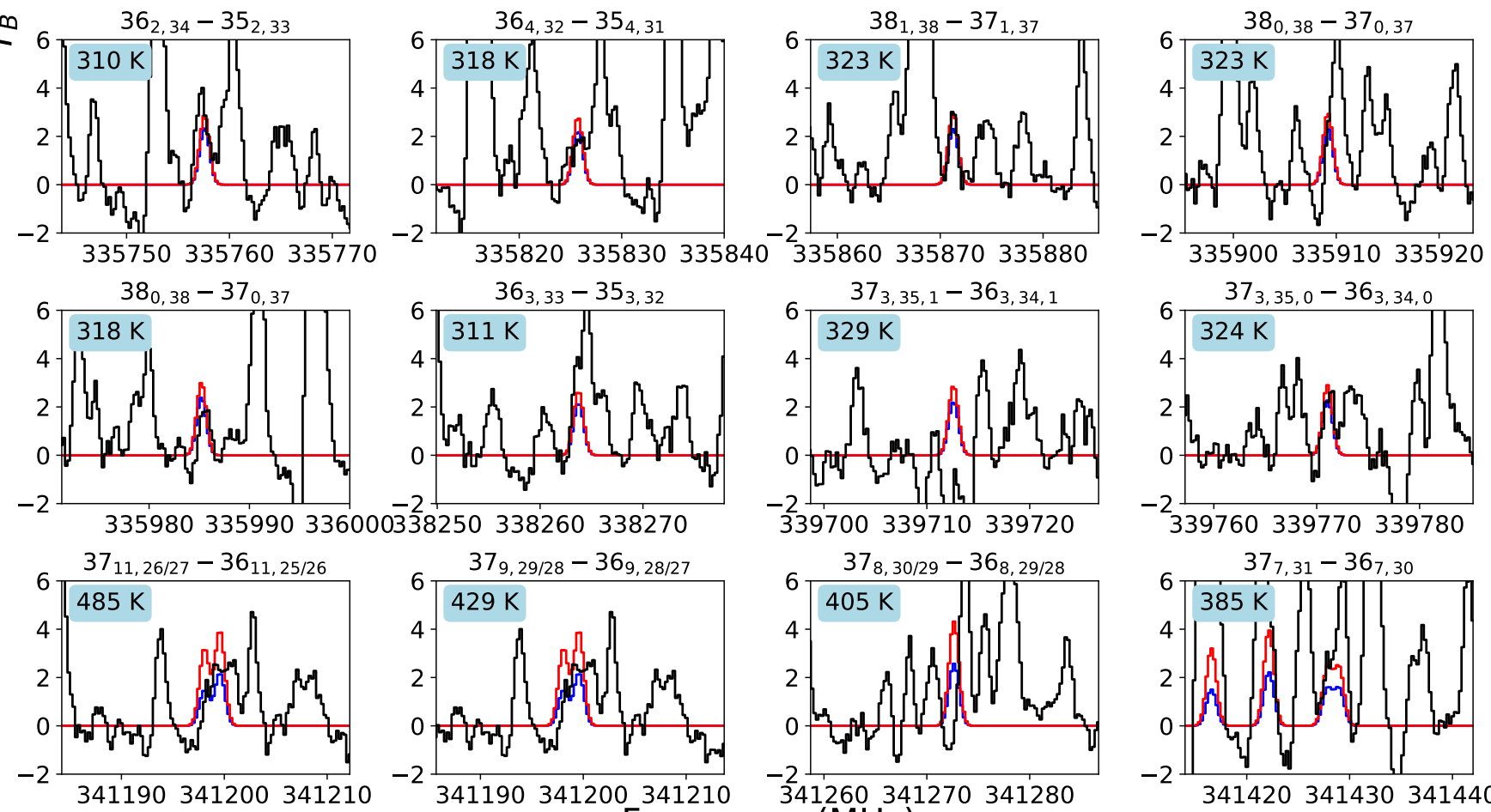

Frequency $(\mathrm{MHz})$

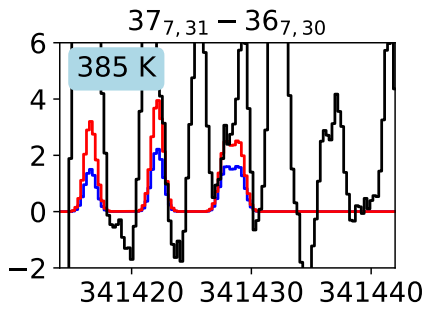

Fig. (C.4) Spectral lines of $\mathrm{HOCH}_{2} \mathrm{CN}$ in the PILS spectrum towards IRAS 16293B at the half-beam offset position. The observed spectrum is plotted in black, with synthetic spectra overplotted $\left(N_{\mathrm{T}}=\left[3.0 \times 10^{15}\right] \mathrm{cm}^{-2}, T_{\mathrm{ex}}=150\right.$, blue, and $300 \mathrm{~K}$, red). All covered transitions with $A_{\mathrm{ij}} \geq 1.0 \times 10^{-3} \mathrm{~s}^{-1}$ that are not blended are shown. The transition is indicated at the top of each panel and the upper state energy is given in the top left of each panel. $\mathrm{HOCH}_{2} \mathrm{CN}$ is detected in the half-beam offset position spectrum towards IRAS 16293B. 
$\mathrm{HOCH}_{2} \mathrm{CN}$ - IRAS 16293-2422B - half-beam offset position
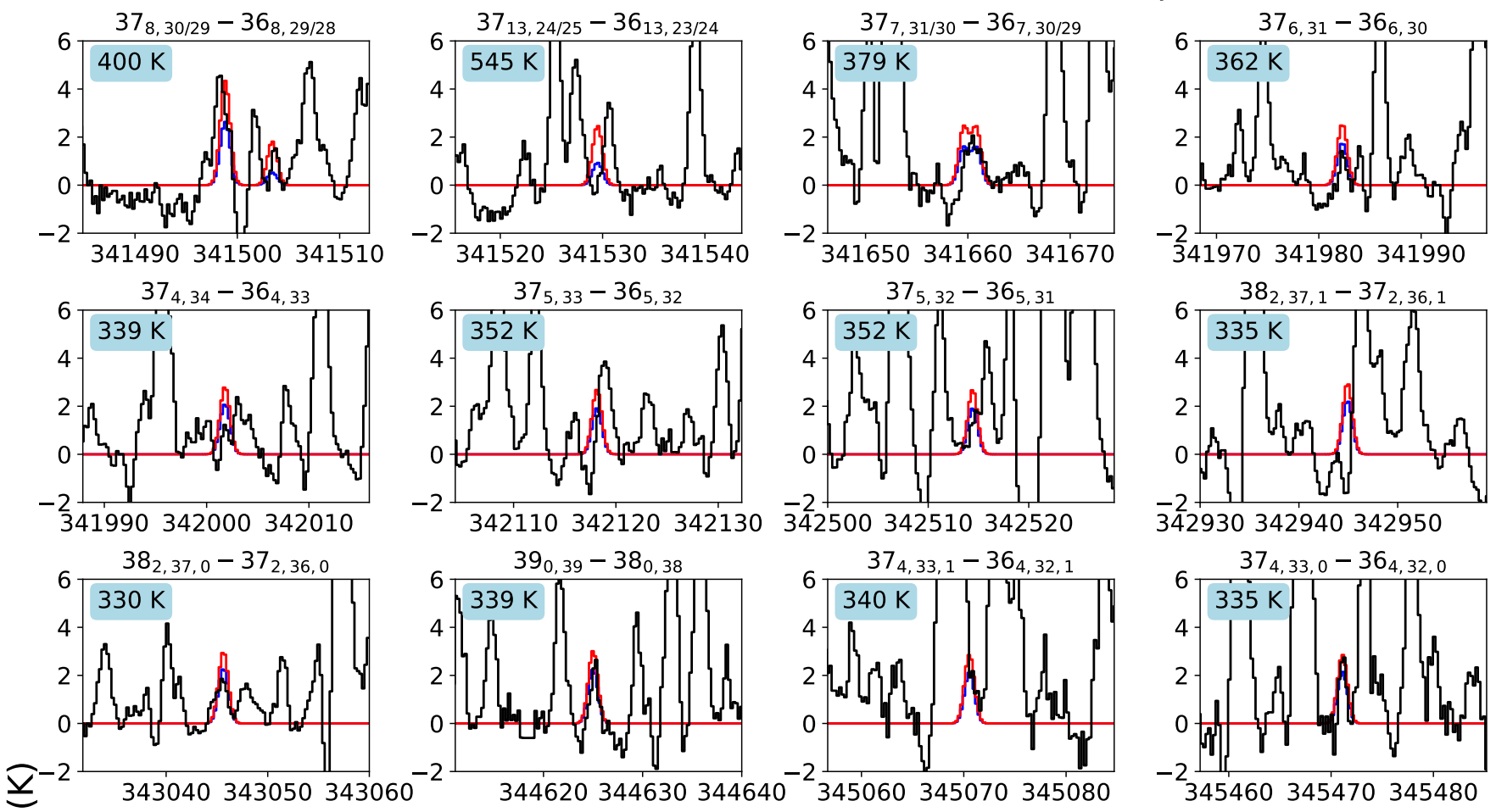

冓
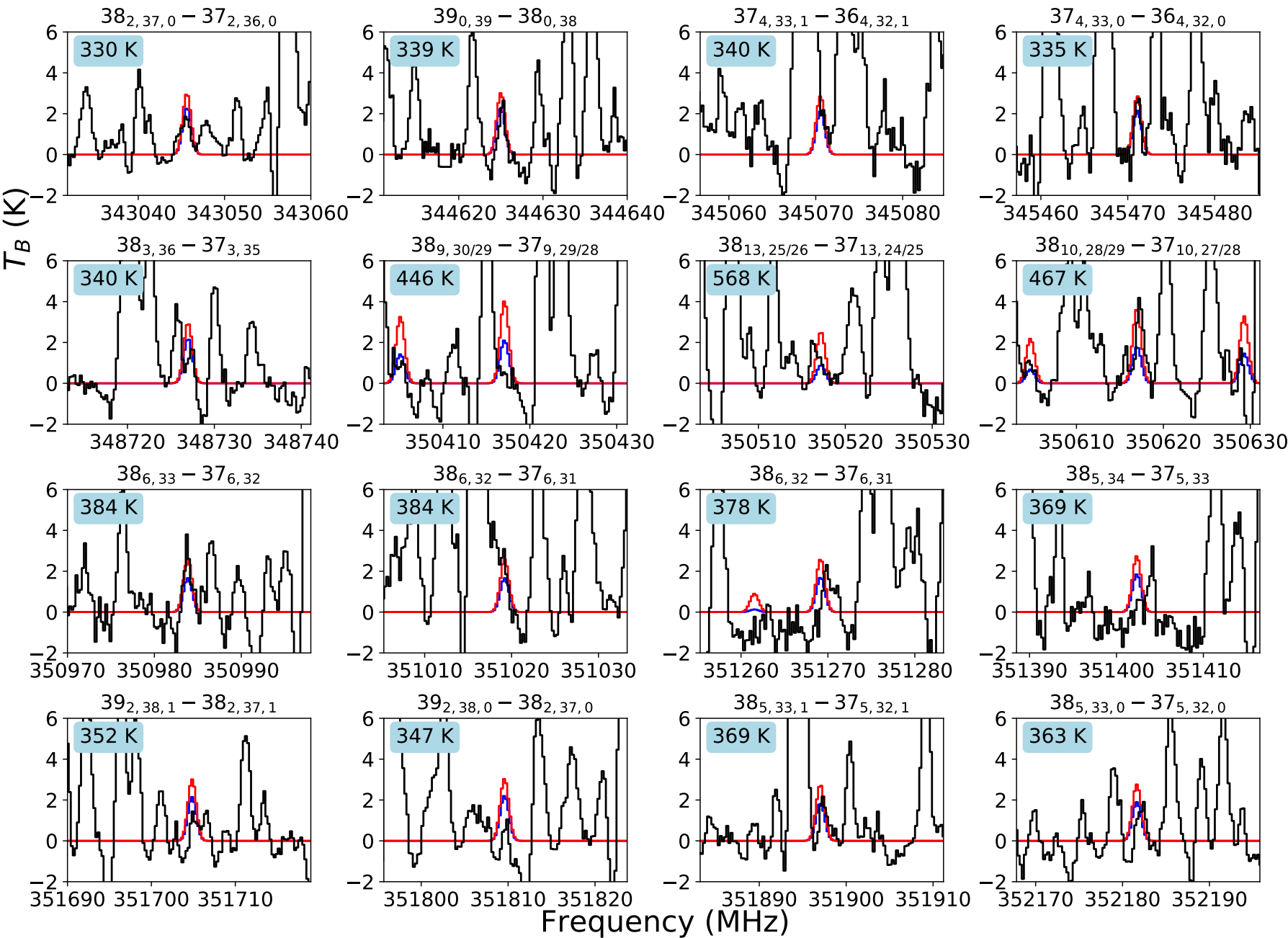

Fig. (C.5) Same as Fig. C.4 
$\mathrm{HOCH}_{2} \mathrm{CN}$ - IRAS 16293-2422B - half-beam offset position
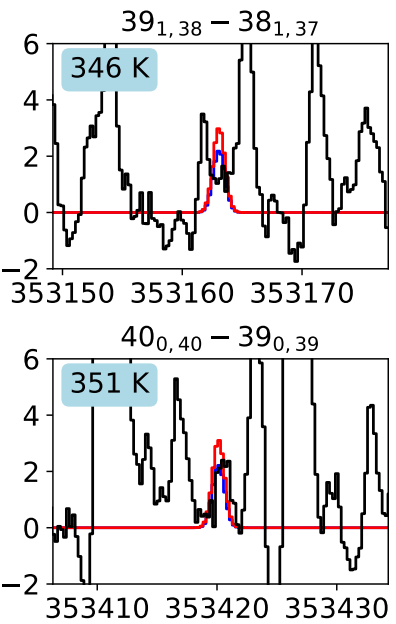

$39_{12,27 / 28}-38_{12,26 / 27}$

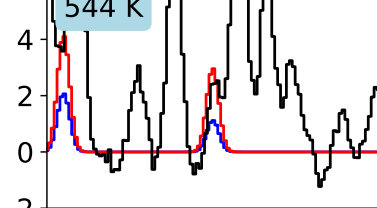

$\underline{\nabla}$

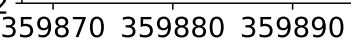

$r^{\infty}$

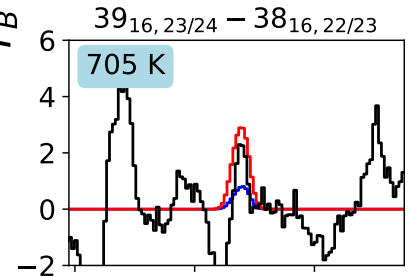

360020360030360040

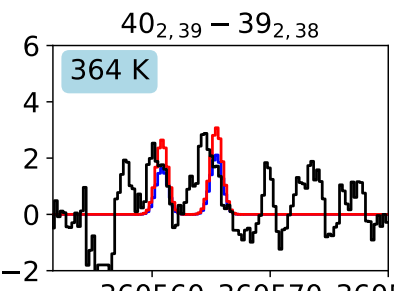

360560360570360580360670360680360690

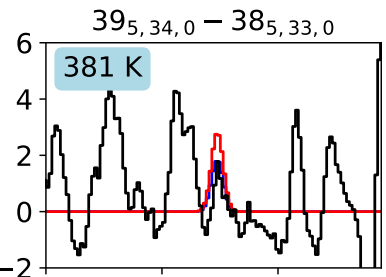

361580361590361600
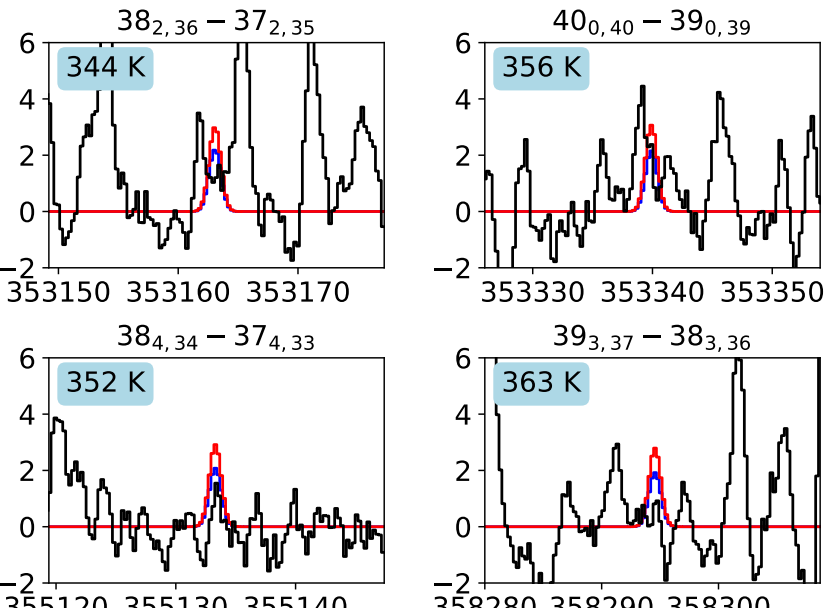

$39_{3,37}-38_{3,36}$

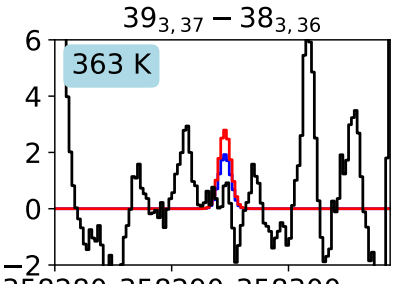

358280358290358300

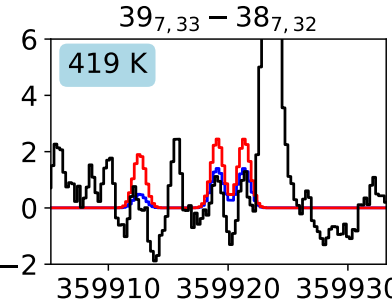

$639_{13,26 / 27}-38_{13,25 / 26}$

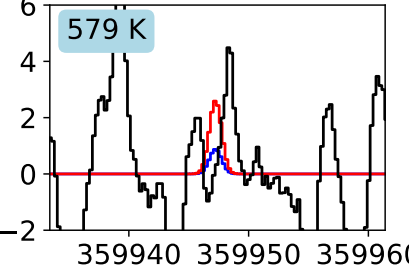

$39_{14,25 / 26}-38_{14,24 / 25}$

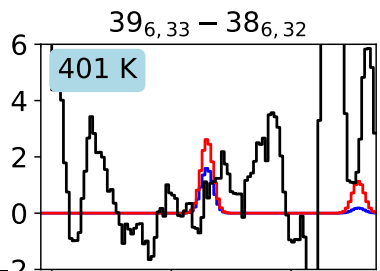

360290360300360310
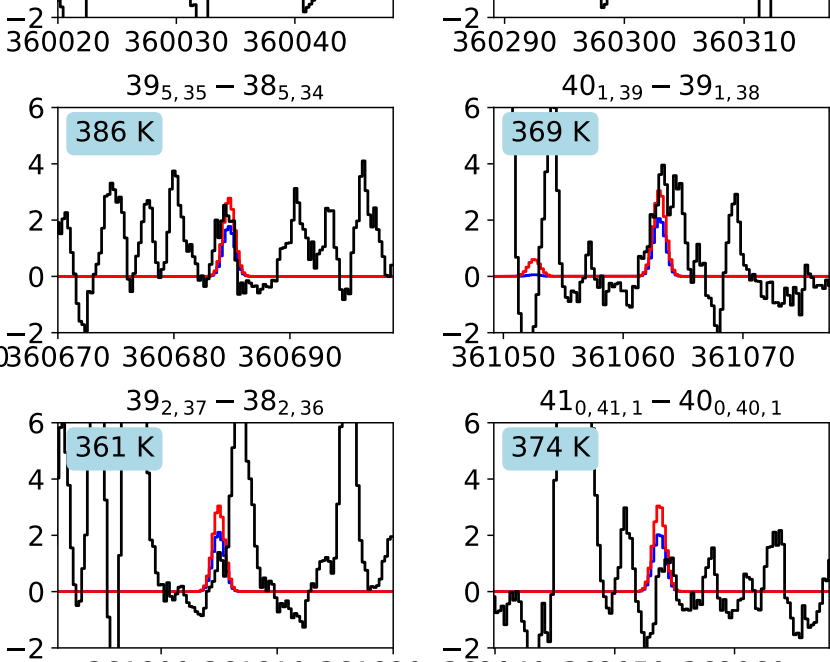

$-2 \frac{1}{362040362050362060}$ Frequency ( $\mathrm{MHz})$
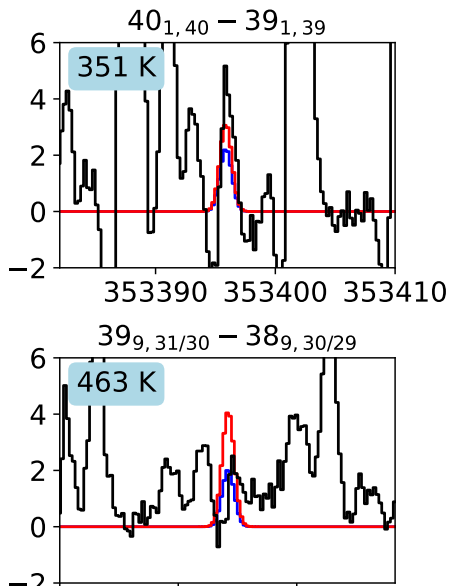

$- 2 \longdiv { 5 9 6 2 0 3 5 9 6 3 0 3 5 9 6 4 0 }$
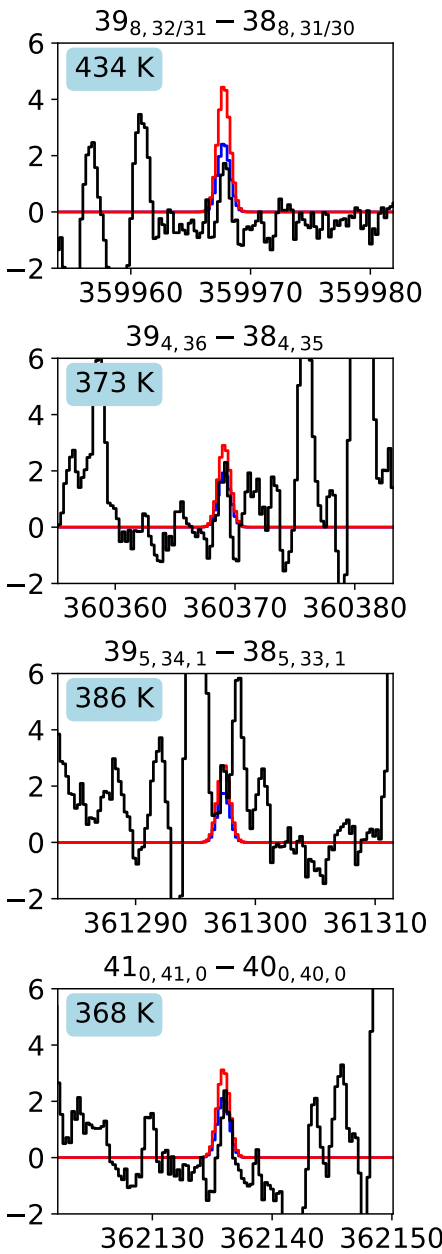

Fig. (C.6) Same as Fig. C.4 
Table (B.1) Spectral information of molecules detected towards SMM1-a

\begin{tabular}{|c|c|c|c|c|c|}
\hline Molecule & Database entry & $\begin{array}{c}\text { Transition } \\
J, K_{\mathrm{a}}, K_{\mathrm{c}},(F)\end{array}$ & $\begin{array}{l}\text { Frequency } \\
(\mathrm{MHz})\end{array}$ & $\begin{array}{l}E_{\text {up }} \\
(\mathrm{K})\end{array}$ & $\begin{array}{l}A_{\mathrm{ij}} \\
\mathrm{s}^{-1}\end{array}$ \\
\hline \multirow[t]{3}{*}{$\mathrm{D}_{2} \mathrm{CO}$} & 32502 & $423-322$ & $233650.441(0.0500)$ & 49.63 & $2.69 \times 10^{-4}$ \\
\hline & CDMS & $432-331$ & $234293.361(0.0500)$ & 76.62 & $1.58 \times 10^{-4}$ \\
\hline & & $431-330$ & $234331.062(0.0500)$ & 76.63 & $1.58 \times 10^{-4}$ \\
\hline \multirow[t]{6}{*}{${ }^{12} \mathrm{CH}_{3} \mathrm{OH}$} & 32504 & $15693-165113$ & $217642.677(0.0220)$ & 746 & $1.89 \times 10^{-5}$ \\
\hline & CDMS & $156103-165123$ & $217642.678(0.0220)$ & 746 & $1.89 \times 10^{-5}$ \\
\hline & & $4231-3121$ & $218440.063(0.0130)$ & 45 & $5.69 \times 10^{-5}$ \\
\hline & & $322302-321311$ & $234523.365(0.1070)$ & 1256 & $8.95 \times 10^{-5}$ \\
\hline & & $4230-5140$ & $234683.370(0.0120)$ & 61 & $1.87 \times 10^{-5}$ \\
\hline & & $5422-6332$ & $234698.519(0.0150)$ & 123 & $6.34 \times 10^{-6}$ \\
\hline \multirow[t]{7}{*}{$\mathrm{CH}_{3}^{18} \mathrm{OH}$} & 34504 & $5050-4040$ & $231758.446(0.0300)$ & 33 & $5.33 \times 10^{-5}$ \\
\hline & CDMS & $5330-4320$ & $231796.218(0.0300)$ & 83 & $3.41 \times 10^{-5}$ \\
\hline & & $5320-4310$ & $231796.521(0.0300)$ & 83 & $3.41 \times 10^{-5}$ \\
\hline & & $5322-4312$ & $231801.304(0.0300)$ & 81 & $3.42 \times 10^{-5}$ \\
\hline & & $5240-4230$ & $231801.466(0.0300)$ & 71 & $4.53 \times 10^{-5}$ \\
\hline & & $5142-4132$ & $231826.744(0.0300)$ & 54 & $5.33 \times 10^{-5}$ \\
\hline & & $5232-4222$ & $231864.501(0.0300)$ & 56 & $4.41 \times 10^{-5}$ \\
\hline \multirow[t]{8}{*}{$\mathrm{CH}_{3} \mathrm{CN}, v_{8}=1$} & 41509 & $1222-11-22$ & $221367.450(0.0011)$ & 649 & $8.98 \times 10^{-4}$ \\
\hline & CDMS & $12-22-1122$ & $221367.450(0.0011)$ & 649 & $8.98 \times 10^{-4}$ \\
\hline & & $1243-11-43$ & $221380.608(0.0011)$ & 655 & $8.21 \times 10^{-4}$ \\
\hline & & $12-43-1143$ & $221380.608(0.0011)$ & 655 & $8.21 \times 10^{-4}$ \\
\hline & & $1212-1112$ & $221387.271(0.0011)$ & 615 & $9.17 \times 10^{-4}$ \\
\hline & & $1202-1102$ & $221394.085(0.0011)$ & 594 & $9.24 \times 10^{-4}$ \\
\hline & & $1233-1133$ & $221403.521(0.0011)$ & 619 & $8.66 \times 10^{-4}$ \\
\hline & & $1213-11-13$ & $221625.840(0.0011)$ & 588 & $9.20 \times 10^{-4}$ \\
\hline \multirow[t]{3}{*}{$\mathrm{NH}_{2} \mathrm{CN}$} & 42003 & $111110-101100$ & $218461.795(0.0200)$ & 77 & $1.08 \times 10^{-3}$ \\
\hline & JPL & $110111-100101$ & $219719.651(0.0200)$ & 135 & $1.08 \times 10^{-3}$ \\
\hline & & $111100-10190$ & $221361.160(0.0200)$ & 78 & $1.12 \times 10^{-3}$ \\
\hline \multirow[t]{5}{*}{$\mathrm{HN}^{12} \mathrm{CO}$} & 43511 & $10110-919$ & $218985.696(0.0192)$ & 101 & $1.48 \times 10^{-4}$ \\
\hline & CDMS & $1029-928$ & $219733.850(0.0300)$ & 228 & $1.35 \times 10^{-4}$ \\
\hline & & $1028-927$ & $219737.193(0.0300)$ & 228 & $1.35 \times 10^{-4}$ \\
\hline & & $10010-909$ & $219798.274(0.0040)$ & 58 & $1.47 \times 10^{-4}$ \\
\hline & & $28128-29029$ & $231873.255(0.0064)$ & 470 & $6.68 \times 10^{-5}$ \\
\hline \multirow[t]{21}{*}{$\mathrm{HN}^{13} \mathrm{CO}$} & 44008 & $101109-9199$ & $218984.716(0.1053)$ & 101 & $1.63 \times 10^{-6}$ \\
\hline & & $1011011-91910$ & $218985.697(0.0192)$ & 101 & $1.48 \times 10^{-4}$ \\
\hline & & $1011010-9199$ & $218985.705(0.0191)$ & 101 & $1.46 \times 10^{-4}$ \\
\hline & & $101109-9198$ & $218985.706(0.0191)$ & 101 & $1.46 \times 10^{-4}$ \\
\hline & & $1011010-91910$ & $218986.596(0.0191)$ & 101 & $1.48 \times 10^{-6}$ \\
\hline & & $1011010-91910$ & $218986.596(0.0191)$ & 101 & $1.48 \times 10^{-6}$ \\
\hline & & $10299-9289$ & $219739.762(0.0962)$ & 231 & $1.60 \times 10^{-6}$ \\
\hline & & $102911-92810$ & $219740.451(0.0274)$ & 231 & $1.45 \times 10^{-4}$ \\
\hline & & $10299-9288$ & $219740.456(0.0274)$ & 231 & $1.43 \times 10^{-4}$ \\
\hline & & $102910-9289$ & $219740.471(0.0274)$ & 231 & $1.43 \times 10^{-4}$ \\
\hline & & $102910-92810$ & $219741.095(0.0885)$ & 231 & $1.45 \times 10^{-6}$ \\
\hline & & $10289-9279$ & $219743.054(0.0966)$ & 231 & $1.60 \times 10^{-6}$ \\
\hline & & $102811-92710$ & $219743.742(0.0288)$ & 231 & $1.45 \times 10^{-4}$ \\
\hline & & $10289-9278$ & $219743.747(0.0288)$ & 231 & $1.43 \times 10^{-4}$ \\
\hline & & $102810-9279$ & $219743.762(0.0288)$ & 231 & $1.43 \times 10^{-4}$ \\
\hline & & $102810-92710$ & $219744.386(0.0890)$ & 231 & $1.45 \times 10^{-6}$ \\
\hline & & $100109-9099$ & $219803.645(0.1070)$ & 58 & $1.67 \times 10^{-6}$ \\
\hline & & $1001011-90910$ & $219804.439(0.0171)$ & 58 & $1.51 \times 10^{-4}$ \\
\hline & & $1001010-9099$ & $219804.442(0.0171)$ & 58 & $1.50 \times 10^{-4}$ \\
\hline & & $100109-9098$ & $219804.446(0.0171)$ & 58 & $1.49 \times 10^{-4}$ \\
\hline & & $1001010-90910$ & $219805.163(0.0965)$ & 58 & $1.51 \times 10^{-6}$ \\
\hline \multirow[t]{3}{*}{$\mathrm{CH}_{3} \mathrm{CH}_{2} \mathrm{OH}$} & 46524 & $354312-353322$ & $218943.289(0.0068)$ & 560 & $7.38 \times 10^{-5}$ \\
\hline & CDMS & $346282-345292$ & $221612.904(0.0080)$ & 548 & $8.84 \times 10^{-5}$ \\
\hline & & $315271-314270$ & $231789.850(0.0120)$ & 506 & $2.24 \times 10^{-5}$ \\
\hline
\end{tabular}


Table (B.1) Continued.

\begin{tabular}{|c|c|c|c|c|c|}
\hline \multirow[t]{14}{*}{ Molecule } & Database entry & $\begin{array}{c}\text { Transition } \\
J, K_{\mathrm{a}}, K_{\mathrm{c}},(F)\end{array}$ & $\begin{array}{l}\text { Frequency } \\
(\mathrm{MHz})\end{array}$ & $\begin{array}{l}E_{\text {up }} \\
(\mathrm{K})\end{array}$ & $\begin{array}{l}A_{\mathrm{ij}} \\
\mathrm{s}^{-1}\end{array}$ \\
\hline & & $225182-224192$ & $231790.056(0.0035)$ & 245 & $8.46 \times 10^{-5}$ \\
\hline & & $13582-13492$ & $233571.051(0.0032)$ & 108 & $7.54 \times 10^{-5}$ \\
\hline & & $145102-144112$ & $233601.554(0.0032)$ & 120 & $7.71 \times 10^{-5}$ \\
\hline & & $12582-12492$ & $234255.240(0.0032)$ & 97 & $7.39 \times 10^{-5}$ \\
\hline & & $11562-11472$ & $234406.433(0.0033)$ & 87 & $7.17 \times 10^{-5}$ \\
\hline & & $10552-10462$ & $234666.142(0.0035)$ & 78 & $6.89 \times 10^{-5}$ \\
\hline & & $10562-10472$ & $234714.782(0.0035)$ & 78 & $6.90 \times 10^{-5}$ \\
\hline & & $231222-230232$ & $234725.620(0.0090)$ & 233 & $3.17 \times 10^{-5}$ \\
\hline & & $9542-9452$ & $234852.862(0.0038)$ & 69 & $6.53 \times 10^{-5}$ \\
\hline & & $364322-363332$ & $234855.010(0.0073)$ & 591 & $8.70 \times 10^{-5}$ \\
\hline & & $9552-9462$ & $234873.873(0.0038)$ & 69 & $6.54 \times 10^{-5}$ \\
\hline & & $142121-133100$ & $234882.537(0.0105)$ & 155 & $3.64 \times 10^{-5}$ \\
\hline & & $140141-131120$ & $235158.494(0.0058)$ & 146 & $1.12 \times 10^{-4}$ \\
\hline \multirow[t]{14}{*}{$\mathrm{CH}_{3} \mathrm{NCO}, v=0$} & 57505 & $25-102-24-102$ & $217595.174(0.0500)$ & 194 & $4.84 \times 10^{-4}$ \\
\hline & CDMS & $25002-24002$ & $217595.174(0.0500)$ & 188 & $4.85 \times 10^{-4}$ \\
\hline & & $25201-24201$ & $217652.088(0.0500)$ & 171 & $4.82 \times 10^{-4}$ \\
\hline & & $24301-23301$ & $217701.086(0.0500)$ & 191 & $4.40 \times 10^{-4}$ \\
\hline & & $2510-3-2410-3$ & $218002.461(0.0500)$ & 258 & $4.93 \times 10^{-4}$ \\
\hline & & $2500-3-24000-3$ & $218014.630(0.0500)$ & 251 & $4.84 \times 10^{-4}$ \\
\hline & & $25103-24103$ & $218069.900(0.0500)$ & 257 & $4.93 \times 10^{-4}$ \\
\hline & & $251240-241230$ & $218541.803(0.0500)$ & 142 & $4.94 \times 10^{-4}$ \\
\hline & & $27-1001-26-101$ & $231793.783(0.0500)$ & 175 & $6.02 \times 10^{-4}$ \\
\hline & & $272260-262250$ & $234088.125(0.0500)$ & 181 & $6.05 \times 10^{-4}$ \\
\hline & & $27002-26002$ & $234932.492(0.0500)$ & 210 & $6.11 \times 10^{-4}$ \\
\hline & & $27-302-26-302$ & $235663.096(0.0500)$ & 264 & $6.06 \times 10^{-4}$ \\
\hline & & $27203-26203$ & $235801.163(0.0500)$ & 296 & $6.12 \times 10^{-4}$ \\
\hline & & $2720-3-2620-3$ & $235803.211(0.0500)$ & 297 & $6.12 \times 10^{-4}$ \\
\hline \multirow[t]{30}{*}{$\mathrm{HOCH}_{2} \mathrm{CN}$} & 57512 & $242231-232221$ & $218994.156(0.0009)$ & 143 & $3.23 \times 10^{-4}$ \\
\hline & CDMS & $248171-238161$ & $221334.546(0.0009)$ & 227 & $2.98 \times 10^{-4}$ \\
\hline & & $248161-238151$ & $221334.546(0.0009)$ & 227 & $2.98 \times 10^{-4}$ \\
\hline & & $249151-239141$ & $221344.331(0.0010)$ & 251 & $2.88 \times 10^{-4}$ \\
\hline & & $249161-239151$ & $221344.331(0.0010)$ & 251 & $2.88 \times 10^{-4}$ \\
\hline & & $2410141-2310131$ & $221372.125(0.0010)$ & 277 & $2.77 \times 10^{-4}$ \\
\hline & & $2410151-2310141$ & $221372.125(0.0010)$ & 277 & $2.77 \times 10^{-4}$ \\
\hline & & $246191-236181$ & $221406.933(0.0009)$ & 188 & $3.15 \times 10^{-4}$ \\
\hline & & $246181-236171$ & $221407.170(0.0009)$ & 188 & $3.15 \times 10^{-4}$ \\
\hline & & $2411131-2311121$ & $221413.638(0.0010)$ & 306 & $2.65 \times 10^{-4}$ \\
\hline & & $2411141-2311131$ & $221413.638(0.0010)$ & 306 & $2.65 \times 10^{-4}$ \\
\hline & & $2412121-2312111$ & $221466.304(0.0011)$ & 338 & $2.52 \times 10^{-4}$ \\
\hline & & $2412131-2312121$ & $221466.304(0.0011)$ & 338 & $2.52 \times 10^{-4}$ \\
\hline & & $243221-233211$ & $221466.604(0.0009)$ & 151 & $3.32 \times 10^{-4}$ \\
\hline & & $248170-238160$ & 221480.199 (0.0009) & 222 & $2.95 \times 10^{-4}$ \\
\hline & & $248160-238150$ & 221480.199 (0.0009) & 222 & $2.95 \times 10^{-4}$ \\
\hline & & $249150-239140$ & $221488.785(0.0010)$ & 245 & $2.86 \times 10^{-4}$ \\
\hline & & $249160-239150$ & $221488.785(0.0010)$ & 245 & $2.86 \times 10^{-4}$ \\
\hline & & $247180-237170$ & 221497.997 (0.0009) & 201 & $3.04 \times 10^{-4}$ \\
\hline & & $247170-237160$ & $221498.002(0.0009)$ & 201 & $3.04 \times 10^{-4}$ \\
\hline & & $2410140-2310130$ & $221515.800(0.0010)$ & 272 & $2.75 \times 10^{-4}$ \\
\hline & & $2410150-2310140$ & $221515.800(0.0010)$ & 272 & $2.75 \times 10^{-4}$ \\
\hline & & $2413111-2313101$ & $221528.501(0.0011)$ & 372 & $2.38 \times 10^{-4}$ \\
\hline & & $2413121-2313111$ & $221528.501(0.0011)$ & 372 & $2.38 \times 10^{-4}$ \\
\hline & & $245201-235191$ & $221533.058(0.0009)$ & 173 & $3.22 \times 10^{-4}$ \\
\hline & & $245191-235181$ & $221542.097(0.0009)$ & 173 & $3.22 \times 10^{-4}$ \\
\hline & & $2411130-2311120$ & $221556.802(0.0010)$ & 301 & $2.63 \times 10^{-4}$ \\
\hline & & $2411140-2311130$ & $221556.802(0.0010)$ & 301 & $2.63 \times 10^{-4}$ \\
\hline & & $246190-236180$ & $221557.660(0.0009)$ & 183 & $3.12 \times 10^{-4}$ \\
\hline & & $246180-236170$ & $221557.911(0.0009)$ & 183 & $3.12 \times 10^{-4}$ \\
\hline
\end{tabular}


Table (B.1) Continued.

\begin{tabular}{|c|c|c|c|c|c|}
\hline \multirow[t]{5}{*}{ Molecule } & Database entry & $\begin{array}{c}\text { Transition } \\
J, K_{\mathrm{a}}, K_{\mathrm{c}},(F)\end{array}$ & $\begin{array}{l}\text { Frequency } \\
(\mathrm{MHz})\end{array}$ & $\begin{array}{l}E_{\text {up }} \\
(\mathrm{K})\end{array}$ & $\begin{array}{l}A_{\mathrm{ij}} \\
\mathrm{s}^{-1}\end{array}$ \\
\hline & & $2412120-2312110$ & $221609.140(0.0010)$ & 332 & $2.50 \times 10^{-4}$ \\
\hline & & $2412130-2312120$ & $221609.140(0.0010)$ & 332 & $2.50 \times 10^{-4}$ \\
\hline & & $252231-242221$ & $234584.932(0.0300)$ & 157 & $4.36 \times 10^{-4}$ \\
\hline & & $252230-242220$ & $235112.110(0.0300)$ & 152 & $3.94 \times 10^{-4}$ \\
\hline \multirow[t]{29}{*}{$\mathrm{CH}_{3} \mathrm{OCHO}$} & 60003 & $181093-171083$ & $219822.126(0.1000)$ & 355 & $1.11 \times 10^{-4}$ \\
\hline & JPL & $181083-171073$ & $219822.126(0.1000)$ & 355 & $1.11 \times 10^{-4}$ \\
\hline & & $181170-171160$ & $221433.019(0.1000)$ & 181 & $1.03 \times 10^{-4}$ \\
\hline & & $181180-171170$ & $221433.019(0.1000)$ & 181 & $1.03 \times 10^{-4}$ \\
\hline & & $181082-171072$ & $221649.411(0.1000)$ & 167 & $1.14 \times 10^{-4}$ \\
\hline & & $194164-184154$ & $231896.060(0.1000)$ & 310 & $1.79 \times 10^{-4}$ \\
\hline & & $198124-188114$ & $233627.478(0.1000)$ & 341 & $1.59 \times 10^{-4}$ \\
\hline & & $1910100-181090$ & $234124.883(0.1000)$ & 179 & $1.40 \times 10^{-4}$ \\
\hline & & $191090-181080$ & $234124.883(0.1000)$ & 179 & $1.40 \times 10^{-4}$ \\
\hline & & $1910101-181091$ & $234134.600(0.0500)$ & 178 & $1.40 \times 10^{-4}$ \\
\hline & & $196143-186133$ & $234336.107(0.1000)$ & 324 & $1.75 \times 10^{-4}$ \\
\hline & & $195153-185143$ & $234381.269(0.1000)$ & 316 & $1.80 \times 10^{-4}$ \\
\hline & & $197134-187124$ & $234441.264(0.1000)$ & 332 & $1.68 \times 10^{-4}$ \\
\hline & & $199102-18992$ & $234486.395(0.1000)$ & 166 & $1.51 \times 10^{-4}$ \\
\hline & & $199110-189100$ & $234502.241(0.0009)$ & 166 & $1.51 \times 10^{-4}$ \\
\hline & & $199100-18990$ & $234502.432(0.0009)$ & 166 & $1.51 \times 10^{-4}$ \\
\hline & & $199111-189101$ & $234508.614(0.1000)$ & 166 & $1.51 \times 10^{-4}$ \\
\hline & & $198112-188102$ & $235029.952(0.1000)$ & 155 & $1.61 \times 10^{-4}$ \\
\hline & & $198120-188110$ & $235046.493(0.1000)$ & 155 & $1.61 \times 10^{-4}$ \\
\hline & & $198110-188100$ & $235051.378(0.1000)$ & 155 & $1.61 \times 10^{-4}$ \\
\hline & & $198121-188111$ & $235051.378(0.1000)$ & 155 & $1.61 \times 10^{-4}$ \\
\hline & & $196135-186125$ & $235084.738(0.1000)$ & 324 & $1.76 \times 10^{-4}$ \\
\hline & & $203184-193174$ & $235200.422(0.1000)$ & 314 & $1.90 \times 10^{-4}$ \\
\hline & & $195154-185144$ & $235633.058(0.1000)$ & 316 & $1.81 \times 10^{-4}$ \\
\hline & & $197130-187120$ & $235844.544(0.1000)$ & 145 & $1.71 \times 10^{-4}$ \\
\hline & & $197131-187121$ & $235865.969(0.1000)$ & 145 & $1.67 \times 10^{-4}$ \\
\hline & & $202183-192173$ & $235904.655(0.1000)$ & 315 & $1.91 \times 10^{-4}$ \\
\hline & & $212203-202193$ & $235919.352(0.1000)$ & 319 & $1.94 \times 10^{-4}$ \\
\hline & & $197120-187110$ & $235932.379(0.1000)$ & 145 & $1.72 \times 10^{-4}$ \\
\hline \multirow[t]{20}{*}{$\mathrm{a}-\left(\mathrm{CH}_{2} \mathrm{OH}\right)_{2}$} & 62503 & $221480-211471$ & $218468.381(0.0044)$ & 221 & $1.51 \times 10^{-4}$ \\
\hline & CDMS & $221490-211481$ & $218468.381(0.0044)$ & 221 & $1.51 \times 10^{-4}$ \\
\hline & & $204161-194150$ & $219764.925(0.0040)$ & 114 & $2.45 \times 10^{-4}$ \\
\hline & & $228140-218131$ & $219809.406(0.0026)$ & 156 & $2.24 \times 10^{-4}$ \\
\hline & & $2812160-2811170$ & $233426.949(0.0036)$ & 270 & $3.11 \times 10^{-5}$ \\
\hline & & $2812170-2811180$ & $233427.018(0.0036)$ & 270 & $3.10 \times 10^{-5}$ \\
\hline & & $2812161-2811171$ & $233451.651(0.0036)$ & 271 & $3.32 \times 10^{-5}$ \\
\hline & & $2812171-2811181$ & $233451.723(0.0036)$ & 271 & $3.32 \times 10^{-5}$ \\
\hline & & $225181-215170$ & $233536.696(0.0025)$ & 138 & $2.93 \times 10^{-4}$ \\
\hline & & $227161-217150$ & $233561.784(0.0024)$ & 149 & $2.79 \times 10^{-4}$ \\
\hline & & $226171-216160$ & $234264.446(0.0026)$ & 143 & $2.84 \times 10^{-4}$ \\
\hline & & $5113391-5112401$ & $235170.476(0.0288)$ & 737 & $4.73 \times 10^{-5}$ \\
\hline & & $233211-223200$ & $235170.573(0.0023)$ & 139 & $2.91 \times 10^{-4}$ \\
\hline & & $226161-216150$ & $235304.050(0.0026)$ & 143 & $2.90 \times 10^{-4}$ \\
\hline & & $14591-134101$ & $235326.413(0.0021)$ & 64 & $2.39 \times 10^{-5}$ \\
\hline & & $214180-203170$ & $235327.161(0.0027)$ & 122 & $6.30 \times 10^{-5}$ \\
\hline & & $232211-222200$ & $235600.178(0.0022)$ & 139 & $3.28 \times 10^{-4}$ \\
\hline & & $244210-234201$ & $235620.372(0.0027)$ & 155 & $2.88 \times 10^{-4}$ \\
\hline & & $261260-251251$ & $235834.239(0.0040)$ & 159 & $3.22 \times 10^{-4}$ \\
\hline & & $260260-250251$ & $235834.327(0.0040)$ & 159 & $3.22 \times 10^{-4}$ \\
\hline
\end{tabular}


Table (C.1) Molecules and parameters used for the IRAS 16293B synthetic spectrum

\begin{tabular}{|c|c|c|c|c|c|}
\hline Molecule & Name & Tag & Database & $\begin{array}{c}N_{\mathrm{T}} \\
\left(\mathrm{cm}^{-2}\right)\end{array}$ & $\begin{array}{l}T_{\mathrm{ex}} \\
(\mathrm{K}) \\
\end{array}$ \\
\hline $\mathrm{CCH}$ & Ethynyl radical & 25501 & CDMS & $3.00 \times 10^{13}$ & 120 \\
\hline $\mathrm{HCN}$ & Hydrogen cyanide & 27501 & CDMS & $5.00 \times 10^{16}$ & 120 \\
\hline $\mathrm{HNC}$ & Hydrogen isocyanide & 27502 & CDMS & $5.00 \times 10^{16}$ & 120 \\
\hline $\mathrm{H}^{13} \mathrm{CN}$ & Hydrogen cyanide & 28501 & CDMS & $2.00 \times 10^{14}$ & 300 \\
\hline $\mathrm{CO}$ & Carbon monoxide & 28503 & CDMS & $1.00 \times 10^{20}$ & 100 \\
\hline $\mathrm{HC}^{15} \mathrm{~N}$ & Hydrogen cyanide & 28506 & CDMS & $2.00 \times 10^{14}$ & 300 \\
\hline DNC & Hydrogen cyanide & 28508 & CDMS & $7.00 \times 10^{14}$ & 300 \\
\hline${ }^{13} \mathrm{CO}$ & Carbon monoxide & 29501 & CDMS & $3.10 \times 10^{19}$ & 100 \\
\hline $\mathrm{C}^{17} \mathrm{O}$ & Carbon monoxide & 29503 & CDMS & $8.00 \times 10^{16}$ & 100 \\
\hline $\mathrm{H}^{13} \mathrm{C}^{15}$ & Hydrogen cyanide & 29512 & CDMS & $2.00 \times 10^{14}$ & 300 \\
\hline $\mathrm{HNCH}_{2}$ & Methanimine & 29518 & CDMS & $8.00 \times 10^{14}$ & 100 \\
\hline $\mathrm{NO}$ & Nitrogen oxide & 30008 & JPL & $2.00 \times 10^{16}$ & 100 \\
\hline $\mathrm{H}_{2} \mathrm{CO}$ & Formaldehyde & 30501 & CDMS & $1.80 \times 10^{18}$ & 105 \\
\hline $\mathrm{C}^{18} \mathrm{O}$ & Carbon monoxide & 30502 & CDMS & $1.00 \times 10^{17}$ & 100 \\
\hline $\mathrm{DCO}^{+}$ & Formyl radical & 30510 & CDMS & $3.00 \times 10^{12}$ & 29 \\
\hline $\mathrm{CH}_{3} \mathrm{NH}_{2}$ & Methylamine & 31008 & JPL & $5.30 \times 10^{14}$ & 100 \\
\hline $\mathrm{HDCO}$ & Formaldehyde & 31501 & CDMS & $1.30 \times 10^{17}$ & 105 \\
\hline $\mathrm{H}_{2}^{13} \mathrm{CO}$ & Formaldehyde & 31503 & CDMS & $3.60 \times 10^{16}$ & 105 \\
\hline $\mathrm{D}_{2}^{2} \mathrm{CO}$ & Formaldehyde & 32502 & CDMS & $1.60 \times 10^{16}$ & 105 \\
\hline $\mathrm{H}_{2} \mathrm{C}^{18} \mathrm{O}$ & Formaldehyde & 32503 & CDMS & $2.50 \times 10^{15}$ & 105 \\
\hline $\mathrm{CH}_{3} \mathrm{OH}$ & Methanol & 32504 & CDMS & $2.00 \times 10^{19}$ & 300 \\
\hline $\mathrm{CH}_{2} \mathrm{DOH}$ & Methanol & 33004 & JPL & $7.10 \times 10^{17}$ & 300 \\
\hline${ }^{13} \mathrm{CH}_{3} \mathrm{OH}$ & Methanol & 33502 & CDMS & $4.00 \times 10^{16}$ & 300 \\
\hline $\mathrm{NH}_{2} \mathrm{OH}$ & Hydroxylamine & 33503 & CDMS & $3.70 \times 10^{14}$ & 100 \\
\hline $\mathrm{D}_{2}^{13} \mathrm{CO}$ & Formaldehyde & 33506 & CDMS & $2.20 \times 10^{14}$ & 105 \\
\hline $\mathrm{HDC}^{18} \mathrm{O}$ & Formaldehyde & 33510 & CDMS & $1.40 \times 10^{14}$ & 105 \\
\hline $\mathrm{H}_{2} \mathrm{~S}$ & Hydrogen sulfide & 34502 & CDMS & $1.00 \times 10^{18}$ & 125 \\
\hline $\mathrm{CH}_{3}^{18} \mathrm{OH}$ & Methanol & 34504 & CDMS & $2.00 \times 10^{16}$ & 300 \\
\hline HDS & Hydrogen sulfide & 35502 & CDMS & $2.00 \times 10^{16}$ & 125 \\
\hline $\mathrm{HD}^{34} \mathrm{~S}$ & Hydrogen sulfide & 37503 & CDMS & $1.00 \times 10^{15}$ & 125 \\
\hline $\mathrm{c}-\mathrm{C}_{3} \mathrm{H}_{2}$ & Cyclopropenylidene & 38508 & CDMS & $2.00 \times 10^{14}$ & 100 \\
\hline $\mathrm{CH}_{3} \mathrm{CCH}$ & Propyne & 40502 & CDMS & $6.80 \times 10^{15}$ & 100 \\
\hline $\mathrm{CH}_{3} \mathrm{CN}$ & Acetonitrile & 41505 & CDMS & $4.00 \times 10^{16}$ & 120 \\
\hline $\mathrm{CH}_{3} \mathrm{CN} v_{8}=1$ & Acetonitrile & 41509 & CDMS & $4.00 \times 10^{16}$ & 120 \\
\hline $\mathrm{CH}_{3} \mathrm{NC}$ & Methyl isocyanide & 41514 & CDMS & $2.00 \times 10^{14}$ & 150 \\
\hline $\mathrm{H}_{2} \mathrm{CCO}$ & Ketene & 42501 & CDMS & $4.80 \times 10^{16}$ & 125 \\
\hline HNCNH & Carbodiimide & 42506 & CDMS & $2.40 \times 10^{16}$ & 300 \\
\hline${ }^{13} \mathrm{CH}_{3} \mathrm{CN}$ & Acetonitrile & 42508 & CDMS & $3.30 \times 10^{14}$ & 130 \\
\hline $\mathrm{CH}_{3}^{13} \mathrm{CN}$ & Acetonitrile & 42509 & CDMS & $3.00 \times 10^{14}$ & 130 \\
\hline $\mathrm{CH}_{3} \mathrm{C}^{15} \mathrm{~N}$ & Acetonitrile & 42510 & CDMS & $8.70 \times 10^{13}$ & 130 \\
\hline $\mathrm{CH}_{2} \mathrm{DCN}$ & Acetonitrile & 42511 & CDMS & $5.60 \times 10^{14}$ & 130 \\
\hline $\mathrm{H}_{2} \mathrm{C}^{13} \mathrm{CO}$ & Ketene & 43505 & CDMS & $7.10 \times 10^{14}$ & 125 \\
\hline $\mathrm{H}_{2}^{13} \mathrm{CCO}$ & Ketene & 43506 & CDMS & $7.10 \times 10^{14}$ & 125 \\
\hline $\mathrm{HDC}_{2} \mathrm{O}$ & Ketene & 43507 & CDMS & $2.00 \times 10^{15}$ & 125 \\
\hline $\mathrm{HNCO}$ & Isocyanic acid & 43511 & CDMS & $3.70 \times 10^{16}$ & 300 \\
\hline $\mathrm{CHD}_{2} \mathrm{CN}$ & Acetonitrile & 43514 & CDMS & $1.20 \times 10^{14}$ & 130 \\
\hline $\mathrm{H}_{2} \mathrm{~N}^{13} \mathrm{CN}$ & Cyanamide & 43515 & CDMS & $3.00 \times 10^{13}$ & 300 \\
\hline $\mathrm{N}_{2} \mathrm{O}$ & Nitrous oxide & 44004 & JPL & $5.00 \times 10^{16}$ & 100 \\
\hline DNCO & Isocyanic acid & 44006 & JPL & $3.00 \times 10^{14}$ & 300 \\
\hline $\mathrm{HN}^{13} \mathrm{CO}$ & Isocyanic acid & 44008 & JPL & $4.00 \times 10^{14}$ & 300 \\
\hline $\mathrm{CS}$ & Carbon monosulfide & 44501 & CDMS & $1.00 \times 10^{16}$ & 125 \\
\hline $\mathrm{c}-\mathrm{C}_{2} \mathrm{H}_{4} \mathrm{O}$ & Ethylene oxide & 44504 & CDMS & $4.10 \times 10^{15}$ & 125 \\
\hline $\mathrm{SiO}$ & Silicon monoxide & 44505 & CDMS & $7.00 \times 10^{13}$ & 300 \\
\hline $\mathrm{s}-\mathrm{H}_{2} \mathrm{CCHOH}$ & Vinylalcohol & 44506 & CDMS & $1.20 \times 10^{17}$ & 125 \\
\hline $\mathrm{a}-\mathrm{H}_{2} \mathrm{CCHOH}$ & Vinylalcohol & 44507 & CDMS & $1.20 \times 10^{17}$ & 125 \\
\hline $\mathrm{C}^{33} \mathrm{~S}$ & Carbon monosulfide & 45502 & CDMS & $1.00 \times 10^{14}$ & 125 \\
\hline
\end{tabular}


Table (C.1) Continued.

\begin{tabular}{|c|c|c|c|c|c|}
\hline Molecule & Name & Tag & Database & $\begin{array}{c}N_{\mathrm{T}} \\
\left(\mathrm{cm}^{-2}\right)\end{array}$ & $\begin{array}{l}T_{\mathrm{ex}} \\
(\mathrm{K})\end{array}$ \\
\hline $\mathrm{NH}_{2} \mathrm{CHO}$ & Formamide & 45512 & CDMS & $1.00 \times 10^{16}$ & 300 \\
\hline $\mathrm{CH}_{3} \mathrm{CDO}$ & Acetaldehyde & 45524 & CDMS & $7.40 \times 10^{15}$ & 125 \\
\hline $\mathrm{CH}_{2} \mathrm{DCHO}$ & Acetaldehyde & 45525 & CDMS & $6.20 \times 10^{15}$ & 125 \\
\hline $\mathrm{C}^{34} \mathrm{~S}$ & Carbon monosulfide & 46501 & CDMS & $3.00 \times 10^{14}$ & 125 \\
\hline $\mathrm{t}-\mathrm{HCOOH}$ & Formic acid & 46506 & CDMS & $5.08 \times 10^{16}$ & 300 \\
\hline $\mathrm{H}_{2} \mathrm{CS}$ & Thioformaldehyde & 46509 & CDMS & $1.50 \times 10^{15}$ & 125 \\
\hline $\mathrm{NH}_{2}^{13} \mathrm{CHO}$ & Formamide & 46512 & CDMS & $1.00 \times 10^{14}$ & 300 \\
\hline $\mathrm{CH}_{3} \mathrm{OCH}_{3}$ & Dimethyl ether & 46514 & CDMS & $3.00 \times 10^{17}$ & 125 \\
\hline $\mathrm{NH}_{2} \mathrm{CDO}$ & Formamide & 46520 & CDMS & $1.40 \times 10^{14}$ & 300 \\
\hline cis-NHDCHO & Formamide & 46521 & CDMS & $1.40 \times 10^{14}$ & 300 \\
\hline trans-NHDCHO & Formamide & 46522 & CDMS & $1.20 \times 10^{14}$ & 300 \\
\hline $\mathrm{C}_{2} \mathrm{H}_{5} \mathrm{OH}$ & Ethanol & 46524 & CDMS & $2.30 \times 10^{17}$ & 300 \\
\hline HONO & Nitrous acid & 47007 & JPL & $9.00 \times 10^{14}$ & 100 \\
\hline $\mathrm{t}-\mathrm{H}^{13} \mathrm{COOH}$ & Formic acid & 47503 & CDMS & $8.30 \times 10^{14}$ & 300 \\
\hline HDCS & Thioformaldehyde & 47504 & CDMS & $1.50 \times 10^{14}$ & 125 \\
\hline $\mathrm{CH}_{3}^{13} \mathrm{CH}_{2} \mathrm{OH}$ & Ethanol & 47511 & CDMS & $4.60 \times 10^{14}$ & 300 \\
\hline${ }^{13} \mathrm{CH}_{3}^{3} \mathrm{CH}_{2} \mathrm{OH}$ & Ethanol & 47512 & CDMS & $4.60 \times 10^{14}$ & 300 \\
\hline $\mathrm{CH}_{3} \mathrm{CH}_{2} \mathrm{OD}$ & Ethanol & 47515 & CDMS & $5.75 \times 10^{14}$ & 300 \\
\hline $\mathrm{CH}_{3} \mathrm{CHDOH}$ & Ethanol & 47516 & CDMS & $1.15 \times 10^{15}$ & 300 \\
\hline $\mathrm{a}-\mathrm{CH}_{2} \mathrm{DCH}_{2} \mathrm{OH}$ & Ethanol & 47517 & CDMS & $1.34 \times 10^{15}$ & 300 \\
\hline $\mathrm{s}-\mathrm{CH}_{2} \mathrm{DCH}_{2} \mathrm{OH}$ & Ethanol & 47518 & CDMS & $6.51 \times 10^{14}$ & 300 \\
\hline SO & Sulfur monoxide & 48501 & CDMS & $5.00 \times 10^{14}$ & 125 \\
\hline$C^{36} S$ & Carbon monosulfide & 48503 & CDMS & $2.00 \times 10^{13}$ & 125 \\
\hline $\mathrm{CH}_{3} \mathrm{SH}$ & Methyl mercaptan & 48510 & CDMS & $5.50 \times 10^{15}$ & 125 \\
\hline $\mathrm{CH}_{3}^{35} \mathrm{Cl}$ & Chloromethane & 50007 & JPL & $3.10 \times 10^{13}$ & 125 \\
\hline $\mathrm{HC}_{3} \mathrm{~N}$ & Cyanoacetylene & 51501 & CDMS & $1.40 \times 10^{14}$ & 100 \\
\hline $\mathrm{CH}_{3}^{37} \mathrm{Cl}$ & Chloromethane & 52009 & JPL & $2.20 \times 10^{14}$ & 125 \\
\hline $\mathrm{C}_{2} \mathrm{H}_{3} \mathrm{CN}$ & Vinyl cyanide & 53515 & CDMS & $4.80 \times 10^{14}$ & 110 \\
\hline $\mathrm{C}_{2} \mathrm{H}_{5} \mathrm{CN}$ & Ethyl cyanide & 55502 & CDMS & $1.50 \times 10^{15}$ & 160 \\
\hline $\mathrm{CH}_{3} \mathrm{NCO}$ & Methyl isocyanate & 57505 & CDMS & $3.00 \times 10^{15}$ & 300 \\
\hline $\mathrm{CH}_{3} \mathrm{C}(\mathrm{O}) \mathrm{CH}_{3}$ & Acetone & 58003 & JPL & $3.40 \times 10^{16}$ & 125 \\
\hline $\mathrm{CH}_{3} \mathrm{CH}_{2} \mathrm{CHO}$ & Propanal & 58505 & CDMS & $1.48 \times 10^{15}$ & 125 \\
\hline $\mathrm{CH}_{3} \mathrm{OCHO}$ & Methylformate & 60003 & JPL & $2.60 \times 10^{17}$ & 300 \\
\hline $\mathrm{HOCH}_{2} \mathrm{CHO}$ & Glycolaldehyde & 60501 & CDMS & $3.40 \times 10^{16}$ & 300 \\
\hline OCS & Carbonyl sulfide & 60503 & CDMS & $2.00 \times 10^{16}$ & 125 \\
\hline $\mathrm{OCS} v_{2}=1$ & Carbonyl sulfide & 60504 & CDMS & $2.00 \times 10^{17}$ & 125 \\
\hline $\mathrm{CH}_{3} \mathrm{COOH}$ & Acetic acid & 60523 & CDMS & $3.00 \times 10^{15}$ & 300 \\
\hline $\mathrm{O}^{13} \mathrm{CS}$ & Carbonyl sulfide & 61502 & CDMS & $5.00 \times 10^{15}$ & 125 \\
\hline $\mathrm{OC}^{33} \mathrm{~S}$ & Carbonyl sulfide & 61503 & CDMS & $3.00 \times 10^{15}$ & 100 \\
\hline $\mathrm{HOCH}_{2}^{13} \mathrm{CHO}$ & Glycolaldehyde & 61513 & CDMS & $4.46 \times 10^{14}$ & 300 \\
\hline $\mathrm{HO}^{13} \mathrm{CH}_{2} \mathrm{CHO}$ & Glycolaldehyde & 61514 & CDMS & $4.46 \times 10^{14}$ & 300 \\
\hline $\mathrm{CH}_{3} \mathrm{O}^{13} \mathrm{CHO}$ & Glycolaldehyde & 61515 & CDMS & $6.30 \times 10^{15}$ & 300 \\
\hline $\mathrm{DOCH}_{2} \mathrm{CHO}$ & Glycolaldehyde & 61516 & CDMS & $4.86 \times 10^{14}$ & 300 \\
\hline HOCHDCHO & Glycolaldehyde & 61517 & CDMS & $1.27 \times 10^{15}$ & 300 \\
\hline $\mathrm{HOCH}_{2} \mathrm{CDO}$ & Glycolaldehyde & 61518 & CDMS & $6.25 \times 10^{14}$ & 300 \\
\hline $\mathrm{a}-\left(\mathrm{CH}_{2} \mathrm{OH}\right)_{2}$ & Ethylene glycol & 62503 & CDMS & $1.37 \times 10^{16}$ & 300 \\
\hline $\mathrm{s}-\left(\mathrm{CH}_{2} \mathrm{OH}\right)_{2}$ & Ethylene glycol & 62504 & CDMS & $3.62 \times 10^{16}$ & 300 \\
\hline $\mathrm{OC}^{34} \mathrm{~S}$ & Carbonyl sulfide & 62505 & CDMS & $1.50 \times 10^{16}$ & 125 \\
\hline${ }^{18} \mathrm{OCS}$ & Carbonyl sulfide & 62506 & CDMS & $7.00 \times 10^{14}$ & 125 \\
\hline $\mathrm{SO}_{2}$ & Sulfur dioxide & 64502 & CDMS & $1.50 \times 10^{15}$ & 125 \\
\hline${ }^{34} \mathrm{O}_{2}$ & Sulfur dioxide & 66501 & CDMS & $4.00 \times 10^{14}$ & 125 \\
\hline
\end{tabular}


Table (C.1) $\mathrm{HOCH}_{2} \mathrm{CN}$ lines in the PILS data towards IRAS 16293B

\begin{tabular}{|c|c|c|c|c|}
\hline $\begin{array}{l}\text { Transition } \\
J, K_{\mathrm{a}}, K_{\mathrm{c}}, F\end{array}$ & $\begin{array}{l}\text { Frequency } \\
(\mathrm{MHz})\end{array}$ & $\begin{array}{l}E_{\text {up }} \\
(\mathrm{K})\end{array}$ & $\begin{array}{l}A_{\mathrm{ij}} \\
\mathrm{s}^{-1}\end{array}$ & Blending species \\
\hline $3611251-3511241$ & 331990.003 & 468 & $1.03 \times 10^{-3}$ & $\mathrm{~g}-\left(\mathrm{CH}_{2} \mathrm{OH}\right)_{2}$ \\
\hline $3611261-3511251$ & 331990.003 & 468 & $1.03 \times 10^{-3}$ & $\mathrm{~g}-\left(\mathrm{CH}_{2} \mathrm{OH}\right)_{2}$ \\
\hline $3612241-3512231$ & 332038.123 & 500 & $1.01 \times 10^{-3}$ & $\mathrm{CH}_{3} \mathrm{OCHO}$ \\
\hline $3612251-3512241$ & 332038.123 & 500 & $1.01 \times 10^{-3}$ & $\mathrm{CH}_{3} \mathrm{OCHO}$ \\
\hline $368291-358281$ & 332045.021 & 389 & $1.08 \times 10^{-3}$ & $\mathrm{~g}-\left(\mathrm{CH}_{2} \mathrm{OH}\right)_{2}$ \\
\hline $368281-358271$ & 332045.044 & 389 & $1.08 \times 10^{-3}$ & $\mathrm{~g}-\left(\mathrm{CH}_{2} \mathrm{OH}\right)_{2}$ \\
\hline $367300-357290$ & 332409.418 & 363 & $1.09 \times 10^{-3}$ & - \\
\hline $367290-357280$ & 332410.281 & 363 & $1.09 \times 10^{-3}$ & - \\
\hline $366310-356300$ & 332678.904 & 345 & $1.10 \times 10^{-3}$ & - \\
\hline $366300-356290$ & 332699.957 & 345 & $1.10 \times 10^{-3}$ & - \\
\hline $364331-354321$ & 332797.489 & 323 & $1.14 \times 10^{-3}$ & - \\
\hline $365311-355301$ & 333147.976 & 335 & $1.13 \times 10^{-3}$ & - \\
\hline $372361-362351$ & 334177.762 & 318 & $1.15 \times 10^{-3}$ & $\mathrm{CH}_{3} \mathrm{OCHO}, \mathrm{CH}_{3} \mathrm{O}^{13} \mathrm{CHO}, \mathrm{C}_{2} \mathrm{H}_{5} \mathrm{CN}, \mathrm{HO}^{13} \mathrm{CH}_{2} \mathrm{CHO}$ \\
\hline $371361-361351$ & 335135.448 & 318 & $1.16 \times 10^{-3}$ & $\mathrm{CH}_{3} \mathrm{OH}$ \\
\hline $371360-361350$ & 335187.943 & 313 & $1.16 \times 10^{-3}$ & - \\
\hline $364321-354311$ & 335446.009 & 324 & $1.17 \times 10^{-3}$ & - \\
\hline $362341-352331$ & 335757.704 & 310 & $1.15 \times 10^{-3}$ & $\mathrm{~g}-\left(\mathrm{CH}_{2} \mathrm{OH}\right)_{2}$ \\
\hline $364320-354310$ & 335825.850 & 318 & $1.15 \times 10^{-3}$ & $\mathrm{~g}-\left(\mathrm{CH}_{2} \mathrm{OH}\right)_{2}, \mathrm{CH}_{3} \mathrm{C}(\mathrm{O}) \mathrm{CH}_{3}, \mathrm{CH}_{3} \mathrm{OCHO}$ \\
\hline $381381-371371$ & 335871.388 & 323 & $1.17 \times 10^{-3}$ & - \\
\hline $380381-370371$ & 335909.319 & 323 & $1.17 \times 10^{-3}$ & - \\
\hline $380380-370370$ & 335985.342 & 318 & $1.17 \times 10^{-3}$ & $\mathrm{CH}_{3} \mathrm{CH}_{2} \mathrm{OH}, \mathrm{g}-\left(\mathrm{CH}_{2} \mathrm{OH}\right)_{2}$ \\
\hline $363330-353320$ & 338263.867 & 311 & $1.07 \times 10^{-3}$ & $\mathrm{CH}_{3} \mathrm{OCHO}$ \\
\hline $373351-363341$ & 339712.712 & 329 & $1.21 \times 10^{-3}$ & $\mathrm{NH}_{2} \mathrm{CHO}$ \\
\hline $373350-363340$ & 339771.178 & 324 & $1.20 \times 10^{-3}$ & - \\
\hline $3711261-3611251$ & 341198.194 & 484 & $1.13 \times 10^{-3}$ & - \\
\hline $3711271-3611261$ & 341198.194 & 484 & $1.13 \times 10^{-3}$ & - \\
\hline $379291-369281$ & 341199.695 & 429 & $1.16 \times 10^{-3}$ & $\mathrm{~g}-\left(\mathrm{CH}_{2} \mathrm{OH}\right)_{2}$ \\
\hline $379281-369271$ & 341199.696 & 429 & $1.16 \times 10^{-3}$ & $\mathrm{~g}-\left(\mathrm{CH}_{2} \mathrm{OH}\right)_{2}$ \\
\hline $378301-368291$ & 341272.746 & 405 & $1.18 \times 10^{-3}$ & $\mathrm{HOCH}_{2} \mathrm{CHO}, \mathrm{CH}_{3} \mathrm{CDO}$ \\
\hline $378291-368281$ & 341272.781 & 405 & $1.18 \times 10^{-3}$ & $\mathrm{HOCH}_{2} \mathrm{CHO}, \mathrm{CH}_{3} \mathrm{CDO}$ \\
\hline $377311-367301$ & 341427.962 & 385 & $1.20 \times 10^{-3}$ & $\mathrm{CH}_{3} \mathrm{CHO}$ \\
\hline $378300-368290$ & 341498.917 & 400 & $1.17 \times 10^{-3}$ & $\mathrm{CH}_{3} \mathrm{OCHO}$ \\
\hline $378290-368280$ & 341498.954 & 400 & $1.17 \times 10^{-3}$ & $\mathrm{CH}_{3} \mathrm{OCHO}$ \\
\hline $3713240-3613230$ & 341529.626 & 545 & $1.08 \times 10^{-3}$ & $\mathrm{a}-\left(\mathrm{CH}_{2} \mathrm{OH}\right)_{2}$ \\
\hline $3713250-3613240$ & 341529.626 & 545 & $1.08 \times 10^{-3}$ & $\mathrm{a}-\left(\mathrm{CH}_{2} \mathrm{OH}\right)_{2}$ \\
\hline $377310-367300$ & 341659.715 & 379 & $1.18 \times 10^{-3}$ & - \\
\hline $377300-367290$ & 341660.941 & 379 & $1.18 \times 10^{-3}$ & - \\
\hline $376310-366300$ & 341982.421 & 362 & $1.20 \times 10^{-3}$ & $\mathrm{CH}_{3} \mathrm{O}^{13} \mathrm{CHO}$ \\
\hline $374341-364331$ & 342001.917 & 339 & $1.23 \times 10^{-3}$ & - \\
\hline $375331-365321$ & 342118.267 & 352 & $1.23 \times 10^{-3}$ & $\mathrm{HOCH}_{2} \mathrm{CHO}$ \\
\hline $375321-365311$ & 342514.548 & 352 & $1.23 \times 10^{-3}$ & $\mathrm{CH}_{3} \mathrm{CDO}$ \\
\hline $382371-372361$ & 342945.040 & 335 & $1.25 \times 10^{-3}$ & $\mathrm{H}_{2} \mathrm{CS}, \mathrm{CH}_{3} \mathrm{O}^{13} \mathrm{CHO}$ \\
\hline $382370-372360$ & 343045.762 & 330 & $1.24 \times 10^{-3}$ & $\mathrm{CH}_{3} \mathrm{CDO}$ \\
\hline $390391-380381$ & 344625.126 & 339 & $1.27 \times 10^{-3}$ & $\mathrm{HONO}, \mathrm{CH}_{2} \mathrm{DOH}, \mathrm{CH}_{3} \mathrm{CHO}$ \\
\hline $374331-364321$ & 345070.674 & 340 & $1.27 \times 10^{-3}$ & $\mathrm{CH}_{3} \mathrm{OCHO}$ \\
\hline $374330-364320$ & 345471.229 & 335 & $1.25 \times 10^{-3}$ & $\mathrm{CH}_{3} \mathrm{OCHO}$ \\
\hline $383360-373350$ & 348727.094 & 340 & $1.30 \times 10^{-3}$ & - \\
\hline $389301-379291$ & 350417.202 & 446 & $1.27 \times 10^{-3}$ & $\mathrm{a}-\left(\mathrm{CH}_{2} \mathrm{OH}\right)_{2}$ \\
\hline $389291-379281$ & 350417.203 & 446 & $1.27 \times 10^{-3}$ & $\mathrm{a}-\left(\mathrm{CH}_{2} \mathrm{OH}\right)_{2}$ \\
\hline $3813251-3713241$ & 350517.318 & 568 & $1.19 \times 10^{-3}$ & - \\
\hline $3813261-3713251$ & 350517.318 & 568 & $1.19 \times 10^{-3}$ & - \\
\hline $3810280-3710270$ & 350617.089 & 467 & $1.24 \times 10^{-3}$ & $\mathrm{CH}_{3} \mathrm{O}^{13} \mathrm{CHO}$ \\
\hline $3810290-3710280$ & 350617.089 & 467 & $1.24 \times 10^{-3}$ & $\mathrm{CH}_{3} \mathrm{O}^{13} \mathrm{CHO}$ \\
\hline $386331-376321$ & 350983.970 & 384 & $1.32 \times 10^{-3}$ & $\mathrm{CH}_{3} \mathrm{OCHO}, \mathrm{CH}_{3} \mathrm{CDO}$ \\
\hline $386321-376311$ & 351019.318 & 384 & $1.32 \times 10^{-3}$ & $\mathrm{H}_{2} \mathrm{C}^{13} \mathrm{CO}, \mathrm{CH}_{3} \mathrm{OCHO}$ \\
\hline $386320-376310$ & 351269.282 & 378 & $1.30 \times 10^{-3}$ & - \\
\hline $385341-375331$ & 351402.459 & 369 & $1.33 \times 10^{-3}$ & - \\
\hline
\end{tabular}


Table (C.1) Continued.

\begin{tabular}{|c|c|c|c|c|}
\hline $\begin{array}{c}\text { Transition } \\
J, K_{\mathrm{a}}, K_{\mathrm{c}}, F\end{array}$ & $\begin{array}{l}\text { Frequency } \\
(\mathrm{MHz})\end{array}$ & $\begin{array}{l}E_{\text {up }} \\
(\mathrm{K})\end{array}$ & $\begin{array}{l}A_{\mathrm{ij}} \\
\mathrm{s}^{-1}\end{array}$ & Blending species \\
\hline $392381-382371$ & 351704.972 & 352 & $1.35 \times 10^{-3}$ & - \\
\hline $392380-382370$ & 351809.704 & 346 & $1.34 \times 10^{-3}$ & - \\
\hline $385331-375321$ & 351897.151 & 369 & $1.34 \times 10^{-3}$ & - \\
\hline $385330-375320$ & 352181.763 & 363 & $1.32 \times 10^{-3}$ & $\mathrm{CH}_{3} \mathrm{O}^{13} \mathrm{CHO}$ \\
\hline $391380-381370$ & 352488.531 & 346 & $1.35 \times 10^{-3}$ & $\mathrm{CH}_{3}^{18} \mathrm{OH}$ \\
\hline $382361-372351$ & 353163.191 & 344 & $1.35 \times 10^{-3}$ & - \\
\hline $400401-390391$ & 353340.026 & 356 & $1.37 \times 10^{-3}$ & $\mathrm{CH}_{3} \mathrm{OCHO}$ \\
\hline $401400-391390$ & 353395.992 & 351 & $1.37 \times 10^{-3}$ & - \\
\hline $400400-390390$ & 353420.250 & 351 & $1.37 \times 10^{-3}$ & - \\
\hline $384340-374330$ & 355133.419 & 352 & $1.36 \times 10^{-3}$ & - \\
\hline $393371-383361$ & 358294.680 & 363 & $1.33 \times 10^{-3}$ & - \\
\hline $399311-389301$ & 359634.337 & 463 & $1.37 \times 10^{-3}$ & - \\
\hline $399301-389291$ & 359634.339 & 463 & $1.37 \times 10^{-3}$ & - \\
\hline $3912270-3812260$ & 359881.373 & 545 & $1.30 \times 10^{-3}$ & - \\
\hline $3912280-3812270$ & 359881.373 & 545 & $1.30 \times 10^{-3}$ & - \\
\hline $397331-387321$ & 359919.218 & 419 & $1.41 \times 10^{-3}$ & - \\
\hline $3913260-3813250$ & 359947.354 & 579 & $1.28 \times 10^{-3}$ & - \\
\hline $3913270-3813260$ & 359947.354 & 579 & $1.28 \times 10^{-3}$ & - \\
\hline $398320-388310$ & 359967.849 & 434 & $1.38 \times 10^{-3}$ & - \\
\hline $398310-388300$ & 359967.931 & 434 & $1.38 \times 10^{-3}$ & - \\
\hline $3916231-3816221$ & 360033.494 & 705 & $1.21 \times 10^{-3}$ & $\mathrm{t}-\mathrm{HCOOH}$ \\
\hline $3916241-3816231$ & 360033.494 & 705 & $1.21 \times 10^{-3}$ & $\mathrm{t}-\mathrm{HCOOH}$ \\
\hline $3914250-3814240$ & 360034.284 & 617 & $1.25 \times 10^{-3}$ & $\mathrm{t}-\mathrm{HCOOH}$ \\
\hline $3914260-3814250$ & 360034.284 & 617 & $1.25 \times 10^{-3}$ & $\mathrm{t}-\mathrm{HCOOH}$ \\
\hline $396331-386321$ & 360303.101 & 401 & $1.43 \times 10^{-3}$ & - \\
\hline $394361-384351$ & 360369.224 & 373 & $1.45 \times 10^{-3}$ & - \\
\hline $402390-392380$ & 360565.572 & 364 & $1.44 \times 10^{-3}$ & - \\
\hline $395351-385341$ & 360684.867 & 386 & $1.44 \times 10^{-3}$ & - \\
\hline $401391-391381$ & 361063.161 & 369 & $1.46 \times 10^{-3}$ & - \\
\hline $395341-385331$ & 361297.474 & 386 & $1.45 \times 10^{-3}$ & $\mathrm{CH}_{3} \mathrm{CH}_{2} \mathrm{OH}$ \\
\hline $395340-385330$ & 361594.894 & 381 & $1.43 \times 10^{-3}$ & - \\
\hline $392371-382361$ & 361805.086 & 361 & $1.46 \times 10^{-3}$ & $\mathrm{CH}_{3} \mathrm{OCHO}$ \\
\hline $410411-400401$ & 362053.851 & 374 & $1.47 \times 10^{-3}$ & $\mathrm{CH}_{3} \mathrm{C}(\mathrm{O}) \mathrm{CH}_{3}$ \\
\hline $410410-400400$ & 362136.053 & 368 & $1.47 \times 10^{-3}$ & - \\
\hline
\end{tabular}

Notes. List of identified and unidentified $\mathrm{HOCH}_{2} \mathrm{CN}$ transitions with $\mathrm{A}_{\mathrm{ij}} \geq 1.0 \times 10^{-3} \mathrm{~s}^{-1}$ towards IRAS 16293B in the PILS data set. 